A RADIOGRAPHIC STUDY OF THE CALCIFICATION AND ERUPTION OF THE PERMANENT TEETH IN INUIT AND INDIAN CHILDREN

A THESIS

SUBMITTED TO THE FACULTY OF GRADUATE STUDIES

IN PARTIAL FULFILLMENT OF THE REQUIREMENTS FOR THE DEGREE OF MASTER OF ARTS

DEPARTMENT OF ANTHROPOLOGY

WINNIPEG, MANITOBA

BY

BONNIE JOY TRODDEN

SEPTEMBER, 1982 


\title{
A RADIOGRAPHIC STUDY OF THE CALCIFICATION AND ERUPTION OF THE PERMANENT TEETH IN INUIT AND INDIAN CHILDREN
}

BY

BONNIE JOY TRODDEN

\begin{abstract}
A thesis submitted to the Faculty of Graduate Studies of the University of Manitoba in partial fulfillment of the requirements of the degree of
\end{abstract}

MASTER OF ARTS

(C) 1982

Permission has been granted to the LIBRARY OF THE UNIVER-

SITY OF MANITOBA to lend or sell copies of this thesis, to the NATIONAL LIBRARY OF CANADA to microfilm this thesis and to lend or sell copies of the film, and UNIVERSITY MICROFILMS to publish an abstract of this thesis.

The author reserves other publication rights, and neither the thesis nor extensive extracts from it may be printed or otherwise reproduced without the author's written permission. 


\section{ACKNOWLEDGEMENTS}

I wish to sincerely thank my advisor Dr. William D. Wade for his guidance, for his encouragement, and in particular for his faith in me the past several years. I would also like to acknowledge his assistance in formulating the Alveolar Emergence Index.

All the members of my committee have also been very helpful. In particular I would like to thank Dr. Arthur T. Storey who always takes the time to listen, to offer suggestions, and to ask a new question.

I also wish to thank the Manitoba Dental Association and the many dentists in Manitoba for their gracious cooperation which permitted me to collect all of the radiographs used in this study.

I am also very much indebted to Dr. F.S. Chebib and Ms. Monele Abdel-Hadi in the Biostatistics Department, Faculty of Dentistry, and also to Ms. Salwa Barakat and Ms. Allison Travis for all their help in computer programming and statistical analyses.

I am very grateful to Ms. Linda Delmage for her long hours typing this manuscript into the word processor; to Ms. Nikki Ryan for typing all the tables; to the Art and Photography Department, Faculty of Dentistry for preparing the histograms, Figure 13, and the printing of the radiographs; and to the Radiology Department, Faculty of Dentistry, for the use of the duplicating printer and the automatic processor to reproduce the radiographs.

I would also like to thank my husband for his encouragement and remarkable patience; and to acknowledge Ms. Marg Miller, Ms. Shirley 
Gelskey, Ms. Marnie Forgay, and my other colleagues for their counselling and encouragement.

I am also grateful for the financial support which I have received from Dr. A. Schwartz, Dean of Dentistry, M.R.C. Grant No. 321-2301-08; and from the Northern Studies Committee, Grant No. $345-1615-03$ 


\section{ABSTRACT}

The purpose of this multidisciplinary study is to determine the mean age and range of variation for the calcification and eruption of the permanent teeth in Native Canadian populations, and to determine whether there are significant differences between these populations and other North American Native and North American White populations.

As more Canadian Inuit and Indian patients seek comprehensive dental treatment, including orthodontics, the recognition of significant genetic and environmental differences in the development of the permanent dentition could facilitate the timing and the type of dental treatment selected. As well, variations in the timing of calcification and eruption of the teeth are extremely relevant to the identification and the assessment of age and sex of skeletal material, for both anthropological and forensic purposes. At the present time, all skeletal remains are compared to Caucasian standards of dental development, particularly gingival emergence.

Panoramic data for this cross-sectional study was obtained from several clinical sources in Manitoba. All of the permanent teeth were studied, using twelve stages of calcification modified from Nolla (1960) and Moorrees et al. (1963). As well, four stages of eruption were considered, modified from Massler and Schour (1941).

The mean age for each calcification score was found to be younger in both the Inuit and Indian samples, compared to studies of White populations, for all teeth except the premolars and second molars. Calcification occurs earlier in Inuit females than males in certain 
teeth. Indian females were clearly advanced in calcification over Indian males. A Dental Calcification Index was calculated using Nevile's (1973) formula in order to derive a dental age from the mean ages of calcification for each subject. A high correlation was found between the dental age and the chronological age.

The results of this study show that while there are slight genetic differences resulting in earlier eruption of certain teeth, particularly in the Inuit sample, the primary cause of differences in the timing of eruption is the premature loss of the deciduous teeth. There is also a significant time lag between the mean age of alveolar and gingival emergence for each sample, which varies for each tooth. Thus, clinical standards for gingival emergence do not accurately predict the mean age of alveolar emergence. An Eruption Index has been developed to more accurately predict age in skeletal material from the age of alveolar emergence. 


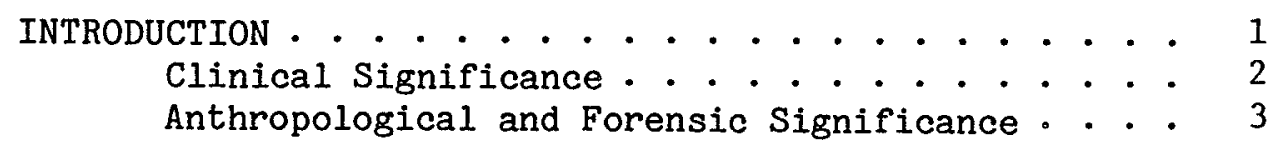

DENTAL DEVELOPMENT . . . . . . . . . . . . 4

Sex Differences............... 9

Third Molars .. . . . . . . . . . . . . 9

Genetic and Environmental Influences . . . . . 11

Correlations of Tooth Formation to Other

Developmental Phenomena... . . . . . 11

INDICES OF DENTAL MATURATION . . . . . . . . . . . 14

GINGIVAL EMERGENCE . . . . . . . . . . . . 15

Sex Differences............... 16

Eruption Sequence . . . . . . . . . . . . 16

Genetic Influences on Dental Eruption . . . . . . 18

Environmental Influences on Dental Eruption . . 19

THE RELATIONSHIP OF CALCIFICATION TO ERUPTION . . . . 21

ALVEOLAR EMERGENCE . . . . . . . . . . . . . . 23

DENTAL DEVELOPMENT IN INUIT AND INDIAN POPULATIONS . . 25

THE SAMPLE . . . . . . . . . . . . . . . . 29

CALCIFICATION AND EMERGENCE SCORING SYSTEMS . • . . . 31

Preliminary Scoring System . . . . . . . . 32

RELIABILITY TESTS . . . . . . . . . . . . . 33

Intra-Observer Reliability ........ . 34 
Inter-Observer Reliability . . . . . . . . 34

Reliability of Interpretation from the

Panoramic Radiograph .......... 35

Film Error. . . . . . . . . . . . 35

FINAL SCORING SYSTEM . . . . . . . . . . . 38

Calcification Scores . . . . . . . . 38

Eruption Stages . . . . . . . . . . . . 40

Calcification Index . . . . . . . . . . 43

Alveolar Emergence Index . . . . . . . . . 44

III RESULTS . . . . . . . . . . . . . . 46

DENTAL CALCIFICATION ............... 46

Tooth Sequence for Calcification... . . . 49

Mean Age of Calcification, Sexes and Quadrants Combined .. . . . . . 51

DENTAL CALCIFICATION INDEX . . . . . . . . . 52

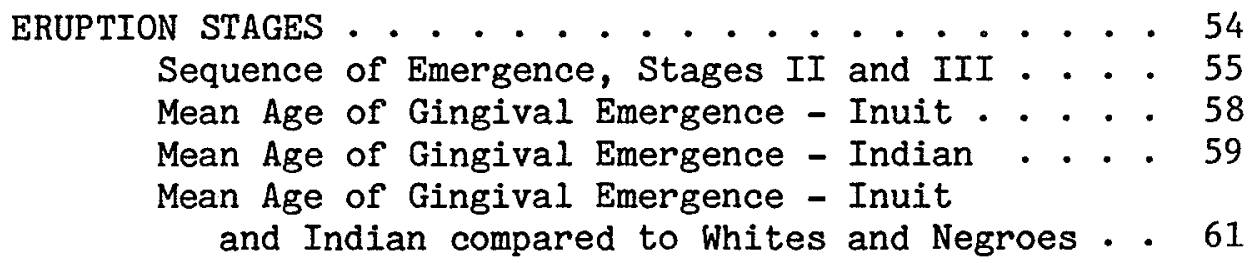

THE RELATIONSHIP BETWEEN ROOT CALCIFICATION

AND EMERGENCE STAGES . . . . . . . . . . . . 62

Alveolar Emergence.... . . . . . . . 62

Gingival Emergence........... . 63

ALVEOLAR EMERGENCE INDEX . . . . . . . . . 66

IV SUMMARY AND CONCLUSIONS ............. 67 
LITERATURE CITED . . . . . . . . . . . . . . . 74

APPENDIX A....................... . . 86

Figure 1 - Histogram - Age and sex distribution of the Inuit sample . . . . . . 86

Figure 2 - Histogram - Age and sex distribution of the Indian sample... . . . . .

Table I - Selected keys for the scoring of calcification. . . . . . . . . 88

Table II - Mean age in years - absence of crypt (calcification score 0 )......

Table III - Mean age in years - crypt visible (calcification score 1)...... 90

Table IV - Mean age in years - initial calcification (calcification score 2) . . . 91

Table V - Mean age in years - crown $1 / 4$ complete (calcification score 3). . . . 92

Table VI - Mean age in years - crown 1/2 complete (calcification score 4). . . 93

Table VII - Mean age in years - crown $3 / 4$ complete (calcification score 5). . . . 94

Table VIII - Mean age in years - crown complete (calcification score 6). . . . . 95

Table IX - Mean age in years - root $1 / 4 \mathrm{com}-$ plete (calcification score 7). . . 96

Table X - Mean age in years - root $1 / 2$ complete (calcification score 8). . . . 97

Table XI - Mean age in years - root $3 / 4$ complete (calcification score 9). . . . 98

Table XII - Mean age in years - root complete, open apex (calcification score 10) . . 99

Table XIII - Mean age in years for each calcification score by tooth type..... 100

Figure 3 - Scattergram of maxillary calcification index and chronological age for Inuit, sexes combined. . . . . . 106 
Figure 4 - Scattergram of mandibular calcification index and chronological age for Inuit, sexes combined . . . . . . 107

Figure 5 - Scattergram of maxillary calcification index and chronological age for Indian, sexes combined . . . . . . 108

Figure 6 - Scattergram of mandibular calcification index and chronological age for Indian, sexes combined . . . . . 109

Table XIV - Mean age in years of Stage I of eruption (Pre-eruption, crown complete) ........... 110

Table XV - Mean age in years of Stage II of eruption (alveolar emergence). . . . 111

Table XVI - Mean age in years of Stage III of eruption (gingival emergence).. . . . 112

Figure 7 - Mean age of gingival emergence Inuit females (compared to other Native samples) . . . . . . . 113

Figure 8 - Mean age of gingival emergence Inuit males (compared to other Native samples) ......... 114

Figure 9 - Mean age of gingival emergence Indian females (compared to other Native samples) . . . . . . . 115

Figure 10 - Mean age of gingival emergence Indian males (compared to other Native samples) . . . . . . . 116

Figure 11 - Mean age of gingival emergence females (compared to other non-Native samples) . . . . . . . 117

Figure 12 - Mean age of gingival emergence males (compared to other non-Native samples). . . . . . . . . 118

Table XVII - Root calcification attained at alveolar emergence . . . . . . 119

Table XVIII - Root calcification attained at gingival emergence . . . . . . . . . 121

Figure 13 - Duration of alveolar-gingival emergence and root calcification scores 


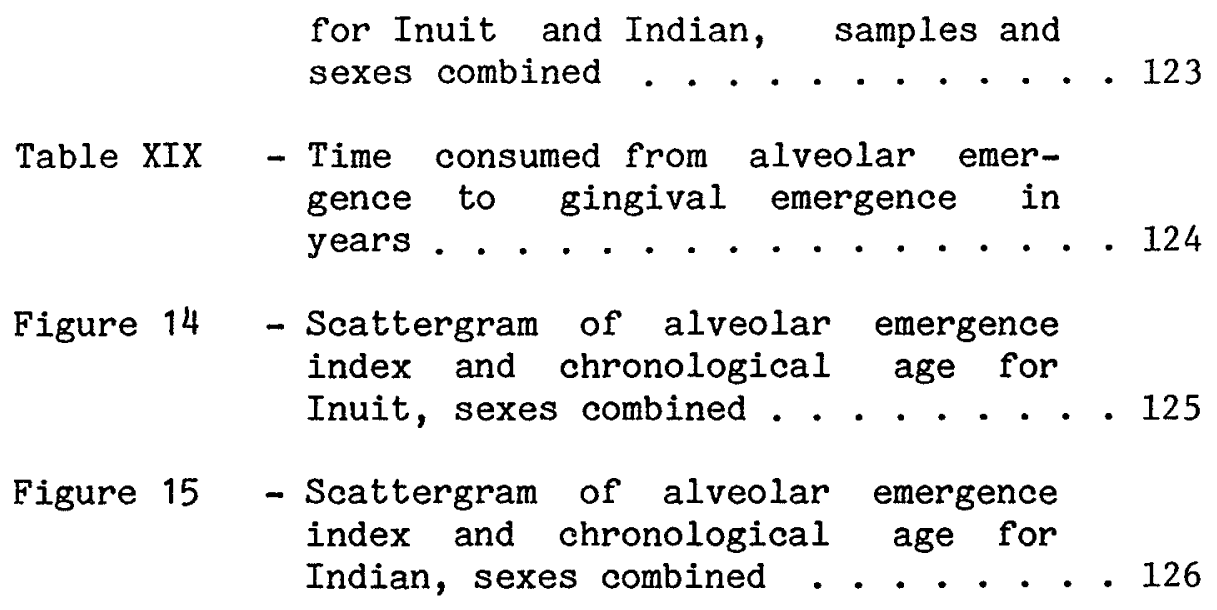

\section{APPENDIX B}

$$
\begin{aligned}
& \text { Figure } 16 \text { - Chart data recording form... . . } 127 \\
& \text { Figure } 17 \text { - Radiographic data recording form • . } 128 \\
& \text { Figure } 18 \text { - Tooth development scoring system . . } 129 \\
& \text { Figure } 19 \text { - Panelipse x-ray - Inuit male, } 2.26 \\
& \text { years (Case No. 694). . . . . . } 132 \\
& \text { Figure } 20 \text { - Panelipse x-ray - Indian female, } \\
& 5.90 \text { years (Case No. 079) . . . . } 133 \\
& \text { Figure } 21 \text { - Panelipse x-ray - Inuit male, } 10.02 \\
& \text { years (Case No. 675). . . . . . . } 134 \\
& \text { Figure } 22 \text { - Panelipse x-ray - Indian female, } \\
& 11.38 \text { years (Case No. 133). . . . . } 135
\end{aligned}
$$


CHAPTER I

INTRODUCTION 
CHAPTER I

\section{INTRODUCTION}

Numerous studies have been done on the development and eruption of the permanent teeth in North American Caucasian children. Most of this work has been done in the United States (Logan \& Kronfeld, 1933; Massler \& Schour, 1941; Carlson, 1944; Garn \& Lewis, 1955, 1957, 1958, 1960, 1963, 1972; Moorrees, 1959; Shumaker, 1960, 1974; Nolla, 1960; Bradley, 1961; Knott \& Meredith, 1966). Work has also been done at the Burlington Orthodontic Research Centre by Posen (1965) and Feasby (1971, 1981), also with Caucasian samples. Lo and Moyers did a study in Toronto (1953) but the ethnic origin of their sample was not defined. More recently Perreault (1974) and Masson (1980) have looked at the timing of gingival emergence in French-Canadian children.

of the studies surveyed, those that considered differences in males and females found that permanent teeth generally erupt earlier in females than in males (Steggerda \& Hill, 1942; Lo \& Moyers, 1953; Moorrees, 1957; Nolla, 1960; Carr, 1962; Posen, 1965; Knott \& Meredith, 1966). The sequence of eruption was also found to differ between males and females, according to Steggerda \& Hill (1942), Moorrees (1957) and Knott and Meredith (1966). As well, the sequence of calcification, emergence through the alveolar process, and clinical emergence through the gingiva, do not always correlate (Garn \& Lewis, 1957; Knott \& Meredith, 1966). The main discrepancy occurs with regard to the premolars and second molars, particularly where the deciduous molars have been lost prematurely (Posen, 1965). 
The only studies on the dental eruption of North American Native populations have been the work of: Hrdlicka (1908) and Dahlberg \& Menegaz-Bock (1958) on the Pima Indians; Steggerda \& Hill (1942) who compared four populations: Whites (Dutch), Negroes (southern rural U.S.A.), Navajo (reserve), and Maya (Yucatan); Garn and Moorrees (1951) on emergence in Aleut children; Mayhall et al. (1977) on Cree and Ojibwa Indians (Northern Ontario); and Mayhall et al. (1978) on the Inuit (Foxe Basin).

Dahlberg and Menegaz-Bock (1958) compared their results to Clement's study of British children (1953). They found that a similar pattern of eruption existed in the maxilla and mandible in both boys and girls, but that the anterior teeth of the Pima erupt later than do those of the English, and the posterior teeth erupt earlier. They felt that the differences may be genetically based, environmentally induced, or "due to some complex of environmental and hereditary factors" (1958:1136). Steggerda and Hill also found that the order of eruption appears to be the same in all populations, but that there are genetic differences in eruption time. The earliest eruption of teeth occurs in the Navajo, followed by the Negro, the Maya, with the latest time of eruption occurring in the White sample (1942:369). No published studies on the stages of dental calcification have been done for Native populations either in the United States or Canada.

\section{Clinical Significance}

As more Canadian Indian and Inuit patients seek comprehensive dental treatment, including orthodontics, it is imperative that their 
dental development not be assumed to be identical to that of Caucasian children. If there are significant differences in the timing and sequence of eruption of the permanent teeth, particularly the canines, premolars, and second molars, this information could facilitate orthodontic treatment: preventive treatment such as space maintenance, limited interceptive treatment, and comprehensive treatment. If significant population differences do exist in the timing and sequence of dental calcification, as well as the timing and sequence of eruption, for Manitoba Native children, then the type of dental treatment selected at different ages may be altered. The population of Manitoba, in particular, is composed of so many ethnic groups that no single eruption standard is representative of the diversity that exists.

Anthropological and Forensic Significance

Anthropologists have long been interested in the physical characteristics of humans and how these characteristics differ between the many ethnic populations. Variations exist, not only between populations, but also between individuals within these populations. Variations in the formation and eruption of the teeth are extremely relevant in the identification and the assessment of age and sex of skeletal material. At present, all prehistoric remains are compared to the standards of dental development and eruption for North American White populations. No studies have been done in North America comparing the mean age of alveolar eruption to the mean age of gingival eruption. If standards for gingival eruption are applied to skeletal 
material without taking into consideration the time interval between alveolar and gingival emergence, there will be a variable amount of error in predicting the age.

In summary then, the major aims of this investigation are:

1). To determine the mean and range of normal variation for the timing and sequence of eruption of the permanent teeth for Native populations in Manitoba and the Northwest Territories.

2). To determine the mean and range of normal variation for the timing and sequence of calcification of the permanent teeth for Native populations in Manitoba and the Northwest Territories.

3). To compare the timing and sequence of calcification and eruption in Native populations to the standards set for North Americal White populations.

4). To determine the differences in the timing and sequence of calcification and eruption males and females in Native populations compared to North American White populations.

5). To determine whether there are significant correlations between the sequence of calcification and the sequence of emergence through the alveolar bone and the gingiva.

DENTAL DEVELOPMENT

In 1929 Logan and Kronfeld began their notable histological and roentgenological investigation. The material consisted of the jaws of 
30 infants and children aged up to 15 years. Logan and Kronfeld (1933) report the times of the initial calcification of permanent teeth, illustrated by histological sections and radiographs. The tables drawn up by Logan and Kronfeld lay out the chronology of the initial calcification of the deciduous and permanent dentitions, the completion of the crown and the termination of the calcification process as well as the eruption of the teeth. Apart from the fact that no idea of the range of variation or of sex differences could be obtained from such a small number of subjects, many of the subjects died from prolonged debilitating illnesses which could have affected the chronology of tooth development. Many contemporary references to tooth formation and its variation are derived from the studies of Logan and Kronfeld, but their ranges are unduly narrow owing to the extremely small sample investigated. Although Logan and Kronfeld did not claim to provide 'norms' in the usual sense, many later authors have unfortunately assigned this authoritative status to their findings, and these tables have found their way into a large portion of the literature up to the 1960's.

In assessing age from dentitions that are immature, use is commonly made of a chart prepared by Schour and Massler (1941), published in slightly modified form by the American Dental Association and reproduced in many textbooks. This chart, like many charts and tables of its kind, is based to a large extent upon the observations made by Logan and Kronfeld (1933) and Kronfeld $(1935 a, b, c)$. In practice, however, the Schour and Massler chart appears to give useful and reasonably reliable results (Brauer and Bahador, 1942; Miles, 1958; Gray and Lamons, 1959). Its use is, however, virtually limited to ages below 
15 years because no stages of growth of the third molars are recorded for the ages between 15 and 21 years.

Review of the earlier literature relating to tooth formation reveals that the technique, material and methods used to do not give a correct picture of continued growth and development. It was not until the 1950's that studies began to appear that were based on new procedures, and no longer copied old tables, because deficiencies had been detected in them. One noteworthy longitudinal research project was started in the United States as early as 1930, under the direction of Dr. H.C. Stuart at the Forsyth Dental Infirmary, Harvard University, which dealt with the development of healthy Boston children. From this material several papers have been published since the mid-1950's that deal with tooth development. Another important longitudinal study was undertaken around the same time at the Fels Research Institute in Ohio, which has produced a number of reports on dental development, by Garn and colleagues.

The Stuart material was used by Gleiser and Hunt (1955) to produce a notable study on the calcification, eruption and decay of the permanent mandibular first molar. In their investigation of the calcification process, Gleiser and Hunt were the first to divide tooth formation into 15 developmental stages. They described in detail the stages of growth of the first molar in radiographs of 25 girls and boys, taken at six month intervals from birth onwards. The mean values given by Gleiser and Hunt for the early stages of formation of the first permanent molar are several months later than those depicted on the Schour and Massler chart, and the data of Garn et al. (1959) put these stages slightly later still. These discrepancies are not gross, 
however, especially when the whole dentition is being assessed.

A similar, but larger and more extensive longitudinal study by Garn et al. (1959) has provided data relating to all the permanent mandibular molars and premolars. Being based on a study of 225 children, and presented with particularly good statistical treatment, this study shows, virtually for the first time, the range of variation that exists. For instance, the 50th percentile value for the age of apical closure of the first permanent molar in girls was 10.4 years, and the 5 th and 95 th percentiles were 9.0 and 11.4 years respectively. These workers modestly issue the warning, however, that the size of their population sample falls short, though not grossly, of the number necessary for the establishment of a system of reliable 'norms' (1959:146). It is worthy of note that Garn et al. (1959) found that the chronology of tooth development was slightly less variable than that of osseous development among the same group of subjects.

A smaller but similar longitudinal study by Fanning (1961), as well as providing data comparable to, but by no means in complete agreement with, that of Garn et al. (1959), has added information about the chronology of resorption of the roots of the deciduous teeth. Using the same material, Moorrees et al. (1963) supplemented the foregoing findings by reporting on the formation of the permanent mandibular teeth, with the exception of the incisors, between the ages of 0 to 21 years, and on the upper and lower incisors from the fourth year of life onward.

In her longitudinal study, Nolla (1960) depicts tooth development from the ages of 2 to 17 years by means of graphs and tables. She concludes that the type of growth displayed by each tooth is the same, 
and that few developmental differences existed between the right and left sides for teeth of the same type (1960:265).

Since among the permanent teeth the first molar begins to form first, the development of this tooth has been studied most. Many researchers have observed the process of calcification to have started from the tip of the mesio-buccal cusp, to continue from the distobuccal, then the mesio-lingual and finally the disto-lingual cusp (Kronfeld, 1935a; Gleiser and Hunt, 1955; Butler, 1967). There are distinctly slower and faster stages in tooth calcification. Carlson (1944), from radiographs; Kronfeld (1935a), from histological sections; and Gleiser \& Hunt (1955) and Moorrees et al. (1963), from radiographs; have noted that the initial calcification becomes more rapid before the completion of the crown. "The rate of tooth development is not constant when judged from the mean interval between stages. For instance, the formation of the second quarter of the mandibular canine and premolar roots required 1.3 years for the second premolar in females and 2.3 years for the canine in males. The fourth quarter root of these teeth was formed in only 0.7 and 0.6 years respectively" (1963:1496-1497). Schour and Massler (1940a) reported that when the root development is half completed, the calcification is accelerated to its maximum. Haavikko (1970) also found that, when the duration of the different stages of root formation are compared, there is a greater length of time between the stages of crown completion and one-quarter root development for all teeth, and that the remaining three-quarters of root formation appear to progress more rapidly than the first (1970:143). 
Sex Differences

When material can be sexed, allowance can be made for the fact that tooth development is very slightly but significantly more advanced in girls than in boys at all stages, even before puberty (Gleiser and Hunt, 1955; Garn et al., 1958). Garn et al. noted that the differences are of the order of 1 month in infancy, and 4 months at 9 years, and are slightly greater in respect to eruption than to tooth formation. These sex differences are, however, about three times less than those for osseous development over the same period so that, where material of unknown sex is concerned, estimates of age based upon the dentition are more likely to be correct than ones based upon osseous development. Sex differences amounting to about 3 percent for calcification are about the same as for the clinical eruption of teeth (5\%). Both events thus represent smaller differences by sex than in bone development, where they amount to between 10 to 20 percent $(1958: 566)$.

Nolla (1960) observed that there were no significant differences in the rates of calcification in males and females, and that, on the average, there were no apparent differences in the general sequences of calcification between the sexes (1960:265).

Third Molars

The data published during the present century on the clinical eruption age of wisdom teeth give a wide range between 16 and 40 years. The most frequently reported age of gingival emergence for 
wisdom teeth is the period between 17 and 21 years (Logan and Kronfeld, 1933).

The differences in the development of wisdom teeth between the sexes are not so clear as for the other teeth. Many researchers have detected no sex differences with respect to the emergence of the third molar (e.g. Steggerda and Hill, 1942). There are some researchers who have found boys to undergo an earlier eruption of this tooth than do girls (Fanning, 1962), and there are others whose observations place the girls first. On the other hand sex differences, though not marked ones, in the formation of the wisdom teeth have been noted by many researchers. According to Nolla (1960), girls experience the calcification process earlier. According to the findings of Demisch and Wartman (1956), girls are earlier in four of the six comparable calcification stages from the crypt to the initial root formation. By contrast, Garn et al. (1962a) observe that no significant sex differences occur during the entire period of development of the wisdom teeth "thus being unique among the teeth." (1962a:278)

Studies on the developmental age of the upper and lower wisdom teeth have reported the maxillary teeth to be more often earlier. However, calcification is observed by Demisch and Wartman (1956) to be generally symmetrical in 71 to 85 percent of the cases. The first radiographically visible calcification stage of a wisdom tooth occurs between the ages of six and thirteen years, the mean falling between nine and ten (Demisch and Wartman, 1956; Garn et al., 1962). At the age of 21 years, on the average, the root formation of the third molar is complete. 
Genetic and Environmental Influences

Garn et al. (1960) compared three stages of calcification for all the teeth in sibling pairs and monozygotic and dizygotic twins in order to determine whether, and to what extent, tooth development shows evidence of genetic control. Their results show very low correlations between the sibling pairs and the dizygotic twins, but very high correlations $(0.91)$ between the monozygotic twins. From these results Garn et al. conclude that the rate of tooth development is largely, though not entirely, under genetic control (1960:174). Nanda and Chawla (1966) conclude, on the other hand, that the retardation in root development seen in tropical zones is intimately related to nutritional status and environmental conditions and that the differences observed were not genetic but due to differences in nutritional status and health standards (1966:850).

Correlations of Tooth Formation to other Developmental Phenomena

The concept of physiological age is based upon the degree of maturation of different tissue systems. Several biological ages have been developed: skeletal age, morphological age, secondary sex character age, and dental age. These criteria can be applied separately or together to assess the degree of physiological maturity of a growing child. Dental age is of particular interest to the orthodontist in planning the treatment of different types of malocclusions in relation to maxillofacial growth. It can also be a help in determining the age of skeletal material where other parts of the body are miss- 
ing.

Numerous studies have been published on the correlations between the formation of teeth and other developmental occurrences. In an investigation carried out with the Stuart material, Gron (1962) noted that "tooth emergence appears to be more closely associated with the stage of root formation than with chronological or skeletal age of the child" (1962:584). In the light of her data, most teeth erupt clinically when root development is three-quarters complete. Data on the correlation between tooth formation and skeletal development have been published by Lamons and Gray (1958), Lauterstein (1961), and Liliequist and Lundberg (1971). Lamons and Gray (1958:690) report that skeletal age and dental development vary independently. Lauterstein (1961) maintains that an intimate correlation exists between root age and bone age (1961:164). Liliequist and Lundberg (1971) found also that there was a high correlation $(r=0.88)$ between tooth development and the skeletal age of the hand-wrist (1971:109). Lauterstein (1961:164) found that there was "an intimate developmental relationship between root age and bone age" with a rank order correlation as high as 0.437 .

Investigating the relationship between tooth formation and other maturational factors, Lewis and Garn (1960) found that the correlation varies at different developmental stages and ages. "Tooth formation proved no more variable and of ten less variable than the age developmental variability of menarche, hand age or the appearance of the ossification centers." (1960:72) They also report a correlation, but not a high one, between dental development and skeletal development $(r=0.40)$ at sexual maturity $(1960: 76)$. 
Krogman $(1968 a, b, c)$ examined the criteria and correlations of biological maturation that have been applied in recently published studies. Considering the factors of skeletal age, dental age, calcification age, ossification, hand age, menarche, and the maximum of the growth spurt, he concludes that tooth formation age and menarche are best suited to the determination of biological maturation because they vary least. He observes further that the application of the tooth formation findings in any given population to other populations can in many cases be of doubtful validity. Hunt and Gleiser (1955) also agree that, "with increasing age, boys and girls diverge much more rapidly in skeletal maturation than in the development of the permanent teeth." (1955:482)

Several authors have asserted that the calcification stage of the teeth is a far more reliable criterion in estimating the dental age than is the clinical eruption of the teeth, which is far more liable to be affected by many external factors. According to Fanning (1961) "tooth formation is preferable to tooth emergence for assessing dental age because it is not influenced as markedly by exogenous factors; and a rating is possible at all times from birth until the completion of the third molar at about twenty years of age." (1961:203) Gleiser and Hunt (1955) and Liliequist and Lundberg (1971) suggest that the calcification of a tooth may be a more meaningful indicator of somatic maturation than its clinical emergence. This view is supported by Nanda (1960) who found only a low correlation between the age at complete emergence of the permanent dentition, the age at the maximum rate of the circumpubertal growth spurt in height in both sexes, and the age at menarche in girls. Moorrees et al. (1963) reported that 
tooth formation is superior to tooth emergence for assessing dental maturation. They also suggested that it is dangerous to assess total maturation of the individual from any one tissue system, particularly the teeth, because it has not been established that there is a direct and strong correlation between tooth development and other indicators of individual maturation (1963:1490).

INDICES OF DENTAL MATURATION

Until quite recently, clinical eruption has been the only criterion used for dental maturity. Norms derived from Logan and Kronfeld's data (1933) as modified by Schour and Massler (1940b), as well as from Hurme's (1949) and Clements et al. (1953) data have been used extensively. If clinical emergence is used as the criterion for dental age assessment, it can only be applied after the age of six years for the permanent dentition.

Bean (1914) was among the first to use clinical emergence to derive a dental age. The teeth were scored according to the sequence in which they erupted. Matiegka (1921) used a similar method for scoring each group of teeth according to their sequence of eruption. Cattell (1928), using his own data, attempted to use both of the previous methods and found that they didn't give satisfactory results because there was often too much variation in the sequence of eruption. He found that an easier and more satisfactory method was just to count the erupted teeth without worrying about the sequence (1928:28-30). Steggerda (1945) also experimented with three different methods for determining dental age from the mean age of eruption for 
each tooth. He concluded as well, that the best method was just to count the teeth that were present. He found that "practically the same correlations were achieved as with the more elaborate methods." $(1945: 341)$

Nolla (1960) was the first to use the developmental value obtained for each tooth to derive a dental age. The values for each tooth were added together and the sum for each arch was matched with a table for the tabulation of the dental age. Demirjian and Tanner (1973), used the approach of Tanner et al. (1962) to give each tooth a score depending on its stage of calcification. The scores on all the teeth were then added together to give a total maturity score which could be converted directly into a dental age, using an appropriate table of standards. Nevile (1973) utilized the mean age values for each tooth stage derived from his sample, to calculate a dental calcification age for each subject. The sum of all the mean ages corresponding to the tooth stages recorded for the subject were divided by the number of mean ages considered (1973:43).

GINGIVAL EMERGENCE

More than any other matter related to dental development, the clinical eruption of teeth has commanded the attention of research workers. Cumulative incidence curves representing the percentage of children at each age with a given tooth erupted have been drawn by various authors in cross-sectional surveys (Cattell, 1928; Hellman, 1943; Clements et al., 1953a; Hurme, 1948, 1949).

Many investigators have observed the existence of differences 
between the upper and lower jaw with respect to the time of eruption of corresponding teeth. The incisors and canines of the lower jaw erupt about a year earlier than the corresponding teeth of the upper jaw in both sexes; the lower second molars emerge about 6 months earlier than the upper ones do, the mandibular and maxillary first molars almost simultaneously, while the first and second premolars make their appearance roughly six months later in the lower jaw (Hurme, 1949; Clements et al., 1953a; Dahlberg and Menegaz-Bock, 1958; Carr, 1962).

\section{Sex Differences}

Sex differences are generally clear in the emergence of teeth. Although the standard deviations in eruption ages are similar in both sexes, girls are on the whole ahead of boys to the extent, on the average, of some two months in regard to the first molars and as much as 11 months in regard to the canines (Cattell, 1928; Hellman, 1943; Hurme, 1948, 1949; Adler, 1958; Magnusson, 1976). According to Adler (1959) in the ten-year span of 1949-1959 alone, 521 international studies dealing with the eruption age of the permanent teeth among 40 different nationalities were published. In 494 of the papers, girls were reported to be earlier than boys in the eruption of their teeth (Adler, 1958:81).

\section{Eruption Sequence}

Massler and Schour (1941) divided the eruption of the permanent 
teeth into three phases: the first phase included the first molar and the incisors, the second phase includes the canines, premolars and the second molars, and the third phase is devoted to the third molars. Lo and Moyers (1953) found that there was greater variation in the eruption sequence in the teeth of the second group than in the other groups.

According to many studies on the eruption sequence of permanent teeth, the mandibular first molars are the first of the permanent teeth to emerge (Cattell, 1928; Hurme, 1948; Lo and Moyers, 1953). But there are also a large number of investigators who report having observed the mandibular first incisors to be the first teeth to emerge (Steggerda and Hill, 1942; Hellman, 1943; Clements et al., 1953b; Butler, 1962). The eruption sequence of the upper and lower jaw differs, as is well known, and distinct sex differences have been noted with regards to the canine teeth. Knott and Meredith (1966) describe four eruption sequences in their longitudinal study, two in the upper and two in the lower jaw, that occur with the highest frequency and in over 15 percent of their subjects. Lo and Moyers (1953) report the same four sequences of eruption, although the percentages of their occurrence differ from those arrived at by Knott and Meredith. In 1950 Schultz presented a tooth eruption sequence schedule for contemporary humans, (I1 M1) I2 (P1 C P2) M2 M3, in which the teeth marked in parentheses may exchange places. This eruption formula does not, however, take into account those sequences in which the second molar emerges before the canine, the first premolar or the second premolar. Such sequences have been reported by Steggerda and Hill (1942), Clements et al. (1953b), and Dahlberg and Menegaz-Bock (1958). 
In the light of their own observations, Koski and Garn (1957) revised Schultz's formula as follows: (I1 M1) I2 (P1 C P2 M2) M3, which includes all the eruption sequences likely to occur in contemporary humans. However, eruptions deviating even from this range of sequences have been reported. According to Schour and Massler (1941), "the order of eruption is far more important than the chronological age of the child. The actual age at eruption of any of the teeth is quite variable, depending upon race, sex, type, and systemic as well as local conditions." (1941:1159).

\section{Genetic Influences on Dental Eruption}

Genetic differences with respect to the eruption of teeth have been observed. In general, the teeth of Whites of European origin erupt at a later date than do those of, for example, American Indians, American Negroes, South African Negroes, Ghanaians, Filipinos, "Jews" and Southeastern Dominicans (Bean, 1914; Catte11, 1928; Steggerda and Hill, 1942; Dahlberg and Menegaz-Bock, 1958; Garcia-Godoy et al., 1982). The tables of Bean (1914) include the most extensive data based on American children. He included separate tables for Americans, Germans and Filipinos. He tabulated separately the upper and lower arches and the sexes, but he gives his norms only within wide age limits.

In Magnusson's study of the mean age of gingival emergence in Icelandic children (1976), there was strong agreement between his results and those of Helm (1974), who did a similar study of Danish children. Magnusson noted a slight tendency for earlier emergence in 
Iceland, but the only significant difference observed was for the maxillary second premolar in females (1976:36).

Masson (1980) compared the timing of gingival emergence in Caucasoid children of Northern Quebec to that of Northern Ontario Indians (Mayhall et al., 1977). He found that there were striking differences in the emergence patterns between the two populations. The population of Northern Quebec showed a retarded emergence of about six months for most teeth. The mandibular lateral incisor and first premolar emerged at about the same time as the Indian sample and the maxillary central and lateral incisors emerged earlier in the Caucasoid sample (1980:645). Masson attributes these differences to genetic rather than environmental influences. "The results suggest that caries or premature extraction of deciduous teeth and the climate and socio-economic status seem to play little role compared to the genetic differences of the populations when tooth emergence is studied." (1980:643).

\section{Environmental Influences on Dental Eruption}

The influence of environmental factors on tooth emergence has been pointed out by Hellman (1923), Cattell (1928) and others. Socio-economic circumstances have also been observed to affect the eruption age of teeth. It has been demonstrated that in children belonging to different socio-economic levels, and in children from city and rural groups, the underprivileged children and those from rural districts were later in their tooth emergence. Clements et al. (1953a) also found that higher socio-economic groups are more advanced 
in their dental development. Hellman (1943), however, reported contrary findings in studying "rich" and "poor" children, but his results may have been conditioned by a genetic difference between his two samples. These differences in tooth emergence are thought to be due to the supposedly better diet of the early eruptors.

Environmental factors other than diet or urbanization may affect tooth emergence. For instance, it has been shown in the laboratory that body growth and eruption of the incisors in rats can be retarded through the addition of a 0.05 to 0.1 percent solution of a fluoride to the food ration (Smith, 1934). These experimental results are also borne out by Short's (1944) observations that in children living in areas where fluoride was present up to 2.6 parts per million in the drinking water, the teeth were delayed in eruption. Adler and Godeny (1952) also reported a later emergence of premolars in children living in regions using naturally fluoridated domestic water than in children in fluorine-free regions. Castaldi and MacRae (n.d.), however, found no significant differences in the emergence time or in the sequence of emergence of the deciduous teeth between the children of two communities in Alberta, one with a low fluoride level in the water, and the other with an optimum level of fluoride ( 1.2 to $2.1 \mathrm{ppm})$.

The effect of premature extraction of the deciduous teeth due to caries or pulp infection, has been studied by several authors (Fanning, 1961, 1962; Adler, 1962; Butler, 1962; Posen, 1965; Lauterstein et al., 1962, 1967). These authors generally agree that, depending on the time at which the extraction occurs, there is a delaying or an accelerating effect on the eruption of the permanent successors. Fanning (1961) noted that while no changes were observed 
in the calcification of the premolars after extraction of the deciduous molar, there was an immediate spurt in the eruption of the premolar. Both Fanning (1961, 1962) and Posen (1965) found that very early extraction of the deciduous molar resulted in delayed eruption of its successor, but that eruption was accelerated if the extraction occurred after about 8 years of age. Fanning also noted that a long standing abscess with alveolar bone destruction caused early emergence, sometimes with immature root development and migration of the premolar (1962:45). Lauterstein et al. (1962) found that when a pulpotomy had been done on a deciduous molar, the underlying premolar erupted earlier than its antimere (1962:1369). Butler (1962), however, found no significant differences in the rate of premolar eruption following extraction of the deciduous molar. She concludes that "there is no evidence to show that the early loss of deciduous teeth is the major factor in causing teeth to erupt earlier, but that this advancement is more probably due to a general association with growth and development." (1962:448).

THE RELATIONSHIP OF CALCIFICATION TO ERUPTION

The movement of the teeth in the alveolar bone toward the oral cavity has been of interest to many of the early investigators (Orban, 1928; Logan and Kronfeld, 1933; Kronfeld, 1935a,b; Sicher, 1942). The actual measurement of tooth growth was inaugurated by Orban (1928), whose measurements from the base of the nasal bone to the germs of the upper incisors and from there to the epithelium of the mouth demonstrated that the Hertwig sheath remains fairly stationary during the 
growth of a tooth. Kronfeld's (1935a) histological and radiographical studies on the relation of the first molar to the mandibular canal support the view of the constant position of the Hertwig sheath.

Many studies have been published on the mechanism of tooth movement. Orban (1928) and Sicher (1942) regard the lengthening of the pulp and root as the chief factor in the movement of a tooth. Many researchers share the view that a tooth begins to move toward the oral cavity only after the crown has completely formed and root development started (Carlson, 1944; Shumaker and El'Hadary, 1960). Slight movement as early as the crypt stage, has been noted by Kronfeld (1935a) who remarks that movements take place even before the calcification of a tooth can be radiographically detected. According to Schour and Massler (1940a), calcification and tooth movement are two different processes. Carlson (1944:587) observes that "in some of the teeth elongation of the tooth and occlusal movement of the crown need not occur together." No lowering of the crypt occurs, either; only at the beginning stage of root formation does the root grow 2 to $4 \mathrm{~mm}$ downward. According to Shumaker and El'Hadary (1960), the movement of a tooth toward occlusion lasts about five years. In their study, Ando et al. (1965) follow the eruption process and report the occlusal surface of a tooth to be about 3 to $8 \mathrm{~mm}$ from the alveolar crest before actual tooth movement and "it would take from six to twelve months for a given tooth to move to the alveolar bone crest from its original position." Lauterstein et al. (1967) observed asymmetry in the eruption within the bone of the canines, first premolars and second premolars on the left and right sides of the jaws, and Lauterstein et al. (1968) report symmetry in the apical growth of teeth. 
Shumaker (1960) also looked at the relationship between tooth development and movement toward occlusion. He concluded that there does not appear to be a direct linear relationship. Therefore, as the developing tooth becomes longer, a corresponding amount of eruption does not necessarily occur (1960:540). Gleiser and Hunt (1955) found that in the interval between alveolar and clinical emergence the tooth elongates at a moderately rapid rate, but that calcification is most rapid following gingival emergence. After the tooth reaches occlusion, the roots continue to elongate slowly for several years (1955:266). According to Gron (1962), the majority of all teeth have attained approximately three-quarters of their roots at the time of gingival emergence. The mandibular first molar and central incisor, however, had generally less root development at emergence than any of the other teeth, with about half of their roots completed (1962:577).

Feasby (1981) found that following the completion of the crown, the tooth erupts toward the occlusal plane at a constant rate until the last year before the tooth reaches occlusion at which time a "preocclusal eruption spurt" occurred, followed by a sharp reduction in the rate of eruption $(1981: 557)$.

\section{ALVEOLAR EMERGENCE}

The literature contains very little information on the chronological age of the alveolar eruption of teeth or on the developmental stage of the roots at the time of this event. In most instances the information is limited to only one or a few teeth which are merely mentioned in addition to other findings. Gleiser and Hunt (1955) 
report that the alveolar emergence of the first molar takes place at the age of 5.4 years, when root formation has nearly reached $1 / 4$ completion. Garn et al. (1958) give mean ages of alveolar emergence for the first and second molars and the first and second premolars, in their work on the sex difference in tooth calcification. Lewis and Garn (1960) likewise view alveolar emergence as one stage of dental development but estimate no mean ages. Fanning (1961) notes that the root of the first molar is about $1 / 3$ complete at the time the tooth penetrates the alveolar bone.

Koski and Garn (1957) and Garn et al. (1957) refer to the alveolar emergence sequence of the mandibular second premolar and second molar in comparing the occurrence of different eruption sequences in fossil and modern humans. Several substitutes for the sequence of gingival emergence have been used for skeletal or fossil remains; primarily the order of calcification, alveolar emergence, and the order of attainment of the occlusal level. As Garn et al. state, "Invariably the assumption is made that these substitute sequences are either equivalent to, or identical with, the order of appearance of the teeth through the gums." (1957:314). Garn and Lewis (1963), referring to their observed discrepancies between the sequence of alveolar emergence and gingival emergence, conclude that this distinction is of major importance but that "most workers, however, seem to have taken alveolar eruption and gingival eruption as equivalent if not identical, whether working with monkeys or men." (1963:55). They found that a large proportion of American White children are of the M2P2 eruption sequence in alveolar emergence, but that the majority of the same children are of the P2M2 or 'modern' order of emergence 
through the gingiva (Garn et al., 1957). Koski and Garn (1957) and Hrdicka (1908) have found that M2P2 is also the most common sequence for the gingival emergence of mandibular teeth in Pima and Apache Indian populations.

To the best of my knowledge only one study has been published (Haavikko, 1970) on the time involved between the alveolar emergence of teeth and their gingival emergence. Haavikko has found that clinical emergence follows alveolar emergence very rapidly in the central incisors, and the mandibular lateral incisors, canines and premolars. The time interval between these two stages of eruption is considerably longer, however, for the maxillary lateral incisors, canines, and molars $(1970: 154)$.

DENTAL DEVELOPMENT IN INUIT AND INDIAN POPULATIONS

Several studies have been done comparing dental eruption in different populations outside of North America (Carr, 1962, 1963; Clements et al., 1953a,b; Helm and Seidler, 1974; Magnusson, 1976; Garcia-Godoy et al., 1982). Most of the published work on the calcification of the teeth has been done in North America, and with different Caucasian groups. Only a few studies have been done on the mean age of gingival emergence in Native populations in North America, and to the best of my knowledge, no work has been done on the timing and the sequence of calcification; the amount of root development at alveolar and gingival emergence; or on the relationship between the timing of alveolar and gingival emergence in these populations.

The earliest research is that of Hrdlicka (1908) who visited 
numerous Indian tribes in the southwestern United States and northwestern Mexico. When comparing the Apache and the Pima, he found very few differences in the timing of eruption except that the canines erupt a little earlier and the second molars are decidedly earlier in both tribes than in White children (1908:123). Steggerda and Hill (1942) compared the eruption times in four groups: American Whites, Negroes, Indians (Navajo) and the Maya, to the eruption standards of Logan and Kronfeld (1933). They found that there were significant differences between the four groups, with eruption being the earliest in the Navajo, then the Negro, the Maya, and finally the White. Steggerda and Hill attributed the wide range of variation to "differences in heredity, biologic function, nutrition, body growth, sex and race" (1942:361).

Garn and Moorrees (1951) compared the age of gingival emergence in Aleut children to the mean ages of emergence given by Hurme (1949). They found that "tooth emergence appears to be markedly and significantly earlier in these Aleut children" (1951:267). They also noted that the younger children appeared to be more advanced in tooth emergence and the older children were less advanced and were more like the White population. Dahlberg and Menegaz-Bock (1958) found that in their studies of the emergence of the teeth of the Pima Indian, that the replacement of the deciduous teeth with the permanent teeth starts later and finishes earlier than in most other populations (1958:1123). In comparing the Pima children to British children (Clements et al., 1953), they found that the anterior teeth erupt later in the Pima, but that the posterior teeth erupt earlier among the Pima (1958:1136). Boesen et al. (1976) compared the mean ages of emergence of the 
permanent teeth between two samples from East and West Greenland. They found that despite differences in the genetic background and environmental conditions, there were no significant differences between the two samples in the timing of gingival emergence. Both samples were advanced in their eruption over two Caucasoid and two Mongoloid populations, and the similarity between the two Greenland samples was greater than between any of the other four populations (1976:247).

In Mayhall's reports $(1971,1972,1978)$ on the Inuit of the Foxe Basin he states that gingival emergence is advanced in the Inuit, particularly among the males, compared to Western European Whites (1972:25). In their 1978 paper, Mayhall et al. compared their sample to that of Perreault et al. (1974). They found that the Inuit were also advanced in the time of emergence over the French-Canadian sample, particularly for the canines and the posterior teeth (1978:213). In their 1977 study of the Cree and 0jibwa of Northern Ontario, which Mayhall et al. also compared to Perreault (1974), they found no significant differences in gingival emergence in the mandible except for the first molar which was advanced in the Indian sample. In the maxilla, however, there were significant differences for both sexes, in the emergence of several teeth. The first premolar and the first molar were advanced, while the second premolar and the incisors were delayed in their emergence $(1978: 8)$ in the Indian sample. Mayhall et al. conclude that these differences are primarily genetic and not due to high caries or extraction rates, as the nutrition of their sample was high in caloric and protein intake, and the caries rate was low $(1978: 215)$ 
Mayhall et al. (1978) also compared the results for their Inuit and Indian samples to the Pima Indian sample studied by Dahlberg and Menegaz-Bock (1958). They found that the maxillary canine of the Cree-0jibwa male emerges before that of the Inuit, but for all the other maxillary teeth, both male and female, the Inuit show an earlier age of emergence. These differences tended to be greater between the females than between the males. In the mandible, however, the Indian samples showed earlier emergence for several teeth, particularly the first molar and the incisors (1978:213). 


\section{CHAPTER II}

METHODS AND MATERIALS 
CHAPTER II

METHODS AND MATERIALS

THE SAMPLE

The sample for this cross-sectional study consists of 236 Indian children from several reserves in Manitoba, Saskatchewan, and northwest Ontario, and 149 Inuit children from several settlements in the Keewatin zone of the Northwest Territories.

Panoramic and intra-oral radiographs are used in this study to assess the calcification and eruption stages of all the permanent teeth. The majority of these films were taken on the G.E. Panelipse machine, with a small percentage taken on the S.S. White Panorex and Siemens Orthopantomograph machines. No new radiographs were taken specifically for this study, but all the available radiographs were collected from private dental clinics throughout the province, and were duplicated at the University of Manitoba, using Kodak X-Omat duplicating film and the BXR MKII Duplicating Printer, to ensure consistent quality.

The sample was not selected at random, as panoramic radiographs are not routinely taken for every Native dental patient. Thus the 385 radiographs used in this study represent a very high percentage of the total number of Native people in Manitoba and the Keewatin zone under the age of 28 years who have ever had a panoramic radiograph taken.

The Inuit sample is composed of children from seven different 
settlements in the Keewatin zone: Baker Lake, Chesterfield Inlet, Coral Harbour, Eskimo Point, Rankin Inlet, Repulse Bay, and Whale Cove. All of the Inuit children had been patients at the Health Centre in Churchill. The Inuit of this Central Arctic area are considered to be culturally distinct from the Aleuts of Alaska and the Greenland Eskimo. The Inuit sample is composed of 81 females and 68 males. The age range is from 2.03 years to 21.59 years, with a mean age of 7.50 years. See Figure 1 for the age and sex distribution of the Inuit sample.

The Indian sample is composed of children from many different reserves throughout the province and consists of four major language groups: Cree, ojibwa (Saulteaux), and Sioux, who are all from the Northwest Plains cultural region. A small percentage are Chipewyan, from the Subarctic cultural region. The Indian sample is composed of 128 females and 108 males. The age range is from 2.43 years to 27.81 years with a mean age of 10.21 years. See Figure 2 for the age and sex distribution of the Indian sample.

The Inuit and Indian samples are considered separately in this study because of physical differences between them. Current anthropological theory holds that Inuit and Indian populations have been separated for a long period of time, except that Athapaskan groups, such as the Chipewyan, more closely resemble the Inuit than any of the other Indian groups (Szathmary and Ossenberg, 1978).

No consideration was made in this study of the amount or type of dental treatment received, or of the nutritional status of the two groups. A record was made of the extractions of deciduous and permanent teeth, where this information was available (Fig. 16 Appendix B). 
From my own personal observations it seemed apparent that the Inuit sample had received only emergency dental treatment except in those communities where there was a dental therapist (Eskimo Point and Rankin Inlet). The Indian sample received more restorative and preventive treatment with slightly fewer extractions recorded. The diet of both samples appeared to be adequate, but considering the high incidence of caries, particularly in the Inuit sample, very high in refined carbohydrates.

CALCIFICATION AND ERUPTION SCORING SYSTEMS

In the literature the most commonly used measure of dental age has been secured by noting the eruption of the teeth clinically. Although the eruption of the teeth may differ greatly in the time of appearance in the mouths of different children, the majority of the children exhibit some pattern in the sequence of eruption. A consideration of eruption alone, however, makes one aware of only one phase of the development of the dentition. A measure of calcification (maturation) at different age levels provides a more precise index for determining dental age. As Moorrees et al. state:

"Dental age can be determined by the emergence and by the formation of the teeth. Tooth formation is superior to tooth emergence for assessing dental maturation, because the majority of the teeth can be studied at each examination. In contrast, emergence is only a specific phase of eruption, rarely observed for more than one or two teeth at a time, if at all. Emergence is also influenced markedly by environmental factors such as loss of deciduous predecessors and the lack of space in the dental arch, explaining some part of the variation in root length at emergence." (Moorrees et al., 1963:1490) 
A survey of the literature revealed that many different categories have been used by various authors to assess the calcification and eruption stages of a tooth. Twenty-two of these categories were identified and then ranked in ascending order and assigned a number from 0 to 10 using Nolla's (1960) classification. The intermediate stages were assigned a decimal number depending on their proximity to the next category. This preliminary scoring system is summarized in the following chart.

\section{PRELIMINARY CALCIFICATION SCORING SYSTEM}

\section{$\underline{\text { Score }}$}

$0 \quad$ No change in bone density, and no crypt visible.

1.0 The crypt is clearly visible, but there is no evidence of calcification. The appearance of an almost circular radiolucent structure.

2.0 Initial cusp calcification. The appearance of small triangular radiopaque points close to the inner coronal border of the crypt.

2.2 Coalescence of at least two centres of calcification.

2.5 The outline of the cusps (incisal ridge) is complete.

2.8 The crown is $1 / 4$ complete.

3.0 The crown is $1 / 3$ complete.

3.5 The crown is $1 / 2$ complete.

4.0 The crown is $2 / 3$ complete.

4.2 The crown is $3 / 4$ complete.

5.0 The crown is almost complete.

6.0 The crown is complete.

6.2 Initial or minimal root formation. 


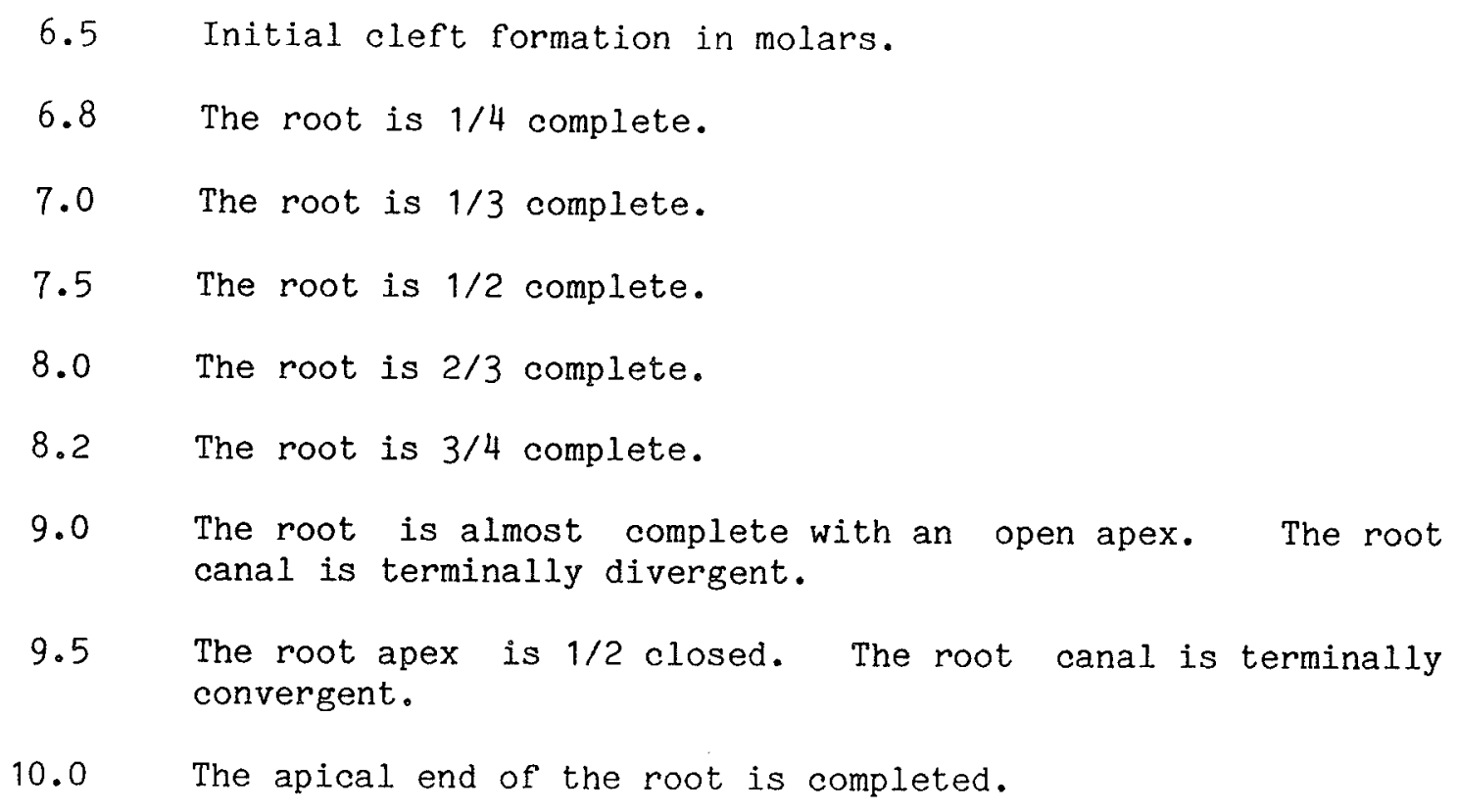

Very few of these categories have been well defined by the authors, but an attempt was made to correlate several selected scoring keys for calcification with my preliminary scoring system (Table I).

\section{RELIABILITY TESTS}

A series of eleven radiographs were scored twice by the author, and once by a second trained observer, in order to determine the ability to identify each of the 22 categories. The first eight radiographs selected did not include very young individuals (between the ages of 2-5 years), so an additional three radiographs were chosen from this age group to ensure that the lower age categories $(0-4$ years) were better represented. The eleven radiographs represented individuals between the ages of 2-12 years. 
Intra-observer Reliability

On the basis of 32 permanent teeth on each film, 352 observations were made on each scoring of the eleven radiographs. The number of errors by more than one category (i.e., a category was skipped on the second observation of the same tooth) was $5.4 \%$. The number of errors where the next category (upward or downward) was selected on the second observation was $51.4 \%$.

\section{Inter-observer Reliability}

The same number of observations were made by the second observer. The number of errors by more than one category was even higher, $12.7 \%$, while the number of errors by one category was slightly lower, $48.6 \%$. As a result of the considerable error in scoring each tooth for two adjacent categories, it was determined that this fine a degree of differentiation between calcification scores was too precise and could not be accurately used for cross-sectional data. With longitudinal data, one has the distinct advantage of the subsequent film, taken probably six months later, with which to compare. By eliminating several intermediate calcification scores, i.e. crown $1 / 3$ and $2 / 3$ complete, root $1 / 3$ and $2 / 3$ complete, $100 \%$ accuracy was achieved on both intra-observer tests, and $95.5 \%$ accuracy on the inter-observer test. 
Reliability of Interpretation from the Panoramic Radiograph

The only studies that have been done on tooth development using panoramic radiographs are Haavikko (1970) and Nevile (1973). Mattila and Haavikko (1969), and Haavikko and Mattila (1970) looked at the reliability of using the orthopantomograph film for interpretation of alveolar emergence and gingival emergence, compared to the clinical picture. Alveolar emergence was tested using skeletal material and gingival emergence was tested by clinical examination, which was done just prior to taking the radiograph. These evaluations were recorded independently and by two investigators. The incorrect evaluations made by the two investigators were almost identical (12 or 13 out of 283) with 9 of these errors involving the same teeth in the same individual (1970:192). More errors were made in evaluations of teeth in the maxilla than the mandible. Overall, the percentage error was 0.5 percent. They conclude that the orthopantomographic appearance of a permanent tooth corresponds very closely to the clinical picture for both alveolar and gingival emergence, but for "critical cases" (where the tooth is less than $2 \mathrm{~mm}$ above or below the mucosa) the radiographic interpretation tends to be slightly ahead of the clinical evaluation of gingival emergence (1970:193).

\section{Film Error}

Another source of error is the panoramic film itself. Ideally the patient sits in a standard chair and the head is positioned between two lateral head supports with the chin supported inferiorly 
so that the Frankfort horizontal plane is parallel to the floor. Within these constraints, however, there is room for approximately 20 degrees variation in head position, in both vertical and horizontal planes, before the resulting exposure appears badly distorted. There is a minimal amount of elongation and foreshortening with the panoramic technique compared to the intra-oral technique, where the patient's head is not constrained. As well, errors in scoring result from viewing a tooth that is inclined lingually or facially in the alveolar bone. Since accurate determination of crown and root development was not possible in these cases, these teeth were not scored.

A test for different types of film error was done to determine the effect of differences in head positioning. A series of four panelipse films was taken using a metal skull, with anatomically correct metal teeth, in the head holder. On the first film, the metal skull was positioned as close to the ideal as possible, with the Frankfort horizontal plane parallel to the floor. On the second film, the head was tipped upward at approximately 10 degrees to the Frankfort horizontal plane. On the third film, the head was tipped downward at approximately 20 degrees to the Frankfort horizontal plane. For the fourth film, the Frankfort horizontal plane was returned to ideal position, but the head was rotated horizontally to the left at approximately 20 degrees. An additional film could have been taken with the head rotated to the right, but this was felt to be unnecessary as the result would have been comparable to the fourth film. To deviate any more than 20 degrees in any direction from the ideal position was not justified, as the technician would most certainly be aware of such a severe malposition, and correct the head posture before exposure. The 
distortion caused by more than a 20 degree horizontal or vertical rotation would be sufficient to make one-half of the film diagnostically unsuitable.

Very little distortion was found between the first and second films, so that a vertical error of 10 degrees was found to be acceptable. The third film showed considerable distortion of the entire dental arch, and slight foreshortening of the mandibular anterior teeth. The foreshortening was calibrated with a Boley gauge, and found to be no more than $2 \mathrm{~mm}$. This was considered serious enough to affect the scoring procedure, and may account for some of the error in accurately determining the intermediate stages, i.e., between root $1 / 4$ complete and root $1 / 3$ complete, the absolute difference in overall root length may be as little as $1 \mathrm{~mm}$. Thus, a variation in the head positioning would result in an error in scoring by one category or more. The fourth film showed severe distortion and overlap on the side of the arch opposite to the direction of rotation. This would indicate that portions of both arches were no longer in the focal trough of the machine. There was a similar amount of foreshortening on the left side of the film, and very slight elongation of a few teeth on the right side of the film.

Other sources of film error were also found when viewing the radiographs. Faulty intensifying screens, static, dirt on the film, and especially, movement by the patient, made accurate scoring difficult and, in some cases, impossible. These results agree with Garn et al. (1957). In these cases, certain portions of the dentition were not assessed.

As a result of the reliability tests and the tests for film 
error, several of the intermediate categories were found to be unreliable and were collapsed. As well, however, it was decided to add categories to assess the amount of resorption of the roots of deciduous teeth. Four of the categories defined by Fanning (1961) were selected.

The final scoring system selected is as follows:

\section{Calcification Scores}

SCORE 0 No change in bone density, and no crypt visible. This category is the same as that used by Nolla.

SCORE 1 The crypt is clearly visible, but there is no evidence of calcification. This category is the same as that used by several authors.

SCORE 2 Initial calcification. Coalescence of at least two centres. This category is a combination of three stages used by Nolla, Moorrees et al., Fanning, and Gleiser and Hunt, as it was found to be impossible to differentiate between initial calcification and partial coalescence of cusps, on a single radiograph.

SCORE 3 The crown is $1 / 4$ complete with complete coalescence of the cusps. This category includes Nolla's stage 3.

SCORE 4 The crown is $1 / 2$ complete. This category was used by Moorrees et al.

SCORE 5 The crown is $3 / 4$ complete. The pulp chamber diverges widely and prominent enamel extensions are evident. This category corresponds to Nolla's stage 4 . 
SCORE 6 Crown completed. This category is the same as that used by several authors. It is marked by the termination of the enamel at the cemento-enamel junction. Thus, it may include very minimal root formation. This category includes Nolla's stages 5 and 6 .

SCORE 7 The root is $1 / 4$ complete. Cleft formation is not necessarily included in this category but is recorded separately for molars. This category includes Nolla's stage 7.

SCORE 8 The root is $1 / 2$ complete. This category corresponds to Nevile's stage G.

SCORE 9 The root is $3 / 4$ complete. This category corresponds to Nolla's stage 8 , and Nevile's stage $\mathrm{H}$.

SCORE 10 This category is defined by initiation of apical closure, with the root canal terminally convergent. Root length was found to be too variable to be accurately used. This category includes Nolla's stage 9 and Nevile's stage I.

SCORE 11 Completion of root development with apical closure. This category is used by several authors and corresponds to Nolla's stage 10.

SCORE 12 Resorption of $1 / 4$ to $1 / 3$ of the deciduous root.

SCORE 13 Resorption of $1 / 2$ of the deciduous root.

SCORE 14 Resorption of $2 / 3$ to $3 / 4$ of the deciduous root.

SCORE 15 Complete resorption of the deciduous root.

SCORE 16 Complete exfoliation of the deciduous tooth.

SCORE 17 Extraction of the permanent or deciduous tooth. This category is used when evidence exists that the deciduous or permanent tooth has been extracted prematurely. 
SCORE 18 This category is used when evidence exists that a tooth is congenitally missing. Third molars are scored as "o" unless the child is over the age of 12 years, by which time the third molars should have begun calcification.

SCORE 19 This category is used for missing permanent teeth where the reason is unknown. The tooth may have been extracted or is congenitally missing.

SCORE 98 This category is used if the tooth is obviously present but an accurate determination of development is not possible due to an abnormal inclination of the tooth.

SCORE 99 This category is used if the film is faulty, so that the presence or absence of the tooth was unknown.

SCORE "V" Cleft formation is recorded separately for the permanent molars.

\section{Eruption Stages}

The term eruption refers to the movement of a tooth toward its final occlusal position. Thus, eruption includes movement within the maxilla and mandible before emergence, as well as movement toward the final occlusal position after emergence (Mayhall et al., 1978:211). Massler and Schour (1941:552) defined six stages of eruption:

Stage I. Preparatory stage (opening of the bony crypt).

Stage II. Migration of the tooth toward the oral epithelium.

Stage III. Emergence of the crown tips into the oral cavity.

Stage IV. First occlusal contact.

Stage V. Full occlusal contact. 
Stage VI. Continuous eruption.

Eruption was considered independently of calcification in this study, due to the wide variation found in the literature as to when each stage of eruption occurs. Shumaker, for example, found that each mandibular tooth studied "starts to move toward occlusion at approximately stage 6 or crown completion" (1960:539). Carlson (1944), however, states that the permanent teeth do not move occlusally until root formation has begun. Gleiser and Hunt, in their study of the mandibular first molar (1955) found that clinical emergence occurred when the root was between $1 / 3$ and $1 / 2$ completed, while Schour and Massler (1940b) stated that "when the roots are approximately one-half calcified, the teeth are ready to assume their places in the mouth" (1940b: 1929).

There is then, varied opinion as to the actual relation between calcification and eruption. The other problem taken into account by considering eruption separately from calcification, is the high incidence in this sample of early emergence of the permanent premolars as a result of premature extraction of deciduous molars. According to Feasby (1981:557) there is a "low correlation between the maximum eruption rate and the increment in root growth... (which) suggests that the eruption surge and root increments were independent variables."

Four stages of eruption were used in this study:

STAGE I: Initial Eruption (Massler \& Schour, Stages I and II)

This initial stage of eruption, or movement toward occlusion, is difficult to determine from a single radiograph, with no prior or subsequent films to actually determine that tooth movement is occurring. 
Therefore, every tooth that had reached the calcification score of 6 , but had not yet pierced the alveolar crest, was assigned the eruption stage $I$.

\section{STAGE II: Alveolar Emergence}

Alveolar emergence is defined as the elevation of the cusps above the margin of the alveolus. The occlusal margin of the alveolus (crypt) is clearly visible on the panoramic radiograph. If intra-oral films taken on the same date were available, they were also used. If there was evidence of the crypt occlusal to the tooth crown, the tooth was not assigned to this stage. It is possible that in a dry skull, however, that one or more cusps of a molar would have pierced the crypt, while radiographically this would not be evident. No presumptions were made with regard to root calcification for this stage. Thus, a tooth could emerge through the alveolus with a calcification score of between 6 and 11 .

STAGE III: Gingival Emergence (Massler \& Schour, Stage III)

Gingival emergence is defined by Garn et al. (1957b:313) as the emergence of any portion of the tooth crown through the gingiva. Mayhall et al. also defined time of emergence as the "moment any portion of the tooth crown pierces the gingiva and is visible in the oral cavity" (1977:8). Gron (1962:574) used the term gingival emergence for "a tooth that had just pierced the gingiva but was no more than 3 $\mathrm{mm}$ above the gingival level, estimated from the tip of the cusp or from the incisal margin. According to this definition, only one or two cusps were visible for the molars".

The soft tissue is normally visible radiographically. If there 
was evidence of soft tissue occlusal to the tooth crown, the tooth was not assigned to this stage. Clinically, however, a tooth could have one cusp tip exposed which may not be evident radiographically. No assumptions were made at this stage pertaining to the amount of root calcification. Thus, a tooth could be erupting clinically anywhere between the calcification scores of 7 to 11 .

STAGE IV: Attainment of the Occlusal Level (Massler \& Schour, Stage V)

Full occlusal contact was necessary for a tooth to be assigned to this stage. In most panoramic radiographs, however, the teeth are held apart by a cotton roll or a film holder. It was therefore necessary to look at the overall line of occlusion (Curve of Spee) and the approximation of contact areas, in order to assess this stage accurately. It is possible that if a tooth were malaligned, that only two or three cusps of a molar, or only a portion of the incisal ridge, would be in occlusion.

Passive eruption (Massler \& Schour, Stage VI) was not considered in this study as there would rarely be radiographic evidence of attrition in individuals under the age of 28 years.

DENTAL CALCIFICATION INDEX

An index of dental maturity, using the mean age of each calcification score for each tooth has been calculated. Nevile's (1973:43) formula for Dental Calcification Age was used: 


$$
\text { Dental Calcification Index }=\frac{\sum \overline{\mathrm{X}} \mathrm{c}}{\mathrm{N}}
$$

where $\bar{X} c$ is the sum of all the mean ages corresponding to the calcification scores recorded for each tooth for each subject; and $\mathrm{N}$ is the number of teeth considered. The index was calculated separately for Inuit males and females, and for Indian males and females. For each subject, the index was calculated for each quadrant, for each arch, and for the entire dentition.

The Calcification Score 11 was not included in the calculation, as apical closure is relatively meaningless in a cross-sectional study, as the apex may have been closed for a significant period of time in certain teeth at the time of the radiographic survey. Similarly, the Calcification Score 0 for the third molar was excluded because it begins calcification so late ( 10 to 12 years) that it artficially raises the dental age of the youngest individuals in the sample.

\section{ALVEOLAR ERUPTION INDEX}

In order to more precisely estimate the dental age from skeletal material, an index was calculated for the number of teeth which had emerged through the alveolar bone. This was done using the formula:

$$
\text { Alveolar Emergence Index }=\frac{\sum \mathrm{e}}{\mathrm{N}} \times 100
$$

where $e$ is the sum of all the teeth erupted; and $N$ is the total num- 
ber of teeth observed. The resulting index ranges from 100 for an individual with all teeth erupted, to 0 for an individual with no teeth erupted. These values for each sample were then plotted on a scattergram against the chronological age (Figures 14 and 15). 
CHAPTER III

RESULTS 
CHAPTER III

RESULTS

DENTAL CALCIFICATION

The mean age and standard deviation were computed for each calcification score for each tooth. The two samples, Inuit and Indian, were kept separate as were the results for males and females, and the teeth of each quadrant. These results are presented in Tables II to XII. There were no values for certain teeth before the Calcification Score 6 because, for example, the first molar had already reached crown completion in most of the youngest individuals observed. Other missing values are the result of inadequate sample size in that particular age range.

For certain teeth, there was a trend toward a younger mean age for females at each stage of calcification than for males, particularly in the Indian sample. The Inuit sample, however, showed no clear trend toward earlier calcification among females. The canines, premolars and second molars were more often later in the females than in the males. In several instances, however, the sample size was inadequate to give a true picture. If the two female samples are combined, and the two male samples are combined, the females are clearly ahead of the males for all teeth at each calcification score, but doing this obscures the fact that between the two samples, Inuit and Indian, there was a definite trend toward earlier calcification in the 
Inuit for all teeth except the premolars and the second molars.

The variance in attainment of calcification scores was the same for males and females. The range of variation, expressed by the plus and minus one standard deviation limits, was usually less than one year for crown development (Tables III to VIII). The most variation was found in the calcification of the third molar where the standard deviation was closer to two years for many of the calcification scores. Individual variation became more pronounced as root calicification progressed. The standard deviations for the mean ages of Score 9 and 10 (Tables XI and XII) were considerably greater than for crown calcification, generally between one and two years.

Garn et al. (1959) also found a much larger range of variability than had been claimed by Logan and Kronfeld (1933). They state, however, that even with this larger range of variability, tooth calcification was considerably less variable than estimates of variability for other age-comparable developmental phenomena. Moorrees et al. (1963) found that root calcification was considerably more variable than crown calcificatioon, with the later stages of root calcification varying by as much as 3-5 years $( \pm 2$ S.D.). At apical closure, the variation was even greater "about 6 years for premolars and second molars, or as large as 8 years for the third molars." (1963:1497). My sample did not include enough individuals over twenty years of age to give an accurate picture of the variability of the third molar during the last scores of root calcification, but in Indian females at Score 10, the standard deviation was over 3 years.

Moorrees et al. (1963) also looked at the overall time taken for each tooth to calcify. They found that crown calcification took 
between 2.1 years for the first molar to 3.4 years for the premolars. Root calcification took from 3.3 years for the incisors in females to 6.2 years for the canines in males (1963:1494).

Schour and Massler (1940a) stated that between 3-6 years was required for the completion of the crowns of the permanent teeth. The first molar consumes the least time because of its rapid rate of calcification, and the canine consumes the longest time because of its long crown (1940:1925). They also found that the time required for root calcification depends on the rate of dentin formation and the length of the root. The permanent teeth take between five and seven years, with the canine taking the longest because of the length of its root (1940:1925). Haavikko also found that root completion took between 6.2 years for the first molar, and 9.0 years for the canine in males and between 5.2 years and 8.2 years respectively in females $(1970: 144)$

Although a direct comparison was not done for the Inuit and Indian samples in this study, as complete results were not available for all the teeth, it was found that the time involved in crown calcification agrees fairly closely with the estimates of Moorrees et al. The Inuit sample completed crown calcification more quickly than the Indian sample (Table XIII) for the maxillary central incisor, first premolar and second molar, and the mandibular first premolar. The second premolars took longer to calcify in the Inuit sample than in the Indian sample. It was found that root calcification took considerably longer than the estimates of Moorrees et al., agreeing more closely with Schour and Massler (1940a) and Haavikko (1970). The time involved in root calcification was found to be at least six years for 
most teeth and approximately 8-9 years for the canines. Although the Inuit sample reached crown completion more quickly than the Indian sample, the opposite was true for root calcification, taking more time than for both Indian males and females (Table XIII). The mean age for root completion was thus earlier in the Indian sample for all teeth except the incisors.

Tooth Sequence for Calcification

In both samples the sequence in which calcification occurred generally followed the most commonly accepted sequence for gingival emergence. The first molars and the anterior teeth began calcification considerably earlier than the premolars, second molars and third molars. The crown was completed (Score 6) earliest for the maxillary and mandibular first molars followed closely by the mandibular central incisor. The mandibular lateral incisor, canine, and maxillary central, lateral and canine reached crown completion one to two years later. The maxillary and mandibular first premolars were very close together, followed by the second premolars and second molars. The last tooth to reach crown completion was invariably the third molar.

At each calcification score, the sequence varied considerably not only between Inuit and Indian, male and female, but also within a given dentition. By the time the root length was completed, however, the mandibular central incisor was consistently ahead of both the maxillary and mandibular first molars, simply because the central is a smaller, shorter tooth so that the calcification process was of shorter duration. Similarly, although the second molar most often 
started calcification earlier than the second premolar, it took longer to complete its root length than the second premolar.

In general, the teeth in the mandibular arch began calcification earlier than the teeth in the maxillary arch, with the exception of the third molar where initial calcification occurred in the maxillary arch first. By the time of crown completion, however, the maxillary second molar was consistently ahead of the mandibular second molar in both samples, males and females. By the time the root length was half completed (Score 8), the maxillary first premolar was also ahead of the mandibular first premolar in both samples, males and females. In the Indian sample, the maxillary first molar also moved ahead of the mandibular first molar toward the end of root calcification.

In most instances, the Inuit sample, both males and females, were ahead of the Indian sample in crown calcification by about one-half the interval between scores. This difference represents a variation of anywhere between 0.5 and 2.0 years, depending on the tooth in question. When the sexes are combined (Table XIII), this difference between the two samples becomes even more apparent.

The sequence for crown completion found in this study agrees closely with Haavikko (1970) except that she found that the maxillary and mandibular central incisors reached crown completion ahead of the first molars. The first premolars reached Score 6 at about the same time in both the Inuit and Indian samples, whereas Haavikko found the mandibular first premolar reached crown completion almost one year ahead of the maxillary first premolar (1970:143). Haavikko also found that the first and second premolars reached crown completion ahead of the second molar, whereas in both arches of the Inuit sample the sec- 
ond molar is ahead of the second premolar at Score 6 (Table VIII). Garn et al. (1956) also found the second molar to be ahead of the second premolar during calcification.

Mean Age of Calcification, Sexes and Quadrants Combined

The mean age of calcification at each score for maxillary and mandibular teeth was compared to the results of a similar study by Nevile (1973) using panoramic radiographs, for Caucasian children in Manitoba. Males and females were combined for each sample and also the corresponding teeth in the right and left quadrants, in order that the results would be comparable to Nevile (Table XIII). The scoring system used by Nevile includes ten of the twelve scores used in this study. He did not include Score 3 (crown 1/4 complete) or Score 5 (crown $3 / 4$ complete). Otherwise the scoring methods were the same.

In almost all instances where there were comparable scores available, the White sample had a consistently later mean age of calcification than either the Inuit or the Indian sample. As previously mentioned, when females and males are combined, the Inuit sample is consistently earlier than the Indian sample.

Except for comparison purposes or because of small sample size, the data for the right and left quadrants and for females and males, were treated separately in this study. The mean age of calcification for the antimeres were found to be very close but in terms of eruption stages there was considerable variation between right and left quadrants. Liliequist and Lundberg (1971) found a very high correlation between the right and left quadrants for each calcification score 
$(r=.99)$ and therefore limited their study to one quadrant. Demisch and Wartman (1956) found that symmetry in the calcification of third molars occurred in $71 \%$ of the cases and that the difference was no more than two scores $(1956: 465)$. There was found to be more asymmetry in the third molar calcification among the Inuit and Indian, however, occasionally by as much as three or four scores. Three wisdom teeth were found to have reached Score 3 or 4 by the time the fourth wisdom tooth began calcification. This difference represented a difference of as much as 2 years between the right and left quadrants.

\section{DENTAL CALCIFICATION INDEX}

The estimated age derived from the Dental Calcification Index for each sample, combining males and females, and left and right quadrants, was plotted against the chronological age for each subject on a scattergram (Figures 3-6). The correlation between the estimated age and the chronological age was found to be very high:

$$
\begin{array}{rlr}
\text { Inuit sample, Maxillary arch } & r=.982 \\
\text { Mandibular arch } & r=.976 \\
\text { Indian sample, Maxillary arch } & r=.957 \\
\text { Mandibular arch } & r=.949
\end{array}
$$

As a measure for determining the dental age of an individual, the Dental Calcification Index appears to be of significant value. The radiograph of an individual of unknown age could be scored and assigned a calcification age which would be very close to the chronological age.

The various methods of deriving a dental age using the different 
stages of calcification have already been mentioned (Nolla, 1960; Demirjian et al., 1973; and Nevile, 1973). Nolla's (1960) method of adding the calcification values together for each tooth in the arch and then comparing the sum to a table of age norms was rejected because it presumes that the ten stages are equivalent to each other and of equal duration. It has been shown by Schour and Massler (1940a), Moorrees et al. (1963), Haavikko (1970) and others that calcification does not progress at an equal rate for all teeth or within any given tooth. Nolla's method does not take this into account.

Demirjian et al. (1973) gave each tooth a "biological weight" at each calcification score. This presumably takes into account this variation, but I was unable to determine from any of their work, how they arrived at their weighting system. Therefore, this system was not applied to this study.

As stated previously, the formula for deriving the Dental Calcification Index used in this study is basically the same as that used by Nevile (1973:43). Nevile did not calculate the correlation between his Dental Calcification Age and chronological age. He presents his results in terms of the mean dental age for each age class (1970:64). Nevile's table reveals that the mean dental age slightly overestimates the age class up to 126 months (10.5 years). After this age, the dental age slightly underestimates the chronological age. After 162 months ( 13.5 years) the chronological age is greatly underestimated by a year or more. Nevile did not include the third molar in his study so that after the age of 13.5 years, the first molars and most of the incisor teeth would have completed calcification, and the canines, premolars and second molars would be completely calcified a 
year or two later.

In the present study the correlation with chronological age remains constant up until the age of 18 years as a result of the inclusion of the third molars. As the other teeth are completing their development, the third molar is just beginning to calcify. Even though the third molar has been found to be the most variable of all the teeth, it is still worthwhile to include it in the determination of the dental age. The mean age for the Calcification Score 0 was not included for the third molar, however, as it artifically raises the dental age of individuals under the age of 10 years. By not including a value for Score 0 , congenitally missing third molars would also not affect the results by artifically lowering the dental age of an individual over the age of 12 years.

ERUPTION STAGES

The mean age for Stage I, II and III of eruption are given in Tables XIV, XV, XVI. The mean age at Stage I for each tooth merely indicates that the crown is complete but that the tooth has not emerged above the alveolar bone. This Stage does not truly indicate whether the tooth has actually begun to erupt. This fact could only be determined in a longitudinal study where each tooth could be followed through the later stages of eruption.

The mean ages of alveolar emergence (Stage II) are shown in Table $\mathrm{XV}$. As was found with calcification, the mean age of emergence in the Inuit sample is generally earlier than in the Indian sample for most teeth. Discrepancies most often occur where the sample size is very 
small for a particular stage. Again, the females are ahead of the males in both samples.

Sequence of Emergence, Stages II and III

After combining the mean age of emergence for the right and left quadrants, the sequence of alveolar and gingival emergence was determined for each arch for both samples, males and females. The most commonly found sequences are as follows:

STAGE II

$\begin{array}{llllllll}\text { Inuit Females } & \text { Max. } & 612 & 4573 & 8 & 612 & 4573 & 8 \\ & \text { Mand. } & 612 & 3475 & 8 & 612 & 4537 & 8 \\ \text { Inuit Males } & \text { Max. } & 612 & 4(573) & 8 & 612 & 4357 & 8 \\ & \text { Mand. } & 612 & 7354 & 8 & 612 & 5437 & 8 \\ \text { Indian Females } & \text { Max. } & 612 & 43(57) & 8 & 612 & 4573 & 8 \\ & \text { Mand. } & 612 & 3(475) & 8 & 612 & 4375 & 8 \\ \text { Indian Males } & \text { Max. } & 612 & (43) 57 & 8 & 612 & 4537 & 8 \\ & \text { Mand. } & 612 & 3475 & 8 & 612 & 4375 & 8\end{array}$

Invariably the first molar was followed by the central incisor and then the lateral incisor. In no instance does the central incisor emerge through the alveolar bone or the gingiva ahead of the first molar. For the second group of teeth (canine, first premolar, second premolar, and second molar) quite a bit of variation is found. The teeth enclosed in brackets may exchange places. For alveolar emergence, the sequence is the same for the maxillary arches of Inuit females and males. The sequence in the mandibular arch varies, how- 
ever, between females and males. In the Indian sample, the sequence for the maxillary arches of females and males is the same, and the sequence for the mandibular arches of females and males is the same. The same consistency does not apply to gingival emergence, where there is even more variability, with only the Indian sample showing the same mandibular sequence for females and males.

The sequence of emergence also changes between Stage II and Stage III for both arches of both samples, males and females. The mandibular second molar is always ahead of the second premolar at alveolar emergence, but for the Inuit sample this changes at gingival emergence, i.e. the second premolar is ahead of the second molar. In the maxillary arch, the second premolar is ahead of the second molar at both stages of eruption for both samples, males and females. The third molar is invariably the last tooth to emerge at both the alveolar and gingival stage in both samples.

Schour and Massler (1941) state that the normal sequence of gingival emergence in the maxillary arch is 6124357 . This sequence was the most common only for Inuit males. The most common sequence in the maxillary arch according to Lo and Moyers (1953) is 6124537 . This sequence was commonly found in Indian males. For the mandibular arch the most common sequence is 6124357 (Schour and Massler, 1941) or 6123457 (Lo and Moyers, 1953). Neither of these sequences was commonly found in either the Inuit or the Indian sample.

Mayhall et al. (1978:212) found the most common sequence of gingival emergence in the maxilla, for both Inuit males and females, was 6124537 , and in the mandible; for males 6123475 and for 


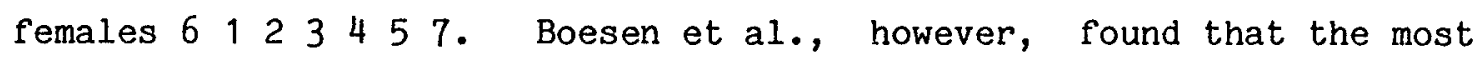
common sequence in the maxilla, for both Inuit samples and sexes, was

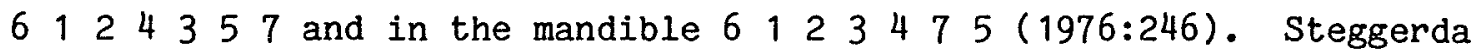
and Hill (1942) found no significant differences in the order of emergence with each of their samples showing great variation. They therefore conclude that the sequence of emergence appears to be the same in all populations $(1942: 369)$.

When comparing the many different sequences which have been commonly found in Inuit or Indian populations, there appears to be no overall concensus. The only trends which do occur are for delayed emergence of the maxillary and mandibular canine and the mandibular second premolar in the Inuit and Indian samples. The teeth in the mandibular arch emerge ahead of the corresponding teeth in the maxillary arch in most instances for both stages II and Stage III. The most notable exceptions are the premolars at alveolar emergence, in both samples, both males and females. The first and second premolars in the maxillary arch emerge ahead of the corresponding premolar in the mandibular arch. This also occurs at gingival emergence in the Indian sample, females and males, but not in the Inuit sample. The earlier emergence of the maxillary premolars at Stage III is in agreement with several other studies (Helm and Seidler, 1974; Perreault et al., 1974; Magnusson, 1976; Mayhall et al., 1977; Masson, 1980). As well, in the Indian sample the maxillary first molar emerged ahead of the mandibular at Stage II in males and at Stage III in females. 
Mean Age of Gingival Emergence - Inuit

For the Inuit sample the results of this study were compared to the only available studies on gingival emergence in Inuit populations: the work of Mayhall et al. (1978) in the Foxe Basin and that of Boesen et al. (1976) in East and West Greenland (Figures 7 and 8). There is a high degree of concordance for mean age of emergence for certain teeth. However, because many of the children in my sample had suffered extensive destruction of the deciduous teeth and numerous extractions before the age of 5 years, there is delayed emergence of the canines in both arches in females, and early eruption of both mandibular premolars in females. For Inuit males (Figure 8) only the mandibular canine is delayed in its emergence, and the maxillary lateral incisor and the mandibular premolars are early in their emergence. My sample size was too small to give a true result for the age of emergence of the maxillary second premolar and second molar for Inuit males, which were both delayed in the individuals observed. Emergence was found to be earlier in Inuit females only for certain teeth. The males were ahead for the incisors, maxillary canine, mandibular second premolar and second molar.

Garn and Moorrees (1951) found in their study of Aleut children that gingival emergence was markedly and significantly earlier in Aleut children (1951:267) compared with the mean age of emergence given by Hurme (1949) for White children. They also noted that the younger children appeared to be more advanced and that the older children were closer to Hurme's standards. The maxillary and the mandibular teeth of the Aleut children were equally advanced in emergence 
(Moorrees, 1957: 105).

The Igloolik-Hall Beach Inuit children studied by Mayhall (1972) also showed advanced emergence for the maxillary incisors, first premolar, mandibular central incisor, and mandibular canine in the males. The females, on the other hand, more closely resembled European White populations but were still slightly advanced in the timing of emergence (1972:25). Mayhall et al. (1978) also noted that for the teeth emerging first (the first molars and the mandibular incisors), there were no significant differences in the timing of emergence between males and females, but that females were significantly advanced in emergence timing for the canines, premolars and second molars. The results of the present study were not as clear: the females were found to be advanced in emergence timing for the maxillary central, first premolar, first molar and second molar and the mandibular central incisor, canine, first premolar, and first molar; with the males actually ahead of the females for the lateral incisors, maxillary canine, mandibular second premolar and second molar.

Boesen et al. (1976) found that the two Inuit samples from East and West Greenland showed very similar mean ages at gingival emergence. Both samples were advanced compared with other Caucasian and Indian samples. They concluded that the two Inuit samples are more similar to each other than to any of the other samples, both in terms of timing and sequence of emergence (1976:247).

Mean Age of Gingival Emergence - Indian

For the Indian sample I compared the results of this study to the 
only other studies available for Indian populations in North America: Mayhall et al. (1977), Dahlberg and Menegaz-Bock (1958), and Steggerda and Hill (1942). These three other studies were done either by clinical examination or with dental casts. Despite the differences in methodology, there is considerable agreement in terms of mean age of gingival emergence for most teeth. The high incidence of premature extraction in my sample results in delayed emergence of the maxillary canine and the mandibular second premolar in Indian females (Figure 9). A similar picture exists for Indian males (Figure 10). There is delayed emergence of the mandibular lateral incisor, and early emergence of the mandibular central incisor and first molar compared with the other studies. As in studies of White populations, the mandibular teeth usually erupt earlier than the maxillary teeth, and females are advanced over males in terms of the timing of gingival emergence.

Mayhall et al. (1978) compared the results of their study on the Cree-0jibwa to their study of the Inuit of the Foxe Basin (1977) and to the work of Dahlberg and Menegaz-Bock (1958) on the Pima Indian. Mayhall et al. conclude that the maxillary canine of the male Cree-0jibwa emerges before that of the Inuit, but in all other maxillary teeth, both male and female, the Inuit show an earlier mean age at gingival emergence. These differences tend to be greater between the female groups than the male. In the mandibular arch, however, the Indian samples show earlier emergence of several teeth, in particular the first molar and the incisors. 
Mean Age of Gingival Emergence - Inuit and Indian compared to Whites and Negroes

When the results of this study are compared to studies of White and Negro populations (Garn et al., 1972; Perreault et al., 1974), there are considerable differences in the mean age of gingival emergence (Figures 11 and 12). Indian females (Figure 11) show delayed emergence of both the maxillary and mandibular canines. Inuit females show delayed emergence of only the maxillary canine, and early emergence of the mandibular first molar, first and second premolars. The early emergence of the third molars for Inuit females was due to the extraction of the permanent first molar in the cases observed.

Similar results are seen for males (Figure 12). Indian males show early emergence for the mandibular first and third molars, and delayed emergence of the maxillary canine and both maxillary and mandibular lateral incisors. The Inuit males show early emergence of the mandibular premolars, and delayed emergence of the maxillary second premolar and second molar.

Mayhall et al. (1978) also compared their results to Perreault's (1974) study. They found that both Indian females and males showed a statistically significant difference in emergence timing in the mandibular arch for the first molar, which was advanced. The Indian males showed significant advancement of the maxillary first premolar, but a significant delay in the emergence of the second premolar and the maxillary lateral incisor. In the females, the maxillary incisors were delayed compared to the French-Canadian sample, and the premolars and first molar are advanced. In the mandibular arch the females show 
advanced emergence times except for the second molar. Hrdlicka (1908) found, however, that the canine and second molars erupt earlier in the Indians than among the Whites, but that the other teeth erupt at about the same time.

From the results of this part of my study, the differences in the timing of gingival emergence may be explained either in terms of genetic differences or as a result of local factors. From my study of the calcification stages, it would appear that there is a genetic difference in terms of the mean age at each score of crown and root calcification, with the Inuit appearing to be slightly advanced in their development of certain teeth. The differences in the time of emergence, however, are primarily due to local factors; infection, caries, and premature loss of deciduous teeth.

THE RELATIONSHIP BETWEEN ROOT CALCIFICATION AND EMERGENCE STAGES

\section{Alveolar Emergence}

The number of individuals having attained each calcification score at alveolar emergence were counted for each pair of teeth (right and left quadrants). The percentage of teeth at each calcification score was calculated. These results are shown in Table XVII. For most teeth, the root was at least one-half completed (Score 8) by the time of alveolar emergence. In the majority of Inuit females, the maxillary central incisor and the mandibular first premolar emerged before Score 8 . The canines and mandibular premolars most often showed three-quarters root completion (Score 9) in the Inuit males. 
In the Indian sample, almost half of the teeth had reached score 9 before alveolar emergence. Only the mandibular central incisor emerged with less than one-half root completion in the Indian females. The only other study that I am aware of that looks at root calcification in relation to alveolar emergence is Haavikko (1970). She also found that the majority of the teeth emerge through the alveolar bone when the root is approximately one-half completed. The first molars, however, emerge with the root only one-quarter complete, followed by the maxillary incisors which emerge with between one-quarter and one-half of their roots completed. Haavikko also noted that the canines and the third molars emerge when root calcification is at least three-quarters complete (1970:159).

\section{Gingival Emergence}

The same calculations were done as for alveolar emergence. These results are given in Table XVIII. The results for the Inuit and Indian samples are compared to Gron's (1962) study of White children in Boston. In all three samples, most teeth emerge through the gingiva with root calcification three-quarters complete (Score 9). In the Inuit sample, the maxillary first premolar and mandibular first molar emerge earlier for both sexes, and the maxillary lateral incisor, mandibular third molar later (Score 10) in the males. In the Indian sample, the maxillary and mandibular central incisor, and the mandibular first molar emerge earlier (Score 8) in males. The mandibular third molar emerges later (Score 10) in Indian females. Gron only reported statistics for the maxillary central and lateral inci- 
sors and for seven teeth in the mandible. In the mandibular arch she also found that the first molar, as well as the central incisor, emerged with less than one-half root completion.

Nanda and Chawla (1966), using intra-oral radiographs, also looked at root calcification at gingival emergence. They found that all of the teeth emerged with less than three-quarters of the root complete except for the mandibular canine. Both maxillary and mandibular first premolars emerged with the root only one-half complete, and the maxillary central incisor and first molar had less than onehalf the root complete at gingival emergence.

Figure 13 depicts the relationship between root calcification and the two stages of eruption (alveolar and gingival emergence), with both the Inuit and Indian samples and sexes combined. The time interval can be seen between the mean age for each successive score for root calcification and also the time interval between the mean age of alveolar and gingival emergence.

The time interval between Score 6 and 7 of root calcification is about equal for all the teeth except the incisors, especially the mandibular central which reaches Score 7 very quickly after crown completion. Between Score 7 and 8 , the first molars calcify more quickly than the rest of the teeth. This is in agreement with the results of Moorrees et al. (1963:1496). The interval between Score 8 and 9 is also of fairly equal length for all teeth except the canine which takes longer to reach Score 9. The canine also takes the longest time for its root to reach completion which is simply due to the fact that the canine has the longest root in the entire dentition. In general then, root calcification appears to progress at a fairly equal 
rate for all of the teeth except for the first three teeth; the first molar, central incisor, and lateral incisor, which calcify more quickly. The duration of each quarter of root calcification is also fairly regular except for the canines as already mentioned.

From the two tables showing the mean age of alveolar emergence (Table XV) and the mean age of gingival emergence (Table XVI), the time lag between these two stages of eruption was plotted with both samples and sexes combined. In Figure 13 it can be seen that there is considerable variation in the time it takes each tooth to emerge through the gingiva once it has emerged through the alveolar bone. As well, there is no consistent time interval that can be applied to all the teeth. Thus, it would be very misleading for anthropologists and forensic pathologists to use clinical standards of gingival emergence to predict dental age from alveolar emergence in skeletal material.

Haavikko (1970) is the only author to have done a similar comparison between alveolar and gingival emergence. Her results are summarized in Table XIX. Haavikko found that the interval between the stages was shorter for those teeth with deciduous predecessors than for those teeth not preceded by a deciduous tooth. She also found that the mandibular incisors and canines pass through this stage twice as rapidly as the maxillary anterior teeth. On the other hand, the maxillary premolars progress more rapidly than the mandibular premolars. There were no clear differences between the maxillary and mandibular molars, except that the first molar moves more rapidly than the second or third molar. Haavikko concludes that while the results for the rapid emergence of the incisors appears to be realistic, the accelerated or delayed emergence of the premolars may be due to prema- 
ture extraction of the deciduous predecessors (1970:157).

ALVEOLAR EMERGENCE INDEX

In order to better predict dental age from skeletal material, the Alveolar Emergence Index was developed by Dr. Wade and myself. Figures 14 and 15 show the resulting scattergrams when the Index is plotted against the chronological age for the Inuit sample (Figure 14) and the Indian sample (Figure 15), with the sexes combined. There is a high correlation between the Alveolar Emergence Index and the chronological age in both samples. For the Inuit sample, $r=0.907$, and for the Indian sample, $r=0.879$.

No studies have been found that calculated an eruption index based on alveolar emergence. Bean, 1914; Matiegka, 1921; Cattell, 1928; and Steggerda and Hill, 1942, all used the mean age of gingival emergence to calculate an eruption index. Because the timing of gingival emergence is so highly variable, the use of alveolar emergence would seem worthwhile as it is less affected by external factors such as premature loss of deciduous teeth. The Alveolar Emergence Index can also be calculated for both clinical patients and for skeletal material provided that a radiograph is available.

The Alveolar Emergence Index would also be a much more meaningful and accurate method for determining the dental age of Inuit or Indian populations than using similar standards for White populations or by using standards of gingival emergence. 
CHAPTER IV

SUMMARY AND CONCLUSIONS 
CHAPTER IV

SUMMARY AND CONCLUSIONS

The purpose of this study to investigate the timing and sequence of dental development in Inuit and Indian children and to determine whether there were significant differences between these populations and other Native and non-Native populations which have been studied. This study was done cross-sectionally using panoramic radiographs which were available in various centres in Manitoba.

All of the permanent and deciduous teeth were scored in each radiograph. Each tooth was assigned a calcification score, from 0 to 11, and an eruption stage, from 0 to 5. Attention was focused on the mean age ( \pm 1 S.D. ) for each calcification score and on Stage II and III of eruption (alveolar emergence and gingival emergence) for the permanent dentition.

The analysis of the mean age of calcification for each stage of each tooth showed that there were definite differences between the two samples. In general, the Inuit sample reached each successive calcification score at an earlier mean age than the Indian samples. For each tooth, each calcification score occurred earlier in the mandibular arch than in the maxillary arch, except for the third molar. Overall, females achieved each calcification score earlier than did males, particularly in the Indian sample.

In order to determine the dental age of an individual from the calcification scores, a Dental Calcification Index was formulated. The estimated age was found to have a high correlation with the chro- 
nological age.

Most of the studies that have been done on eruption have concentrated on one particular stage of eruption, namely gingival emergence. The timing and sequence of gingival emergence has proven to be highly variable between populations and within populations. In this study it was found to be extremely variable, primarily because the samples included many individuals who had suffered from rampant caries, dental infection and subsequently, premature loss of the deciduous teeth.

Alveolar emergence was also studied because it was thought to be less variable than gingival emergence and thus a better measure of dental maturity. The timing of alveolar emergence is also extremely useful in the determination of age in skeletal material for anthropological and forensic purposes. In order to more accurately predict the dental age from alveolar emergence, an Alveolar Emergence Index was formulated based on the number of teeth which have emerged. The estimated age derived from this Index was found to correlate very well with the chronological age.

Although the results of this study clearly show that there are definite differences in the calcification and eruption of the permanent dentition in Inuit and Indian populations, the nature of these differences is more difficult to assess. In order to collect an adequate sample of radiographs it was necessary to include in each sample individuals who had experienced extractions of deciduous or permanent teeth or who were congenitally missing permanent teeth. The effect of these missing teeth is most clearly evident on the mean age of gingival emergence for certain teeth. Premature extraction of deciduous molars has been shown to directly affect the eruption of the premo- 
lars, either by accelerating or delaying their movement through the alveolar bone and the gingiva. The delayed emergence of the maxillary and mandibular canine and second molars may be directly attributable to early loss of the deciduous predecessor and to the resulting loss of space in the arch. On the other hand it may be that the first premolar is erupting early due to genetic influences or to the loss of the deciduous molar at a time when the first premolar was in the process of erupting.

If the differences in the timing and sequence of eruption were due primarily to genetic influences, one would assume that the sequence of emergence would be fairly symmetrical between right and left sides; that the amount of root calcification at emergence for each tooth would be reasonably constant; and that the correlations between related individuals and small isolated populations would be fairly high. In many studies of White populations, a fairly high correlation exists between right and left quadrants but there is still tremendous variability. Both the Inuit and Indian samples showed a wide range of variation in the timing of eruption between right and left sides, and highly variable root calcification at emergence. Although the Indian populations are widely dispersed throughout Manitoba and the Inuit population are from fairly small isolated communities, both samples showed an equally high amount of variability in terms of gingival emergence.

Despite the variability in both the timing and the sequence of gingival emergence, both the Inuit and Indian samples clearly exhibited earlier emergence than has been found in White samples. If the commonly accepted standards for emergence in Caucasian populations are 
used to assess the dental age in Inuit children in particular, the Inuit children would consistently have their chronological age overestimated by several months for the anterior teeth and by more than a year for the posterior teeth. The differences in the timing of emergence are much less in the Indian sample, as they more closely approximate the mean ages found in white populations.

The timing and the sequence of gingival emergence is important in forensic studies, in growth and development studies, but also in terms of the delivery of dental services, particularly orthodontics. The early emergence of the mandibular first premolars for example may result in the mandibular canine being blocked out, while the early emergence of the mandibular second molar can cause the second premolar to be delayed in its emergence if there is a loss of space in the arch. In the maxillary arch a loss of space will most often affect the emergence of the canine. Almost fifty years ago Price (1934) noted that with a change in diet from native foods to modern foods, and a resulting increase in dental caries, dramatic facial changes occurred in both the Inuit and Indian populations he observed (1934:68). Price observed that "the Eskimos who are living in isolated districts and on native foods have produced uniformly broad dental arches and typical Eskimo facial patterns. Even the first generation forsaking that diet and using the modern diet, presents large numbers of individuals with marked changes in facial and dental arch form" (1934:70). Curzon and Curzon (1970) reported a similar deterioration in the dental health of Inuit children in the Keewatin zone with the adoption of a high carbohydrate diet. Mayhall et al. (1978) concluded, however, that the early emergence in the Inuit was due pri- 
marily to hereditary factors and not to the premature extraction of the deciduous teeth, as the caries incidence was low in the Foxe Basin region (1978:215).

Considering the high caries rate among the Inuit and Indian samples in this study, I would conclude that although there are genetic differences which result in earlier tooth emergence among Inuit and Indian children, these differences are greatly exaggerated by the effects of a high caries incidence: the premature loss of deciduous teeth which results in accelerated or delayed emergence of the permanent teeth, and certain types of malocclusions which usually involve crowding of the teeth.

Alveolar emergence was found to be much less variable and a better indicator of dental maturity than gingival emergence. Alveolar emergence is also influenced by local factors such as premature loss of the deciduous tooth or infection, but to a lesser degree than gingival emergence. Although the timing of alveolar emergence is a better predictor of dental age than gingival emergence, the sequence of emergence appears to be just as variable. The only instance where the entire sequence remained unchanged between alveolar and gingival emergence was in the maxillary arch of Inuit females. This discrepancy has also been reported by Hunt and Gleiser (1955) and Garn and Lewis (1963). Garn and Lewis observed (1963:55) that although in nearly 40 percent of American White children the mandibular second molar is ahead of the second premolar (M2 P2) at alveolar emergence, the majority of these same children have the second premolar emerge through the gingiva ahead of the second molar (P2 M2). The M2 P2 sequence occurred in the mandibular arch of both samples in this study at alveolar 
emergence but it occurred only in the Indian sample, males and females, at gingival emergence. Hrdlicka (1908), Koski and Garn (1957) and Dahlberg and Menegaz-Bock (1958) also reported that M2 P2 was the most common mandibular sequence for gingival emergence in the Pima Indian. It is possible that there is a genetic difference in the eruption sequence between Indian and White populations. Further study of this problem is required but it appears from this study, however, that environmental factors, and primarily local factors, exert a very strong effect on the eruption of the permanent dentition.

Calcification of the teeth is the least influenced by local factors. Nutritional deficiencies, hormonal disorders, or other systemic diseases can affect both the quality and the quantity of tooth formation, however. Assessment of dental maturity from tooth formation is much more accurate than the emergence of the teeth through the gingiva. Studies of the mean ages of calcification would be a far more reliable way of comparing different populations.

Hunt and Gleiser (1955) compared different methods of estimating dental age in skeletal material. They reported that a study of calcification has many advantages over eruption. One of these advantages is that sex differences in dental maturation are far less than those occurring in the skeleton. Garn et al. (1958) found similar results. Hence, estimates of dental age from skeletal material would be more reliable than estimates of age from osseous maturation, when the sex of the individual is unknown.

In terms of their overall dental development, I would conclude that both Inuit and Indian populations are advanced over White populations. This difference is genetically based but is exaggerated by 
environmental factors. Further work needs to be done to better determine the total effect of these factors. If a larger sample was available, then variables such as extraction of deciduous teeth could be controlled. Longitudinal studies of the sequence of calcification and eruption would be of value in determining whether there are genetic differences between populations and how large a part they play in dental maturation. Standards for dental maturity related to skeletal maturity also need to be developed for both Inuit and Indian populations in order to aid the anthropologist in the assessment of population differences and to aid the dentist and the orthodontist in the treatment of dental disease and malocclusions. 
Adler, P (1958) Studies on the eruption of the permanent teeth. Acta Genet. Stat. Med. 8: 78-94.

Adler, $P$ (1963) Effect of some environmental factors on sequence of permanent tooth eruption. J. Dent. Res. 43: 605-616.

Ando, S, Aizawa, K, Nakashima, T, Shinbo, K, Sanka, Y, Kiyokawa, K, and Oshima, S (1965) Studies on the consecutive survey of succedaneous and permanent dentition in the Japanese children. I Eruptive process of permanent teeth. J. Nikon Univ., Sch. Dent. I: $\quad 141-181$.

Bambha, JK and Van Natta, P (1959) A longitudinal study of occlusion and tooth eruption in relation to skeletal maturation. Am. J. Orthod. 45: 847-855.

Barrett, MJ (1957) Dental observations on Australian aborigines: tooth eruption sequence. Aust. Dent. J. 2: 217-227.

Barrett, MJ, Brown, T, and Cellier, KM (1964) Tooth eruption sequence in a tribe of Central Australian Aborigines. Am. J. Phys. Anthropol. 22: 79-89.

Bean, RB (1914) The stature and the eruption of the permanent teeth of American, German-American, and Filipino children. Deductions from the measurements and examination of 1445 public school children in Ann Arbor, Michigan, and 776 in Manila, P.I. Am. J. Anat. 17: 113-160.

Birket-Smith, K (1940) Anthropological observations on the Central Eskimos. Report of the Fifth Thule Expedition 1921-24, vol. 3, no. 2. Copenhagen: Gyldendal.

Boesen, P, Eriksen, JH, and Helm, S (1976) Timing of permanent tooth emergence in two Greenland Eskimo populations. Community Dent. Oral Epidemiol. 4: 244-247.

Bradley, RE (1961) The relationship between eruption, calcification, and crowding of certain mandibular teeth. Angle Orthod. 31: $230-236$. 
Brauer, JC and Bahador, MA (1942) Variations in calcification and eruption of the deciduous and the permanent teeth. J. Am. Dent. Assoc. 29: 1373-1387.

Butler, DJ (1962) The eruption of teeth and it's association with early loss of the deciduous teeth. Br. Dent. J. 112: 443-449.

Butler, PM (1967) The prenatal development of the human first upper permanent molar. Arch. Oral. Biol. 12: 551-563.

Carlson, H (1944) Studies on the rate and amount of eruption of certain human teeth. Am. J. Orthod. Oral Surg. 30: 575-588.

Carr, LM (1962) Eruption ages of permanent teeth. Aust. Dent. J. I: $367-373$.

Carr, LM (1963) The effect of extraction of deciduous molars on the eruption of bicuspid teeth. Aust. Dent. J. ㅁ: 130-136.

Castaldi, CR, and MacRae, PD. The effect of water-borne fluorides on the time and sequence of eruption of the deciduous dentition. Unpublished manuscript.

Cattell, P (1928) Dentition as a measure of maturity. Cambridge: Harvard Univ. Press.

Clements, EMB, Davies-Thomas, E, and Pickett, KG (1953a) Time of eruption of permanent teeth in British children in 1947-48. Br. Med. J. 1: 1421-1424.

Clements, EMB, Davies-Thomas, E, and Pickett, KG (1953b) Order of eruption of the permanent human dentition. $\mathrm{Br} . \mathrm{Med} . \mathrm{J}$. $1: 1425-1427$.

Colby, WB (1972) Cephalometric analysis of the Northern Foxe Basin Eskimo: A cross sectional study. M.Sc. Thesis, Univ. of Manitoba.

Curzon, MEJ, and Curzon, JA (1970) Dental caries in Eskimo children of the Keewatin District in the Northwest Territories. Can. Dent. Assoc. J. 36: 342-345.

Dahlberg, AA, and Menegaz-Bock, RM (1958) Emergence of the permanent 
teeth in Pima Indian children. A critical analysis of method and an estimate of population parameters. J. Dent. Res. 37: $1123-1140$.

Demirjian, A (1980) Development dentaire: indice de maturite physiologique. Union. Med. Can. 109: 832-839.

Demirjian, A and Goldstein, $\mathrm{H}$ (1976) New systems for dental maturity based on seven and four teeth. Ann. Hum. Biol. 3: 411-421.

Demirjian, A, Goldstein, H, and Tanner, JM (1973) A new system of dental age assessment. Human Biology 45: 211-227.

Demirjian, A, and Levesque, GY (1980) Sexual differences in dental development and prediction of emergence. J. Dent. Res. 59: 1110-1122.

Demisch, A, and Wartmann, P (1956) Calcification of the mandibular third molar and it's relation to skeletal and chronological age in children. Child Dev. 27: 459-473.

Eveleth, PB (1966) Eruption of permanent dentition and menarche of American children living in the tropics. Hum. Biol. 38: 60-70.

Eveleth, PB, and Tanner, JM (1976) International Biological Programme 8, Worldwide Variation in Human Growth. Cambridge: Cambridge Univ. Press, pp. 206-212.

Explorers Guide (1982) Canada's Arctic. Dept. of Information: Government of the Northwest Territories, Yellowknife, Northwest Territories.

Fanning, EA (1961) Longitudinal study of tooth function and root resorption. N. Z. Dent. J. 57: 202-217.

Fanning, EA (1962) Effect of extraction of deciduous molars on the formation and eruption of their successors. Angle Orthod. 32: 44-53.

Fannning, EA (1964) Some practical applications of research findings in tooth development. Aust. Dent. J. 9: 374-379. 
Fanning, EA (1971) Primary and permanent tooth development. Aust. Dent. J. 16: 41-43.

Feasby, WH (1971) A radiograph study of dental eruption. M.Sc. Thesis, Univ. of Manitoba.

Feasby, WH (1981) A radiograph study of dental eruption. Amer. J. Orthod. 80: 554-560.

Garcia-Godoy, F, Diaz, AN, del Valle, JM, and Arana, EJ (1982) Timing of permanent tooth emergence in a Southeastern Dominican schoolchildren population sample. Community Dent. Oral Epidemiol. 10: 43-46.

Garn, SM, Koski, K, and Lewis, AB (1957) Problems in determining the tooth eruption sequence in fossil and modern man. Am. J. Phys. Anthropol. 15: 313-331.

Garn, SM, and Lewis, AB (1957) Relationship between the sequence of calcification and the sequence of eruption of the mandibular molar and premolar teeth. J. Dent. Res. 36: 992-995.

Garn, SM, and Lewis, AB (1963) Phylogenetic and intra-specific variations in tooth sequence polymorphism. In DR Brothwell, VM Carbonell, and DH Goose (eds): Dental Anthropology, Symposia of the Society for the Study of Human Biology, Vol.5. New York: Pergamon Press, pp. 53-73.

Garn, SM, Lewis, AB, and Blizzard, $R$ (1965a) Endocrine factors in dental development. J. Dent. Res. 44: 243-258.

Garn, SM, Lewis, AB, and Bonne, B (1962) Third molar formation and its development course. Angle Orthod. 32: 270-279.

Garn, SM, Lewis, AB, and Kerewsky, R (1965b) Genetic, nutritional, and maturational correlates of dental development. J. Dent. Res. 44: $228-242$.

Garn, SM, Lewis, AB, Koski, K, and Polacheck, DL (1958a) The sex differences in tooth calcification. J. Dent. Res. 37: 561-567.

Garn, SM, Lewis, AB, and Polacheck, DL (1958b) Variability of tooth formation in man. Science 128: 1510. 
Garn, SM, Lewis, AB, and Polacheck, DL (1959) Variability of tooth formation. J. Dent. Res. 38: 135-148.

Garn, SM, Lewis, AB, and Polacheck, DL (1960) Sibling similarities in dental development. J. Dent. Res. 39: 170-175.

Garn, SM, Lewis, AB, and Shoemaker, D (1956) The sequence of calcification of the mandibular molar and premolar teeth. J. Dent. Res. 35: $555-561$.

Garn, $S$ and Moorrees, CFA (1951) Body build and tooth emergence in Aleutian Aleut children. Child Dev. 22: 261-270.

Garn, SM, Wertheimer, F, Sandusky, ST, and McCann, MB (1972) Advanced tooth emergence in Negro individuals. J. Dent. Res. 51: 1506.

Gleiser, I, and Hunt, EE (1955) The permanent mandibular first molar: It's calcification, eruption and decay. Am. J. Phys. Anthropol. 13: 253-281.

Goldstein, MS (1932) Congenital absence and impaction of the third molar in the Eskimo mandible. Am. J. Phys. Anthropol. 16: $381-388$.

Gron, A (1962) Prediction of tooth emergence. J. Dent. Res. 41: $573-585$.

Haavikko, K (1970) The formation and the alveolar and clinical eruption of the permanent teeth. Suom. Hammaslaak. Toim. 66: $107-152$.

Haavikko, K, and Mattila, K (1970) The correspondence between the roentgenological and the clinical appearance of an erupting succedaneous permanent tooth. Suom. Hammaslaak. Toim. 66: $190-195$.

Healy, Jr, and Goldstein, $H(1976)$ An approach to the scaling of categorized attributes. Biometrika 63: 219-229.

Hellman, M (1923) Nutrition, growth and dentition. Dent. Cosmos 65: $34-49$. 
Hellman, M (1936) Our third molar teeth, their eruption, presence and absence. Dent. Cosmos 78: 750-762.

Hellman, M (1943) The phase of development concerned with erupting the permanent teeth. Am. J. Orthod. Oral Surg. 29: 507-526.

Helm, S, and Seidler, B (1974) Timing of permanent tooth emergence in Danish children. Community Dent. Oral Epidemiol. 2: 122-129.

Hildes, JA (1976) Health care - Keewatin district. Univ. Man. Med. J. 46: $100-105$.

Hooton, EA (1930) The Indians of Pecos Pueblo, a study of their skeletal remains. New Haven: Yale Univ. Press.

Hrdlicka, A (1908) Physiological and medical observations among the Indians of Southwestern United States and Northern Mexico. Smithsonian Institute, Washington Bur. Am. Ethnol. Bull. no. 34.

Hrdlicka, A (1929) Anthropological survey in Alaska. Bur. Am. Ethnol., 1928-1929. Ann. Rep. 느: 19-374.

Hunt, EE Jr, and Gleiser, I (1955) The estimation of age and sex of preadolescent children from bones and teeth. Amer. J. Phys. Anthropol. 13: 479-487.

Hurme, VO (1948) Standards of variation in the eruption of the first six permanent teeth. Child Dev. 19: 213-231.

Hurme, Vo (1949) Ranges of normalcy in the eruption of permanent teeth. J. Dent. Child. 16: 11-15.

Jenness, D (1977) Indians of Canada, 7 th edition. Toronto: Univ. of Toronto Press.

Knott, VB, and Meredith, HV (1966) Statistics on eruption of the permanent dentition from serial data for North American white children. Angle Orthod. 36: 68-79.

Koski, K, and Garn, SM (1957) Tooth eruption sequence in fossil and modern man. Am. J. Phys. Anthropol. 15: 469-488. 
Krogman, WM (1950) Growth of the "whole child" in relation to dental problems. Oral Surg. Oral Med. Oral Path. 3: 427-445.

Krogman, WM (1968a) Biological timing and the dento-facial complex. Part I. J. Dent. Child. 35: 175-185.

Krogman, WM (1968b) Biological timing and the dento-facial complex. Part II. J. Dent. Child. 35: 328-341.

Krogman, WM (1968c) Biological timing and the dento-facial complex. Part III. J. Dent. Child. 35: 377-381.

Kronfeld, R (1935a) First permanent molar; its condition at birth and its postnatal development. J. Am. Dent. Assoc. 22: 1131-1155.

Kronfeld, $R$ (1935b) Postnatal development and calcification of the anterior permanent teeth. J. Am. Dent. Assoc. 22: 1521-1536.

Kronfeld, $R$ (1935c) Development and calcification of human deciduous and permanent dentition. The Bur 35: 18-25.

Lamons, FF and Gray, SW (1958) A study of the relationship between tooth eruption age, skeletal development age, and chronological age in sixty-one Atlanta children. Am. J. Orthod. 44: 687-691.

Lauterstein, AM (1961) Cross-sectional study in dental development and skeletal age. J. Am. Dent. Assoc. 62: 161-167.

Lauterstein, AM, and Pruzansky, S (1968) Bilateral symmetry in human mandibular apical tooth growth. Arch. Oral Biol. 13: 1047-1055.

Lauterstein, AM, Pruzansky, S, and Barber, TK (1962) Effect of deciduous mandibular molar pulpotomy on the eruption of succedaneous premolar. J. Dent. Res. 41: 1367-1372.

Lauterstein, AM, Pruzansky, S, and Levine, NL (1967) Bilateral asymmetry in mandibular tooth development. J. Dent. Res. 46: 279-285.

Leske, GS, Ripa, LW, Sposato, AL, Simon, GA, and Moresco, TV (1981) The probability of primary tooth exfoliation: A reference source for programs that treat children during their mixed dentition. J. 
Public Health Dent. 41: 236-243.

Levesque, GY, and Demirjian, A (1980) The inter-examiner variation in rating dental formation from radiographs. J. Dent. Res. 59: $1123-1126$.

Levesque, GY, Demirjian, A, and Tanguay, R (1981) Sexual dimorphism in the development, emergence and agenesis of the mandibular third molar. J. Dent. Res. 60: 1735-1741.

Lewis, AB and Garn SM (1960) The relationship between tooth formation and other maturational factors. Angle Orthod. 30: 70-77.

Liliequist, B and Lundberg M (1971) Skeletal and tooth development. A methodologic investigation. Acta. Radiol. 11: 97-112.

Lo, RT, and Moyers, RE (1953) Studies in the etiology and prevention of malocclusion. I Sequence of eruption of the permanent dentitions. Am. J. Orthod. 39: 460-467.

Logan, WHG and Kronfeld, R (1933) Development of human jaws and surrounding structures from birth to age of 15 years. J. Am. Dent. Assoc. 20: $379-427$.

Magnusson, TE (1976) Emergence of permanent teeth and onset of dental stages in the population of Iceland. Community Dent. Oral Epidemio1. ㄴ. $30-37$.

Magnusson, TE (1982) Emergence of primary teeth and onset of dental stages in Icelandic children. Community Dent. Oral Epidemiol. 10: $91-97$.

Massler, M, and Schour, I (1941) Studies in tooth development: Theories of eruption. Am. J. Orthod. Oral Surg. 27: 552-575.

Massler, M, Schour, I, and Poncher, HG (1941) Developmental pattern of the child as reflected in the calcification pattern of the teeth. Am. J. Dis. Child 62: 33-67.

Masson, $J(1980)$ Permanent tooth emergence timing of northern Quebec caucasoid children. Can. Dent. Assoc. J. 10: 643-645. 
Mathiassen, T (1927) Archeology of the Central Eskimos. Report of the Fifth Thule Expedition 1921-24, vol. 4. Copenhagen: Gyldendal.

Matiegka, J (1921) L'age dentaire comme signe du development total. Revue Anthropol. 31: 333-335.

Mattila, K, and Haavikko, K (1969) The correspondence between the orthopantomographic and the clinical appearance of an erupting tooth (first molar). Odont. T. 77: 39-45.

Mayhall, JT (1970) The effect of culture change upon the Eskimo dentition. Arctic Anthropol. 7: 117-121.

Mayhall, JT (1971) Dental studies: Progress report. In International Biological Programme, Human Adaptability Project, Annual Report Number 3. Toronto: Univ. of Toronto, pp. 49-61.

Mayhall, JT (1972) Dental studies: Progress report 1971. In International Biological Programme, Human Adaptability Project, Annual Report Number 4. Toronto: Univ. of Toronto, pp. 20-32.

Mayhall, JT (1976) Inuit culture change and oral health: a four-year study. In RJ Shephard and S Itoh (eds): Circumpolar Health, Proceedings of the Third International Symposium. Toronto: Univ. of Toronto Press, pp. 414-420.

Mayhall, JT (1977a) The oral health of a Canadian Inuit community: An anthropological approach. J. Dent. Res. Special Issue C $\underline{56}$ : 55-61.

Mayhall, JT (1977b) Cultural and environmental influences on the Eskimo dentition. In AA Dahlberg and TM Graber (eds): Orofacial growth and development. Chicago: Aldine, pp. 216-227.

Mayhall, JT, Belier, PL, and Mayhall, MF (1977) Permanent tooth emergence timing of Northern Ontario Indians. Ont. Dent. 54: 8-10.

Mayhall, JT, Belier, PL, and Mayhall, MF (1978) Canadian Eskimo permanent tooth emergence timing. Am. J. Phys. Anthropol. 49 : 211-216.

Meredith, HV (1959) Relation between the eruption of selected mandibular permanent teeth and the circumpuberal acceleration in 
stature. J. Dent. Child. 26: 75-78.

Miles, AEW (1958) The assessment of age from the dentition. Proc. R. Soc. Med. 51: 1057-1060.

Miles, AEW (1963) The dentition in the assessment of individual age in skeletal material. In DR Brothwell, VM Carbonell, and DH Goose (eds): Dental Anthropology, Symposia of the Society for the Study of Human Biology, Vol. 5. New York: Pergamon Press, pp. 191-209.

Moir, RW (1978) A cephalometric analysis of a North American Indian tribe: A cross-sectional study. M.Sc. Thesis, Univ. of Manitoba.

Moorrees, CFA (1957) The Aleut dentition. Cambridge: Harvard Univ. Press.

Moorrees, CFA (1959) The dentition of the growing child. Cambridge: Harvard Univ. Press.

Moorrees, CFA, Fanning, EA, and Hunt, EE (1963) Age variation of formation stages for ten permanent teeth. J. Dent. Res. 42: 1490-1502.

Nanda, RS (1960) Eruption of human teeth. Am. J. Orthod. 46: 363-378.

Nanda, RS, and Chawla, TN (1966) Growth and development of dentitions in Indian children. I. Development of permanent teeth. Am. J. Orthod. 52: $837-853$.

Nevile, MD (1973) Dental and skeletal maturation in Trisomy 21 (Down's Syndrome). M.Sc. Thesis, Univ. of Manitoba.

Nolla, CM (1960) Development of the permanent teeth. J. Dent. Child. 27: $254-266$.

Orban, B (1928) Growth and movement of tooth germs and teeth. J. Am. Dent. Assoc. 15: 1004-1016.

Pedersen, PO (1949) The East Greenland dentition. CA Reitzel Farlay Meddelelser, Copenhagen. 
Pedersen, PO (1967) Anatomical studies of the East Greenland dentition. In S Tax (ed): Indian Tribes of Aboriginal America, 29th International Congress of Americanists. New York: Cooper Square Inc. pp. 46-49.

Perreault, JG, Demirjian, A, and Jenicek, M (1974) Emergence des dents permanentes chez les enfants canadiens-francais. Can. Dent. Assoc. J. 40: 306-313.

Posen, AL (1965) The effect of premature loss of deciduous molars on premolar eruption. Angle Orthod. 35: 249-252.

Price, WA (1939) Nutrition and physical degeneration. Los Angeles: Citizen's Print Shop.

Report on Health Conditions in the Northwest Territories (1981) Medical Services, NWT Region: National Health and Welfare, Canada.

Schour, I, and Massler, M (1940a) Studies in tooth development: The growth of the human teeth. Part I J. Am. Dent. Assoc. 27: $1778-1793$.

Schour, I, and Massler, M (1940b) Studies in tooth development: The growth of the human teeth. Part II J. Am. Dent. Assoc. 27: $1918-1931$.

Schour, I, and Massler, M (1941) The development of the human dentition. J. Am. Dent. Assoc. 28: 1153-1160.

Schour, I, and Massler, M (1962) Development and growth of teeth. In H Sicher (ed): Orban's Oral Histology and Embryology, 5th edition. St. Louis: CV Mosby Co., pp. 31-51.

Schour, I, and Poncher, HG (1940) Chronology of tooth development. Chicago: Univ. of Illinois.

Schultz, AH (1950) The physical distinctions of man. Proc. Am. Phil. Soc. 94: 428-449.

Short, EM (1962) Domestic water and dental caries VI. The relation of fluoride domestic waters to permanent tooth eruption. In FJ McClure (ed.): Fluoride drinking waters. U.S. Public Health 
Service Publications, No. 825: 137-141.

Shumaker, DB (1974) A comparison of chronologic age and physiologic age as predictors of tooth eruption. Am. J. Orthod. 66: 50-57.

Shumaker, DB, and E1 Hadary, MS (1960) Roentgenographic study of eruption. J. Am. Dent. Assoc. 61: 535-541.

Sicher, $H$ (1942) The axial movement of the continuously growing teeth. J. Dent. Res. 21: 201-210.

Smith, MC (1934) Effects of fluoride upon the rate of eruption of rat incisors and its correlation with bone development and body growth. J. Dent. Res. 14:139-144.

Steggerda, M (1945) Anthropometry and the eruption time of teeth. J. Am. Dent. Assoc. 32: 339-342.

Steggerda, M, and Hill, TJ (1942) Eruption time of teeth among whites, negroes and indians. Am. J. Orthod. Oral Surg. 28: 361-370.

Szathmary, EJE, and Ossenberg, N (1978) Are the biological differences between North American Indians and Eskimos truly profound. Current Anthro. 19: 673-685.

Tanner, JM, Whitehouse, RH, and Healy, MJR (1962) A new system for estimating skeletal maturity from the hand and wrist with standards derived from a study of 2,600 healthy British children. Dept. of Growth and Development: Univ. of London.

Titley, KC, and Mayhall, JT (1976) The dental disease status of Indians resident in the Sioux Lookout zone of northern Ontario. In RJ Shephard and S Itoh (eds): Circumpolar Health, Proceedings of the Third International Symposium. Toronto: Univ. of Toronto Press, pp. 421-425.

Wolanski, N (1967) New method for the evaluation of tooth formation. J. Dent. Res. 46: 875 . 
A P PENDIX A 
AGE IN YEARS

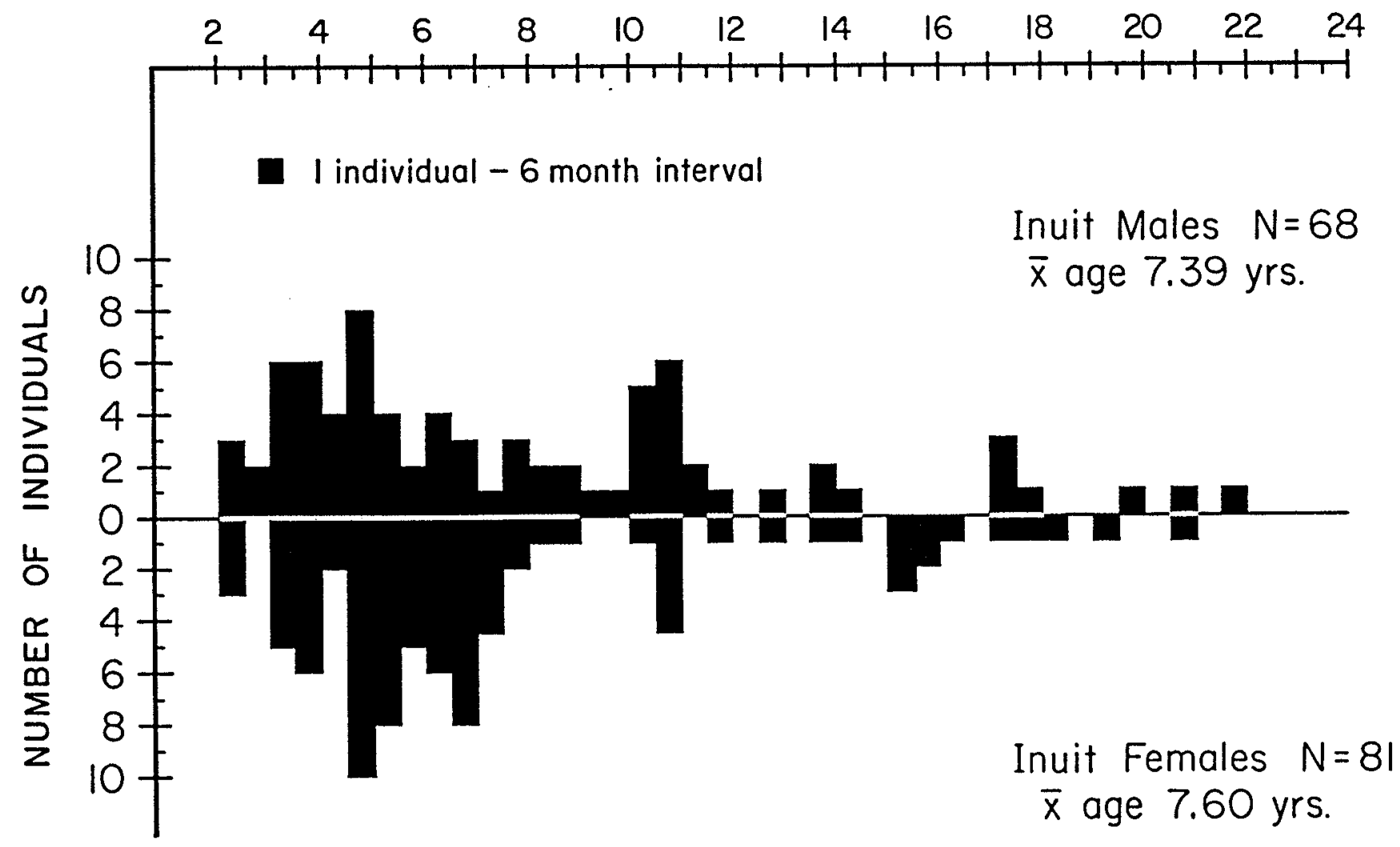

Figure I. 


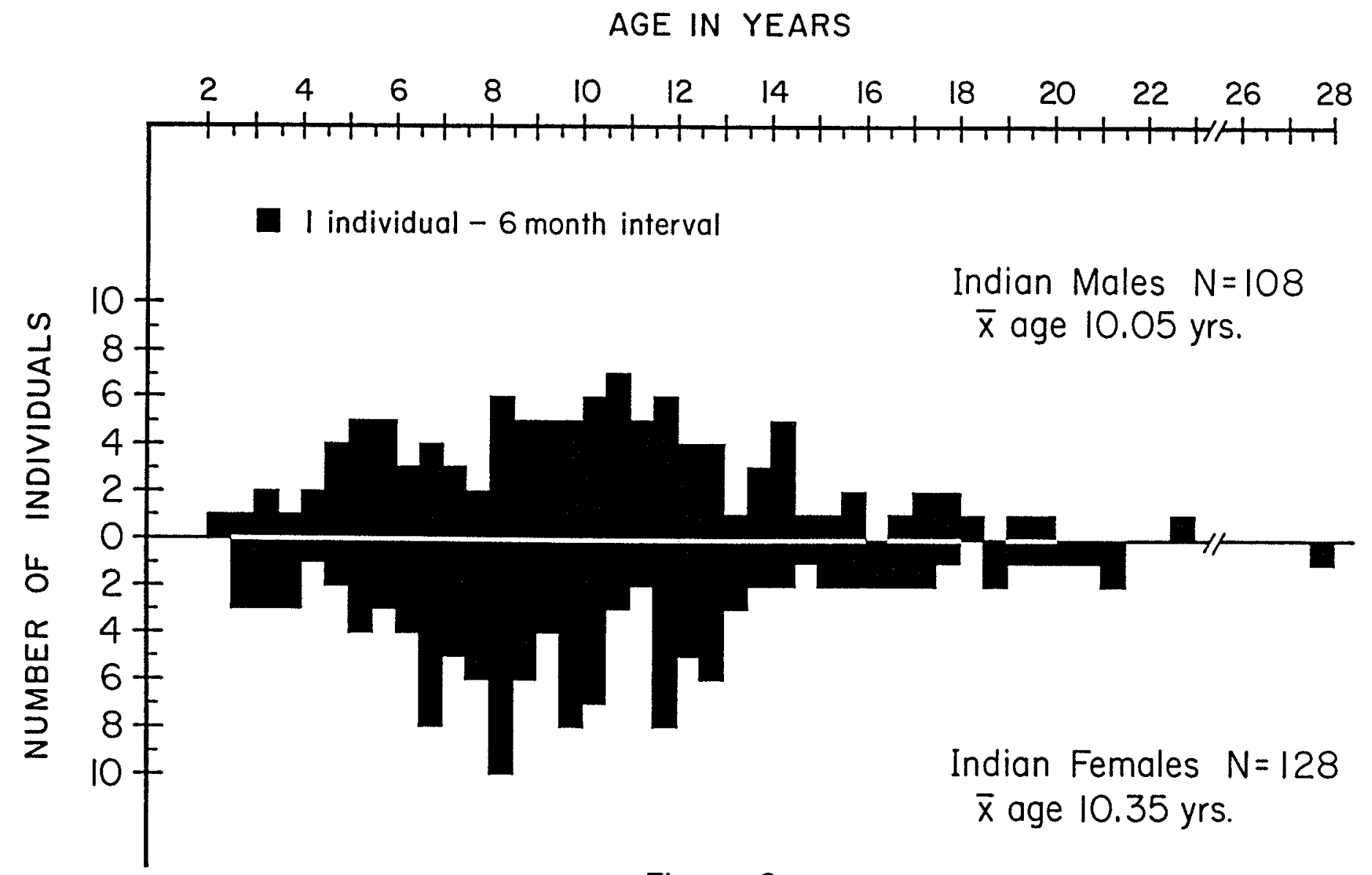

Figure 2. 
TABLE I

Selected Keys for the Scoring of Calcification

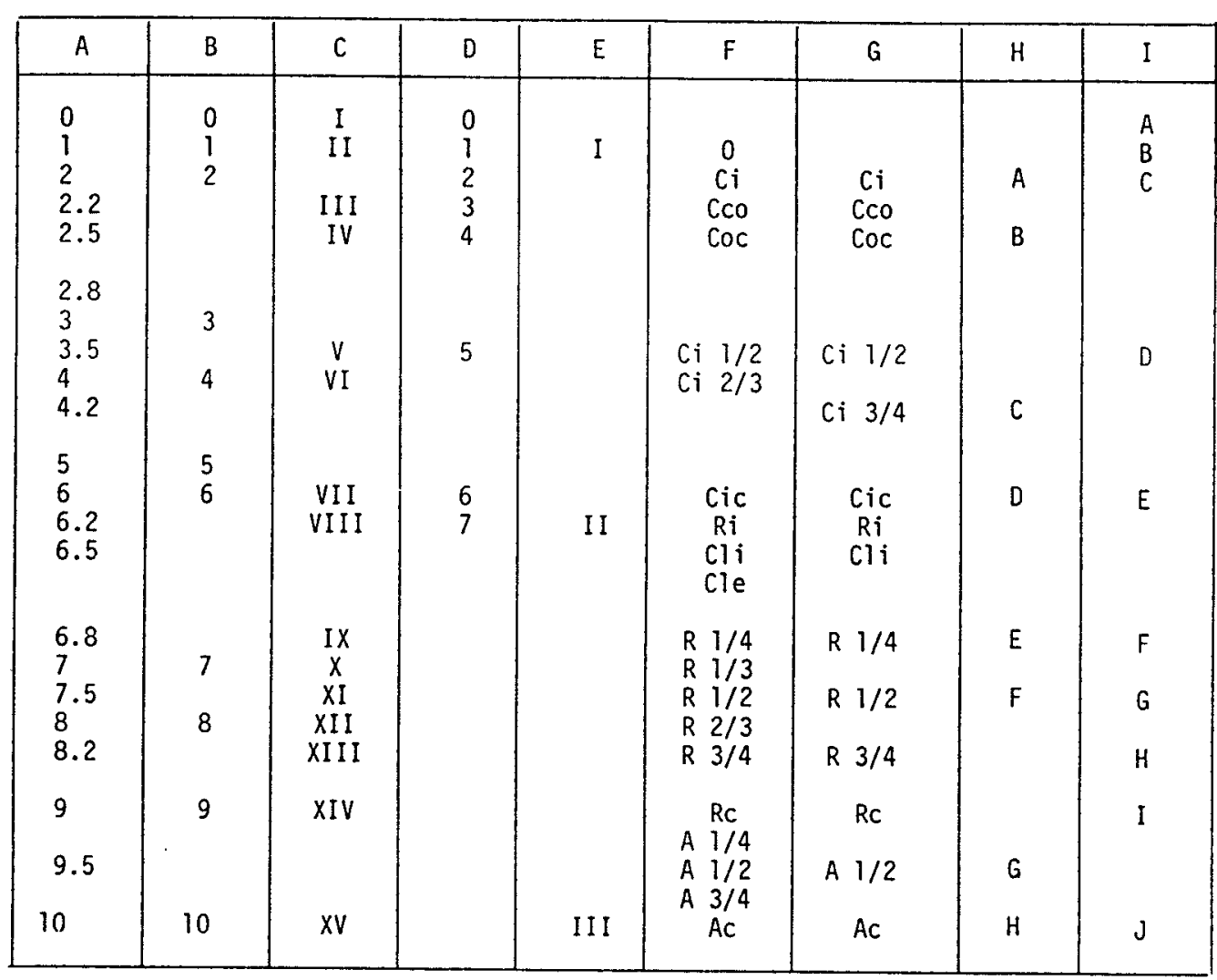

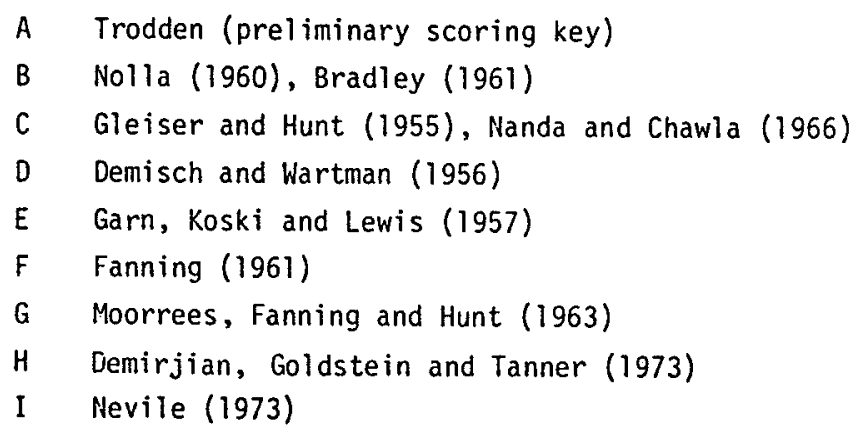


Table II

Mean Age in Years - Absence of Crypt (Calcification Score 0)

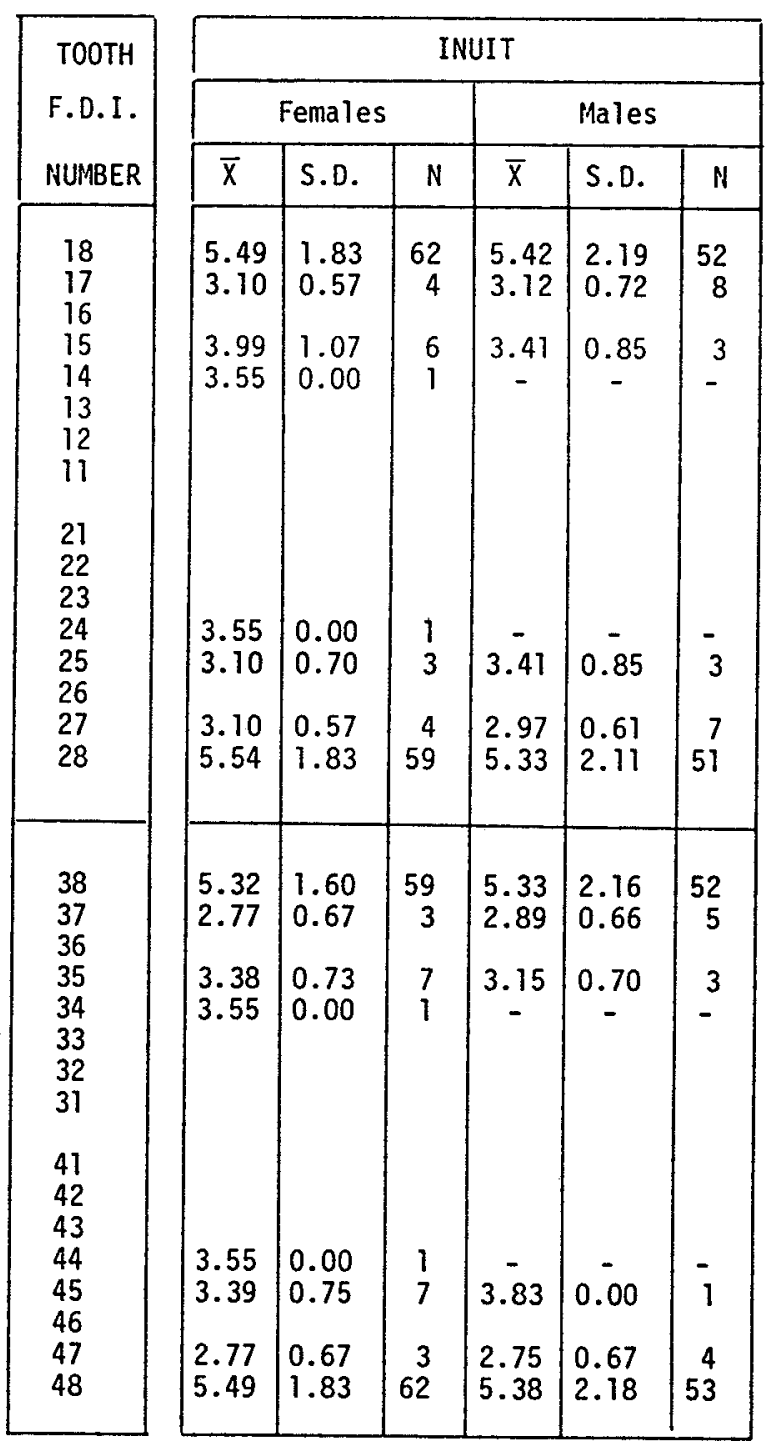

\begin{tabular}{|c|c|c|c|c|c|}
\hline \multicolumn{6}{|c|}{ INDIAN } \\
\hline \multicolumn{3}{|c|}{ Females } & \multicolumn{3}{|c|}{ Males } \\
\hline $\bar{x}$ & S.D. & $N$ & $\bar{x}$ & S.D. & $N$ \\
\hline $\begin{array}{l}6.93 \\
3.11\end{array}$ & $\begin{array}{l}2.30 \\
0.31\end{array}$ & $\begin{array}{r}57 \\
6\end{array}$ & $\begin{array}{l}6.97 \\
2.57\end{array}$ & $\begin{array}{l}2.39 \\
0.20\end{array}$ & $\begin{array}{r}52 \\
2\end{array}$ \\
\hline 2.97 & 0.25 & 4 & 2.57 & 0.20 & 2 \\
\hline- & - & - & - & - & - \\
\hline $3 . \overline{38}$ & $0 . \overline{95}$ & $\overline{5}$ & $2 . \overline{57}$ & $0 . \overline{20}$ & - \\
\hline $\begin{array}{l}3.05 \\
6.74\end{array}$ & $\begin{array}{l}0.24 \\
2.25\end{array}$ & $\begin{array}{r}6 \\
53\end{array}$ & $\begin{array}{l}2.57 \\
6.90\end{array}$ & $\begin{array}{l}0.20 \\
2.25\end{array}$ & $\begin{array}{r}2 \\
47\end{array}$ \\
\hline $\begin{array}{l}6.49 \\
2.85\end{array}$ & $\begin{array}{l}2.08 \\
0.00\end{array}$ & $\begin{array}{r}49 \\
2\end{array}$ & $\begin{array}{l}6.75 \\
2.57\end{array}$ & $\begin{array}{l}2.28 \\
0.20\end{array}$ & $\begin{array}{r}43 \\
2\end{array}$ \\
\hline 2.97 & 0.25 & 4 & 2.57 & 0.20 & 2 \\
\hline- & - & - & - & - & - \\
\hline $2 . \overline{97}$ & $0 . \overline{25}$ & - & 2.57 & $\begin{array}{c}- \\
0.20\end{array}$ & - \\
\hline $\begin{array}{l}2.85 \\
6.65\end{array}$ & $\begin{array}{l}0.00 \\
2.28\end{array}$ & $\begin{array}{r}2 \\
50\end{array}$ & $\begin{array}{l}2.57 \\
6.34\end{array}$ & $\begin{array}{l}0.20 \\
2.15\end{array}$ & $\begin{array}{r}2 \\
42\end{array}$ \\
\hline
\end{tabular}


Table III

Mean Age in Years - Crypt Visible (Calcification Score 1)

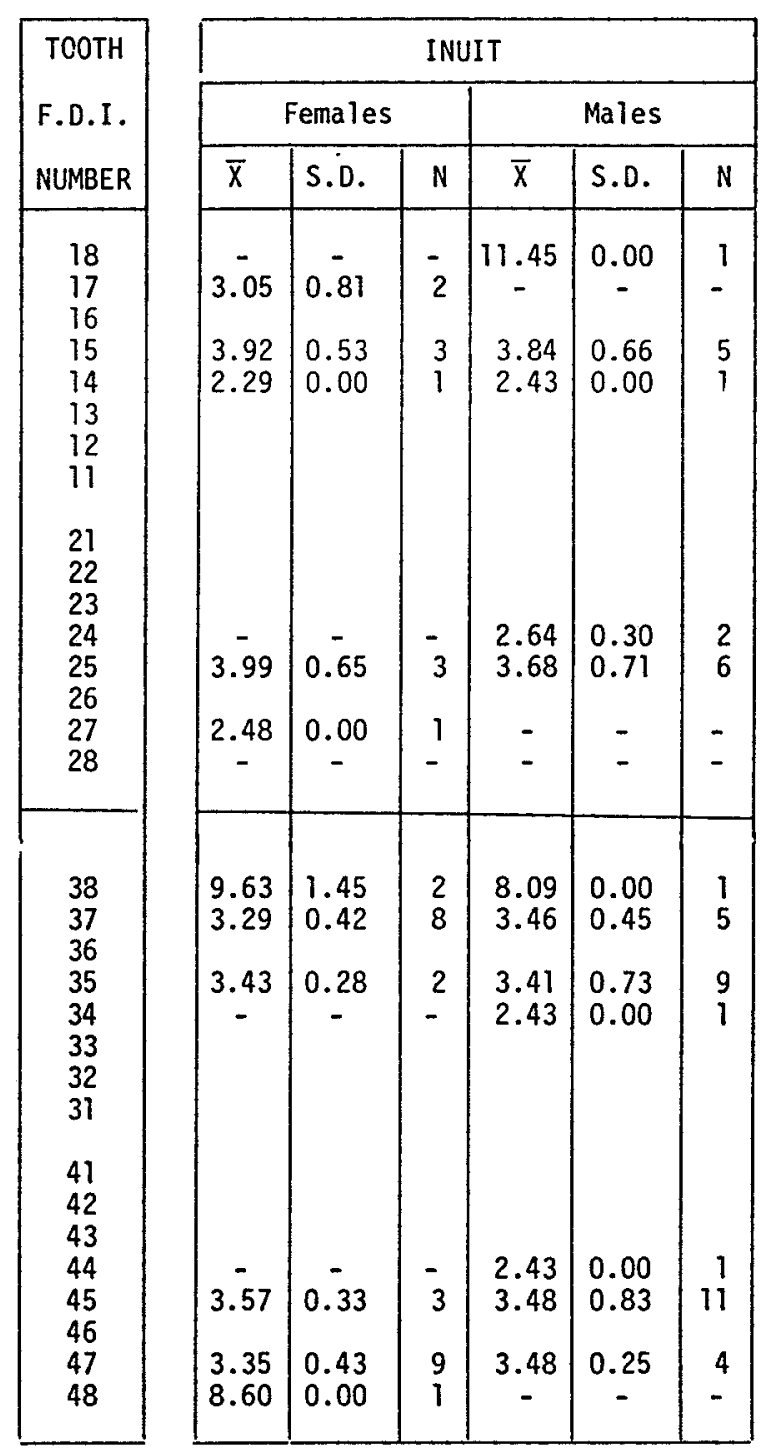

\begin{tabular}{|c|c|c|c|c|c|}
\hline \multicolumn{6}{|c|}{ INDIAN } \\
\hline \multicolumn{3}{|c|}{ Females } & \multicolumn{3}{|c|}{ Males } \\
\hline $\bar{x}$ & S.D. & $N$ & $\bar{x}$ & S.D. & N \\
\hline $\begin{array}{l}8.41 \\
3.18\end{array}$ & $\begin{array}{l}0.00 \\
0.00\end{array}$ & 1 & - & - & - \\
\hline $\begin{array}{l}3.22 \\
2.82\end{array}$ & $\begin{array}{l}0.05 \\
0.00\end{array}$ & $\begin{array}{l}2 \\
1\end{array}$ & 3.20 & $\begin{array}{c}0.00 \\
-\end{array}$ & 1 \\
\hline $\begin{array}{l}2.83 \\
3.22\end{array}$ & $\begin{array}{l}0.02 \\
0.05\end{array}$ & $\begin{array}{l}2 \\
2\end{array}$ & $3 . \overline{20}$ & $0 . \overline{0}$ & $\overline{1}$ \\
\hline $8 . \overline{30}$ & $0 . \overline{15}$ & $\overline{2}$ & - & - & - \\
\hline $\begin{array}{l}9.26 \\
3.15\end{array}$ & $\begin{array}{l}1.10 \\
0.23\end{array}$ & $\begin{array}{l}9 \\
4\end{array}$ & $\begin{array}{c}8.44 \\
-\end{array}$ & $\begin{array}{c}1.29 \\
-\end{array}$ & $\begin{array}{l}6 \\
-\end{array}$ \\
\hline $\begin{array}{l}3.26 \\
2.85\end{array}$ & $\begin{array}{l}0.00 \\
0.00\end{array}$ & $\begin{array}{l}1 \\
1\end{array}$ & - & - & - \\
\hline $\begin{array}{l}2.85 \\
3.26\end{array}$ & $\begin{array}{l}0.00 \\
0.00\end{array}$ & 1 & - & - & - \\
\hline $\begin{array}{l}3.15 \\
8.93\end{array}$ & $\begin{array}{l}0.23 \\
1.31\end{array}$ & $\begin{array}{l}4 \\
8\end{array}$ & $8 . \overline{9}$ & $0 . \overline{80}$ & $\overline{7}$ \\
\hline
\end{tabular}


Table IV

Mean Age in Years - Initial Calcification (Calcification Score 2)

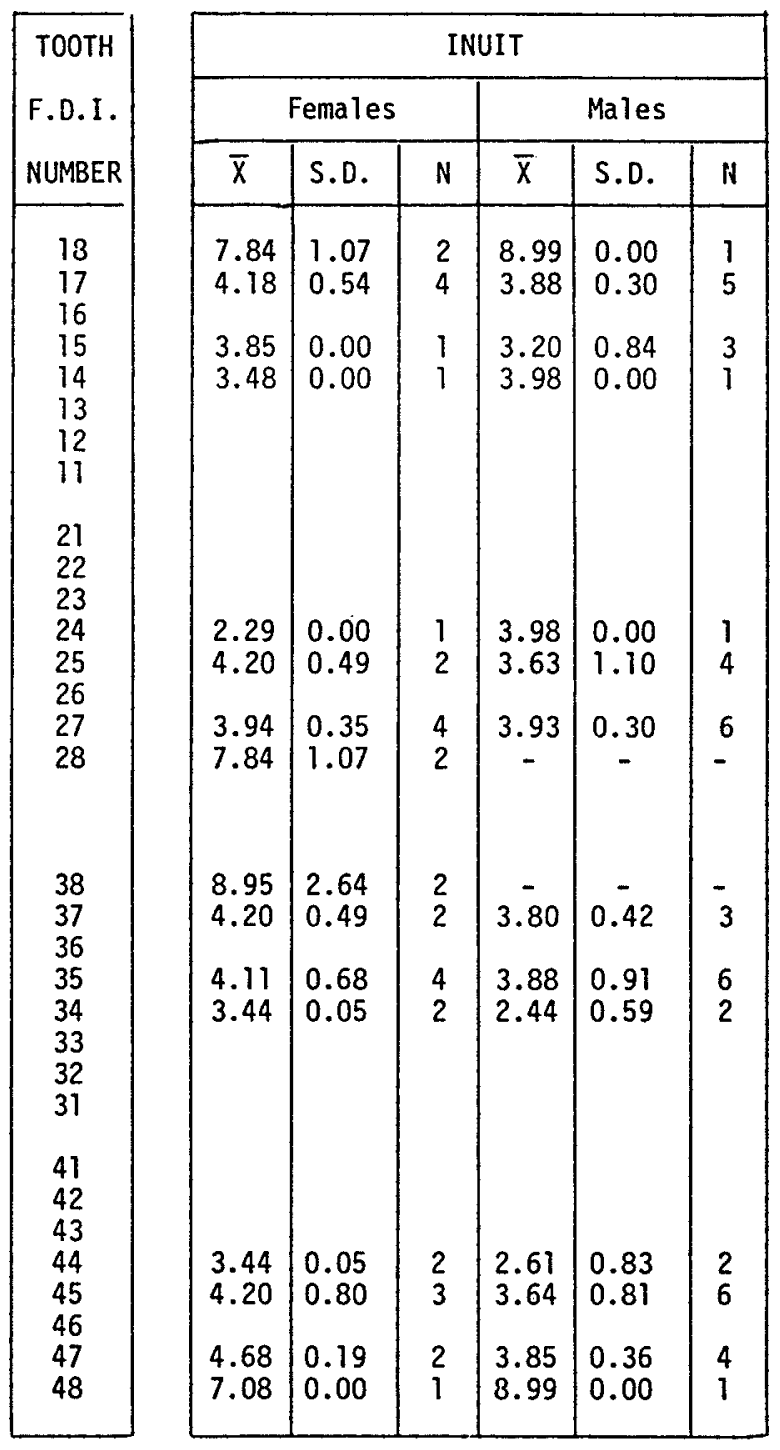

\begin{tabular}{|c|c|c|c|c|c|}
\hline \multicolumn{6}{|c|}{ INDIAN } \\
\hline \multicolumn{3}{|c|}{ Females } & \multicolumn{3}{|c|}{ Males } \\
\hline $\bar{x}$ & S.D. & $N$ & $\bar{x}$ & S.0. & $N$ \\
\hline $\begin{array}{c}9.26 \\
-\end{array}$ & $\begin{array}{c}0.93 \\
-\end{array}$ & $\begin{array}{l}3 \\
-\end{array}$ & $\begin{array}{l}9.21 \\
3.20\end{array}$ & $\begin{array}{l}1.45 \\
0.00\end{array}$ & $\begin{array}{l}7 \\
1\end{array}$ \\
\hline $\begin{array}{l}4.37 \\
3.15\end{array}$ & $\begin{array}{l}1.17 \\
0.26\end{array}$ & $\begin{array}{l}2 \\
3\end{array}$ & $\begin{array}{c}3.56 \\
-\end{array}$ & $\begin{array}{c}0.56 \\
-\end{array}$ & 2 \\
\hline $\begin{array}{l}3.31 \\
4.58\end{array}$ & $\begin{array}{l}0.06 \\
0.87\end{array}$ & $\begin{array}{l}2 \\
2\end{array}$ & 3.16 & 0.00 & $\overline{1}$ \\
\hline 9.67 & $1 . \overline{35}$ & - & $\begin{array}{l}3.20 \\
9.92\end{array}$ & $\begin{array}{l}0.00 \\
1.32\end{array}$ & $\begin{array}{l}1 \\
9\end{array}$ \\
\hline $\begin{array}{c}9.56 \\
-\end{array}$ & 1.52 & 5 & $\begin{array}{l}9.11 \\
3.60\end{array}$ & $\begin{array}{l}0.64 \\
0.56\end{array}$ & $\begin{array}{l}5 \\
2\end{array}$ \\
\hline $\begin{array}{l}3.56 \\
2.82\end{array}$ & $\begin{array}{l}0.38 \\
0.00\end{array}$ & $\begin{array}{l}3 \\
1\end{array}$ & $\begin{array}{l}3.45 \\
2.57\end{array}$ & $\begin{array}{l}0.47 \\
0.20\end{array}$ & $\begin{array}{l}3 \\
2\end{array}$ \\
\hline $\begin{array}{l}2.82 \\
3.56\end{array}$ & $\begin{array}{l}0.00 \\
0.38\end{array}$ & $\begin{array}{l}1 \\
3\end{array}$ & $\begin{array}{l}2.57 \\
3.18\end{array}$ & $\begin{array}{l}0.20 \\
0.03\end{array}$ & $\begin{array}{l}2 \\
2\end{array}$ \\
\hline $\begin{array}{l}3.54 \\
8.79\end{array}$ & $\begin{array}{l}0.00 \\
0.98\end{array}$ & $\begin{array}{l}1 \\
5\end{array}$ & $\begin{array}{l}3.60 \\
8.91\end{array}$ & $\begin{array}{l}0.56 \\
1.17\end{array}$ & $\begin{array}{l}2 \\
6\end{array}$ \\
\hline
\end{tabular}


Table V

Mean Age in Years - Crown $\frac{1}{4}$ Complete (Calcification Score 3)

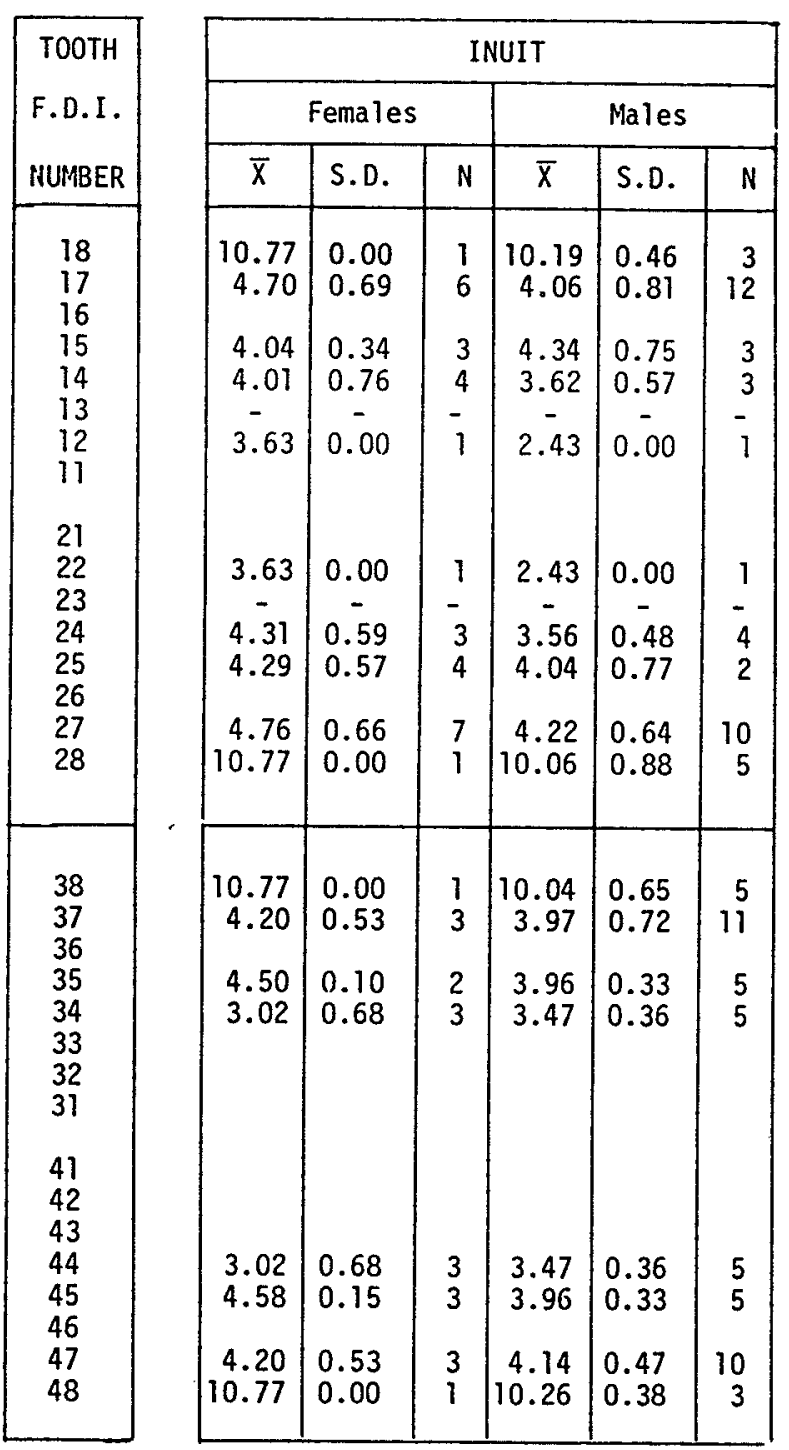

\begin{tabular}{|c|c|c|c|c|c|}
\hline \multicolumn{6}{|c|}{ INDIAN } \\
\hline \multicolumn{3}{|c|}{ Females } & \multicolumn{3}{|c|}{ Males } \\
\hline $\bar{x}$ & S.D. & $\mathbf{N}$ & $\bar{x}$ & S.D. & $N$ \\
\hline $\begin{array}{l}9.78 \\
3.93\end{array}$ & $\begin{array}{l}1.01 \\
0.04\end{array}$ & $\begin{array}{l}4 \\
2\end{array}$ & $\begin{array}{r}10.46 \\
3.16\end{array}$ & $\begin{array}{l}1.65 \\
0.00\end{array}$ & $\begin{array}{l}2 \\
1\end{array}$ \\
\hline 4.47 & 0.79 & 2 & 4.58 & 0.00 & 1 \\
\hline- & - & - & - & - & 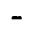 \\
\hline - & - & - & 2.42 & 0.00 & 1 \\
\hline - & - & - & - & - & - \\
\hline- & - & - & - & - & - \\
\hline - & - & - & 2.42 & 0.00 & 1 \\
\hline $3 . \overline{90}$ & $0 . \overline{0}$ & $i$ & $4 . \overline{29}$ & 0. & - \\
\hline & & & & & \\
\hline $\begin{array}{l}3.93 \\
9.16\end{array}$ & $\begin{array}{l}0.04 \\
0.90\end{array}$ & $\begin{array}{l}2 \\
4\end{array}$ & $\begin{array}{r}3.93 \\
11.63\end{array}$ & $\begin{array}{l}0.00 \\
0.00\end{array}$ & $\begin{array}{l}1 \\
1\end{array}$ \\
\hline $\begin{array}{r}10.56 \\
4.58\end{array}$ & $\begin{array}{l}1.48 \\
0.87\end{array}$ & $\begin{array}{l}6 \\
2\end{array}$ & $\begin{array}{r}10.45 \\
4.51\end{array}$ & $\begin{array}{l}0.84 \\
0.51\end{array}$ & $\begin{array}{l}5 \\
3\end{array}$ \\
\hline $\begin{array}{l}5.12 \\
3.31\end{array}$ & $\begin{array}{l}0.11 \\
0.06\end{array}$ & 2 & 4.27 & 0.43 & 2 \\
\hline $\begin{array}{l}3.31 \\
5.03\end{array}$ & $\begin{array}{l}0.06 \\
0.00\end{array}$ & $\begin{array}{l}2 \\
1\end{array}$ & 4.16 & $0 . \overline{28}$ & $\overline{4}$ \\
\hline $\begin{array}{r}4.58 \\
10.64\end{array}$ & $\begin{array}{l}0.87 \\
0.79\end{array}$ & $\begin{array}{l}2 \\
6\end{array}$ & $\begin{array}{r}4.24 \\
10.45\end{array}$ & $\begin{array}{l}0.95 \\
0.84\end{array}$ & $\begin{array}{l}3 \\
5\end{array}$ \\
\hline
\end{tabular}


Table VI

Mean Age in Years - Crown $\frac{1}{2}$ Complete (Calcification Score 4 )

\begin{tabular}{|c|c|c|c|c|c|c|}
\hline \multirow{3}{*}{$\begin{array}{l}\text { TOOTH } \\
\text { F.D.I. } \\
\text { NUMBER }\end{array}$} & \multicolumn{6}{|c|}{ INUIT } \\
\hline & \multicolumn{3}{|c|}{ Females } & \multicolumn{3}{|c|}{ Males } \\
\hline & $\bar{x}$ & S.D. & $N$ & $\bar{x}$ & S.D. & $\mathbf{N}$ \\
\hline $\begin{array}{l}18 \\
17 \\
16 \\
15 \\
14 \\
13 \\
12 \\
11\end{array}$ & $\begin{array}{c}- \\
4.82 \\
4.96 \\
3.78 \\
3.57 \\
3.48 \\
-\end{array}$ & $\begin{array}{c}- \\
0.61 \\
0.64 \\
0.12 \\
0.08 \\
0.00 \\
-\end{array}$ & $\begin{array}{l}- \\
5 \\
5 \\
4 \\
3 \\
1 \\
-\end{array}$ & $\begin{array}{r}10.34 \\
5.03 \\
5.21 \\
4.04 \\
3.02 \\
3.60 \\
2.43\end{array}$ & $\begin{array}{l}0.11 \\
0.50 \\
\\
1.01 \\
0.56 \\
0.42 \\
0.22 \\
0.00\end{array}$ & $\begin{array}{l}2 \\
4 \\
\\
5 \\
9 \\
5 \\
5 \\
1\end{array}$ \\
\hline $\begin{array}{l}21 \\
22 \\
23 \\
24 \\
25 \\
26 \\
27 \\
28\end{array}$ & $\begin{array}{c}- \\
3.48 \\
3.57 \\
3.78 \\
4.75 \\
5.06 \\
-\end{array}$ & $\begin{array}{c}- \\
0.00 \\
0.08 \\
0.12 \\
0.42 \\
0.30 \\
-\end{array}$ & $\begin{array}{l}- \\
1 \\
3 \\
4 \\
3 \\
3 \\
3\end{array}$ & $\begin{array}{r}2.43 \\
3.60 \\
3.02 \\
4.01 \\
5.32 \\
\\
4.48 \\
10.46\end{array}$ & $\begin{array}{l}0.00 \\
0.22 \\
0.42 \\
0.46 \\
0.90 \\
\\
1.31 \\
0.22\end{array}$ & $\begin{array}{l}1 \\
5 \\
5 \\
7 \\
5 \\
\\
5 \\
3\end{array}$ \\
\hline $\begin{array}{l}38 \\
37 \\
36 \\
35 \\
34 \\
33 \\
32 \\
31\end{array}$ & $\begin{array}{c}- \\
4.87 \\
4.94 \\
3.82 \\
3.60 \\
-\end{array}$ & $\begin{array}{c}- \\
0.54 \\
0.53 \\
0.57 \\
0.00 \\
-\end{array}$ & $\begin{array}{r}- \\
12 \\
7 \\
4 \\
1 \\
-\end{array}$ & $\begin{array}{r}10.26 \\
5.05 \\
4.90 \\
4.02 \\
2.82 \\
2.02\end{array}$ & $\begin{array}{l}0.00 \\
0.35 \\
0.36 \\
0.32 \\
0.73 \\
0.00\end{array}$ & $\begin{array}{l}1 \\
6 \\
5 \\
8 \\
3 \\
1\end{array}$ \\
\hline $\begin{array}{l}41 \\
42 \\
43 \\
44 \\
45 \\
46 \\
47 \\
48\end{array}$ & $\begin{array}{r}- \\
3.60 \\
3.82 \\
4.99 \\
4.89 \\
15.17\end{array}$ & $\begin{array}{c}0 . \overline{0} \\
0.57 \\
0.51 \\
0.54 \\
0.00\end{array}$ & $\begin{array}{r}- \\
1 \\
4 \\
8 \\
12 \\
1\end{array}$ & $\begin{array}{r}2.02 \\
2.82 \\
4.02 \\
4.90 \\
4.65 \\
10.34\end{array}$ & $\begin{array}{l}0.00 \\
0.73 \\
0.32 \\
0.36 \\
1.02 \\
0.11\end{array}$ & $\begin{array}{l}1 \\
3 \\
8 \\
5\end{array}$ \\
\hline
\end{tabular}

\begin{tabular}{|c|c|c|c|c|c|}
\hline \multicolumn{6}{|c|}{ INDIAN } \\
\hline \multicolumn{3}{|c|}{ Females } & \multicolumn{3}{|c|}{ Males } \\
\hline $\bar{x}$ & S.D. & $N$ & $\bar{x}$ & S.D. & $\mathrm{N}$ \\
\hline $\begin{array}{r}11.09 \\
5.12\end{array}$ & $\begin{array}{l}1.01 \\
0.11\end{array}$ & $\begin{array}{l}9 \\
2\end{array}$ & $\begin{array}{r}11.28 \\
4.57\end{array}$ & $\begin{array}{l}1.45 \\
0.36\end{array}$ & $\begin{array}{l}8 \\
4\end{array}$ \\
\hline 6.35 & 0.00 & 1 & 5.04 & 0.38 & 5 \\
\hline 3.36 & 0.25 & 2 & 3.79 & 0.79 & 4 \\
\hline 2.85 & 0.00 & 1 & - & - & - \\
\hline 3.02 & 0.23 & 2 & 2.42 & 0.00 & 1 \\
\hline - & - & - & - & - & - \\
\hline - & - & - & - & - & - \\
\hline 3.02 & 0.23 & 2 & 2.42 & 0.00 & 1 \\
\hline 2.85 & 0.00 & 1 & 2.71 & 0.00 & 1 \\
\hline 3.57 & 0.54 & 2 & 3.74 & 0.95 & 3 \\
\hline 6.35 & 0.00 & 1 & 5.04 & 0.38 & 5 \\
\hline 5.12 & 0.11 & 2 & 4.72 & 0.23 & 3 \\
\hline 11.05 & 1.03 & 9 & 11.01 & 1.50 & 9 \\
\hline $\begin{array}{r}10.53 \\
4.47\end{array}$ & $\begin{array}{l}1.25 \\
0.79\end{array}$ & $\begin{array}{l}7 \\
2\end{array}$ & $\begin{array}{r}11.22 \\
4.84\end{array}$ & $\begin{array}{l}0.63 \\
0.00\end{array}$ & $\begin{array}{l}7 \\
1\end{array}$ \\
\hline 5.12 & 1.72 & 2 & 5.19 & 0.29 & 4 \\
\hline 3.57 & 0.54 & 2 & 3.72 & 0.44 & 3 \\
\hline- & - & - & 2.57 & 0.20 & 2 \\
\hline- & - & - & 2.42 & 0.00 & 1 \\
\hline - & - & - & - & - & - \\
\hline $\begin{array}{l}3.26 \\
3.57 \\
5.15\end{array}$ & $\begin{array}{l}0.00 \\
0.54 \\
1.22\end{array}$ & $\begin{array}{l}1 \\
2 \\
3\end{array}$ & $\begin{array}{l}2.57 \\
3.75 \\
5.19\end{array}$ & $\begin{array}{l}0.20 \\
0.47 \\
0.29\end{array}$ & $\begin{array}{l}2 \\
3 \\
4\end{array}$ \\
\hline & & & & & \\
\hline 4.59 & 0.60 & 3 & 4.51 & 0.38 & 3 \\
\hline 10.56 & 1.19 & 9 & 11.31 & 0.65 & 8 \\
\hline
\end{tabular}


Table VII

Mean Age in Years - Crown $\frac{3}{4}$ Complete (Calcification Score 5)

\begin{tabular}{|c|c|c|c|c|c|c|}
\hline \multirow{3}{*}{$\begin{array}{c}\text { TOOTH } \\
\text { F.D.I. } \\
\text { NUMBER }\end{array}$} & \multicolumn{6}{|c|}{ INUIT } \\
\hline & \multicolumn{3}{|c|}{ Females } & \multicolumn{3}{|c|}{ Males } \\
\hline & $\bar{x}$ & S.D. & $\mathbf{N}$ & $\bar{x}$ & S.D. & N \\
\hline $\begin{array}{l}18 \\
17 \\
16 \\
15 \\
14 \\
13 \\
12 \\
11\end{array}$ & $\mid \begin{array}{c}10.14 \\
5.14 \\
- \\
5.57 \\
4.88 \\
3.44 \\
3.86 \\
2.88\end{array}$ & $\begin{array}{c}0.00 \\
0.56 \\
- \\
0.74 \\
0.42 \\
0.96 \\
0.86 \\
0.84\end{array}$ & $\begin{array}{r}1 \\
8 \\
- \\
11 \\
10 \\
4 \\
6 \\
2\end{array}$ & $\begin{array}{c}- \\
5.78 \\
- \\
5.80 \\
4.75 \\
3.88 \\
4.04 \\
3.33\end{array}$ & $\begin{array}{c}- \\
0.89 \\
- \\
0.62 \\
1.15 \\
0.35 \\
0.55 \\
0.30\end{array}$ & $\begin{array}{r}- \\
7 \\
- \\
5 \\
12 \\
10 \\
9 \\
8\end{array}$ \\
\hline $\begin{array}{l}21 \\
22 \\
23 \\
24 \\
25 \\
26 \\
27 \\
28\end{array}$ & $\begin{array}{c}2.88 \\
2.86 \\
3.43 \\
4.88 \\
5.70 \\
5.14 \\
10.94\end{array}$ & $\begin{array}{c}0.84 \\
0.86 \\
0.83 \\
0.44 \\
0.80 \\
- \\
0.56 \\
0.00\end{array}$ & $\begin{array}{r}2 \\
6 \\
5 \\
9 \\
14 \\
- \\
8 \\
1\end{array}$ & $\begin{array}{c}3.33 \\
3.98 \\
3.88 \\
4.81 \\
5.80 \\
- \\
5.78 \\
-\end{array}$ & $\begin{array}{c}0.30 \\
0.56 \\
0.35 \\
1.14 \\
0.62 \\
- \\
0.89 \\
-\end{array}$ & $\begin{array}{r}8 \\
10 \\
10 \\
12 \\
5 \\
- \\
7 \\
-\end{array}$ \\
\hline $\begin{array}{l}38 \\
37 \\
36 \\
35 \\
34 \\
33 \\
32 \\
31\end{array}$ & $\mid \begin{array}{c}14.62 \\
5.95 \\
- \\
5.29 \\
4.76 \\
4.12 \\
3.06 \\
2.49\end{array}$ & $\begin{array}{c}0.77 \\
0.77 \\
- \\
0.74 \\
0.64 \\
0.95 \\
0.54 \\
0.00\end{array}$ & $\begin{array}{r}2 \\
8 \\
- \\
16 \\
12 \\
13 \\
6 \\
1\end{array}$ & $\begin{array}{c}- \\
5.85 \\
- \\
6.30 \\
4.21 \\
3.73 \\
3.59 \\
2.49\end{array}$ & $\begin{array}{c}0 . \\
0.99 \\
- \\
1.24 \\
0.86 \\
0.51 \\
0.64 \\
0.66\end{array}$ & $\begin{array}{r}\overline{7} \\
- \\
12 \\
14 \\
15 \\
9 \\
2\end{array}$ \\
\hline $\begin{array}{l}41 \\
42 \\
43 \\
44 \\
45 \\
46 \\
47 \\
48\end{array}$ & $\begin{array}{c}2.49 \\
3.06 \\
4.12 \\
4.79 \\
5.42 \\
- \\
5.92 \\
11.72\end{array}$ & $\begin{array}{c}0.00 \\
0.54 \\
0.95 \\
0.59 \\
0.92 \\
- \\
0.81 \\
2.08\end{array}$ & $\begin{array}{r}1 \\
6 \\
13 \\
15 \\
16 \\
- \\
8 \\
3\end{array}$ & $\begin{array}{c}2.49 \\
3.59 \\
3.73 \\
4.29 \\
6.04 \\
- \\
6.05 \\
-\end{array}$ & $\begin{array}{c}0.66 \\
0.64 \\
0.53 \\
0.84 \\
0.99 \\
-\overline{9} \\
0.92\end{array}$ & $\begin{array}{r}2 \\
9 \\
14 \\
13 \\
10 \\
- \\
6 \\
-\end{array}$ \\
\hline
\end{tabular}

\begin{tabular}{|c|c|c|c|c|c|}
\hline \multicolumn{5}{|c|}{ INDIAN } \\
\hline \multicolumn{5}{|c|}{ Females } \\
\hline $\bar{X}$ & S.D. & $N$ & $\bar{X}$ & S.D. & $N$ \\
\hline 10.98 & 1.48 & 13 & 11.99 & 1.72 & 11 \\
5.75 & 0.91 & 7 & 5.39 & 0.41 & 7 \\
- & - & - & 2.71 & 0.00 & 1 \\
5.46 & 0.65 & 7 & 5.83 & 0.50 & 11 \\
4.44 & 0.93 & 6 & 5.52 & 0.59 & 13 \\
3.23 & 0.26 & 5 & 4.12 & 0.80 & 6 \\
3.39 & 0.41 & 5 & 4.12 & 0.80 & 6 \\
3.24 & 0.41 & 6 & 3.49 & 0.99 & 6 \\
3.24 & 0.41 & 6 & 3.49 & 0.99 & 6 \\
3.35 & 0.46 & 4 & 4.12 & 0.80 & 6 \\
3.31 & 0.41 & 5 & 3.96 & 0.68 & 6 \\
4.71 & 1.12 & 7 & 5.41 & 0.70 & 14 \\
5.44 & 0.71 & 6 & 5.83 & 0.50 & 11 \\
- & - & - & 2.71 & 0.00 & 1 \\
5.70 & 0.86 & 8 & 5.39 & 0.41 & 7 \\
10.95 & 1.43 & 14 & 11.61 & 1.17 & 11 \\
\hline & & & & & \\
\hline & & & & & \\
11.54 & 1.32 & 17 & 11.91 & 1.43 & 11 \\
5.80 & 0.80 & 10 & 5.84 & 0.86 & 13 \\
- & - & - & - & - & - \\
5.74 & 0.94 & 9 & 5.89 & 0.91 & 13 \\
4.55 & 1.11 & 8 & 5.03 & 0.73 & 11 \\
3.43 & 0.80 & 8 & 3.98 & 0.72 & 6 \\
3.09 & 0.24 & 5 & 3.26 & 0.51 & 4 \\
- & - & - & - & - & - \\
3.17 & 0.28 & $-\overline{1}$ & - & - & - \\
3.47 & 0.80 & 8 & 3.29 & 0.63 & 3 \\
4.51 & 1.19 & 7 & 5.03 & 0.81 & 5 \\
5.71 & 0.89 & 9 & 5.72 & 0.69 & 11 \\
- & - & - & - & - & - \\
11.63 & 0.84 & 9 & 5.89 & 0.83 & 11 \\
& 1.31 & 15 & 11.90 & 1.51 & 10 \\
\hline
\end{tabular}


Table VIII

Mean Age in Years - Crown Complete (Calcification Score 6)

\begin{tabular}{|c|c|c|c|c|c|c|}
\hline \multirow{3}{*}{$\begin{array}{l}\text { TOOTH } \\
\text { F.D.I. } \\
\text { NUMBER }\end{array}$} & \multicolumn{6}{|c|}{ INUIT } \\
\hline & \multicolumn{3}{|c|}{ Females } & \multicolumn{3}{|c|}{ Males } \\
\hline & $\bar{x}$ & S.D. & $N$ & $\bar{x}$ & S.D. & $N$ \\
\hline $\begin{array}{l}18 \\
17 \\
16 \\
15 \\
14 \\
13 \\
12 \\
11\end{array}$ & $\begin{array}{r}13.81 \\
6.28 \\
3.18 \\
6.58 \\
5.98 \\
5.11 \\
4.78 \\
4.28\end{array}$ & $\begin{array}{l}1.84 \\
0.83 \\
0.51 \\
0.39 \\
0.74 \\
0.89 \\
0.72 \\
0.86\end{array}$ & $\begin{array}{r}6 \\
22 \\
12 \\
12 \\
18 \\
26 \\
15 \\
7\end{array}$ & $\begin{array}{r}13.50 \\
7.06 \\
3.43 \\
7.23 \\
6.39 \\
4.88 \\
5.25 \\
4.13\end{array}$ & $\begin{array}{l}0.00 \\
1.08 \\
0.51 \\
1.05 \\
0.82 \\
1.01 \\
0.84 \\
0.43\end{array}$ & $\begin{array}{r}1 \\
10 \\
12 \\
8 \\
8 \\
14 \\
11 \\
8\end{array}$ \\
\hline $\begin{array}{l}21 \\
22 \\
23 \\
24 \\
25 \\
26 \\
27 \\
28\end{array}$ & $\begin{array}{r}4.28 \\
4.76 \\
5.13 \\
6.11 \\
6.76 \\
3.49 \\
6.29 \\
12.60\end{array}$ & $\begin{array}{l}0.86 \\
0.74 \\
0.90 \\
0.75 \\
0.50 \\
0.96 \\
0.85 \\
3.42\end{array}$ & $\begin{array}{r}7 \\
14 \\
25 \\
19 \\
12 \\
12 \\
21 \\
7\end{array}$ & $\begin{array}{l}4.06 \\
5.36 \\
4.88 \\
6.39 \\
7.40 \\
3.43 \\
7.06\end{array}$ & $\begin{array}{l}0.42 \\
0.81 \\
1.01 \\
0.82 \\
1.01 \\
0.51 \\
1.08\end{array}$ & $\begin{array}{r}7 \\
10 \\
14 \\
8 \\
8 \\
12 \\
10\end{array}$ \\
\hline $\begin{array}{l}38 \\
37 \\
36 \\
35 \\
34 \\
33 \\
32 \\
31\end{array}$ & $\begin{array}{r}12.46 \\
6.24 \\
3.18 \\
6.70 \\
5.82 \\
4.54 \\
4.62 \\
3.34\end{array}$ & $\begin{array}{l}1.38 \\
0.88 \\
0.51 \\
0.53 \\
0.80 \\
0.84 \\
0.77 \\
0.51\end{array}$ & $\begin{array}{r}3 \\
17 \\
12 \\
11 \\
15 \\
12 \\
12 \\
7\end{array}$ & $\begin{array}{r}13.50 \\
7.08 \\
3.22 \\
6.70 \\
6.26 \\
4.73 \\
4.07 \\
3.62\end{array}$ & $\begin{array}{l}0.00 \\
1.14 \\
0.62 \\
0.92 \\
1.02 \\
0.96 \\
0.70 \\
0.54\end{array}$ & $\begin{array}{r}1 \\
11 \\
11 \\
5 \\
13 \\
15 \\
11 \\
12\end{array}$ \\
\hline $\begin{array}{l}41 \\
42 \\
43 \\
44 \\
45 \\
46 \\
47 \\
48\end{array}$ & $\begin{array}{r}3.29 \\
4.62 \\
4.56 \\
5.69 \\
6.67 \\
3.18 \\
6.24 \\
13.22\end{array}$ & $\begin{array}{l}0.54 \\
0.77 \\
0.77 \\
0.76 \\
0.49 \\
0.51 \\
0.88 \\
0.60\end{array}$ & $\begin{array}{r}6 \\
12 \\
14 \\
14 \\
11 \\
12 \\
17 \\
2\end{array}$ & $\begin{array}{r}3.65 \\
4.07 \\
4.67 \\
6.27 \\
7.17 \\
3.22 \\
7.08 \\
15.36\end{array}$ & $\begin{array}{l}0.52 \\
0.70 \\
0.96 \\
1.06 \\
1.17 \\
0.62 \\
1.14 \\
2.62\end{array}$ & $\begin{array}{r}13 \\
11 \\
16 \\
12 \\
7 \\
11 \\
11 \\
2\end{array}$ \\
\hline
\end{tabular}

\begin{tabular}{|r|r|r|r|r|r|}
\hline \multicolumn{6}{|c|}{ INDIAN } \\
\hline \multicolumn{3}{|c|}{ Females } & \multicolumn{3}{c|}{ Males } \\
\hline \multicolumn{1}{|c|}{$\bar{X}$} & 5.0. & $N$ & $\bar{X}$ & S.D. & $N$ \\
\hline 13.11 & 1.27 & 11 & 13.65 & 1.03 & 9 \\
7.21 & 0.92 & 24 & 7.24 & 1.33 & 20 \\
3.23 & 0.39 & 8 & 3.20 & 0.64 & 4 \\
7.14 & 0.73 & 16 & 6.92 & 0.97 & 8 \\
6.57 & 0.74 & 16 & 6.38 & 0.98 & 9 \\
5.02 & 0.64 & 8 & 5.71 & 0.63 & 14 \\
4.72 & 0.71 & 3 & 5.59 & 0.62 & 8 \\
- & - & - & 5.50 & 0.71 & 2 \\
& & & & & \\
- & - & - & 5.50 & 0.71 & 2 \\
4.72 & 0.71 & 3 & 5.54 & 0.60 & 9 \\
5.02 & 0.64 & 8 & 5.66 & 0.63 & 15 \\
6.52 & 0.78 & 14 & 6.38 & 0.98 & 9 \\
7.05 & 0.79 & 17 & 6.88 & 1.04 & 7 \\
3.23 & 0.39 & 8 & 2.93 & 0.43 & 3 \\
7.26 & 0.94 & 25 & 7.24 & 1.33 & 20 \\
12.88 & 1.08 & 10 & 13.86 & 1.18 & 10 \\
& & & & & \\
\hline & & & & & \\
13.72 & 2.14 & 10 & 13.66 & 1.25 & 11 \\
7.49 & 0.91 & 27 & 7.39 & 1.45 & 15 \\
3.12 & 0.28 & 7 & 3.10 & 0.59 & 5 \\
6.88 & 0.64 & 14 & 7.13 & 1.33 & 7 \\
6.49 & 0.74 & 15 & 6.22 & 0.83 & 12 \\
5.18 & 0.74 & 9 & 5.45 & 0.47 & 13 \\
3.57 & 0.62 & 3 & 5.11 & 0.67 & 4 \\
3.15 & 0.43 & 6 & 3.52 & 0.74 & 5 \\
3.15 & 0.43 & 6 & 3.52 & 0.74 & 5 \\
3.57 & 0.62 & 3 & 4.72 & 1.04 & 5 \\
5.18 & 0.74 & 9 & 5.45 & 0.47 & 13 \\
6.29 & 0.83 & 14 & 6.08 & 0.70 & 11 \\
6.92 & 0.62 & 15 & 7.24 & 1.27 & 8 \\
3.12 & 0.28 & 7 & 3.10 & 0.59 & 5 \\
7.45 & 0.91 & 25 & 7.34 & 1.41 & 16 \\
13.77 & 2.04 & 11 & 13.66 & 1.25 & 11 \\
& & & & & \\
\hline
\end{tabular}


Table IX

Mean Age in Years - Root $\frac{1}{4}$ Complete (Calcification Score 7)

\begin{tabular}{|c|c|c|c|c|c|c|}
\hline \multirow{3}{*}{$\begin{array}{l}\text { TOOTH } \\
\text { F.D.I. } \\
\text { NUMBER }\end{array}$} & \multicolumn{6}{|c|}{ INUIT } \\
\hline & \multicolumn{3}{|c|}{ Females } & \multicolumn{3}{|c|}{ Males } \\
\hline & $\bar{x}$ & S.D. & $N$ & $\bar{x}$ & S.D. & N \\
\hline $\begin{array}{l}18 \\
17 \\
16 \\
15 \\
14 \\
13 \\
12 \\
11\end{array}$ & \begin{tabular}{|r|}
15.12 \\
7.44 \\
4.77 \\
7.28 \\
6.77 \\
6.46 \\
6.18 \\
5.02
\end{tabular} & $\begin{array}{l}0.00 \\
0.83 \\
0.59 \\
0.57 \\
0.40 \\
0.75 \\
0.76 \\
0.81\end{array}$ & $\begin{array}{r}1 \\
6 \\
5 \\
6 \\
6 \\
7 \\
13 \\
13 \\
20\end{array}$ & \begin{tabular}{|r|}
17.21 \\
8.39 \\
4.12 \\
7.88 \\
7.98 \\
6.38 \\
5.19 \\
5.09
\end{tabular} & $\begin{array}{l}0.00 \\
0.51 \\
0.85 \\
0.31 \\
0.65 \\
1.09 \\
1.63 \\
1.09\end{array}$ & $\begin{array}{r}1 \\
3 \\
13 \\
2 \\
5 \\
11 \\
7 \\
16\end{array}$ \\
\hline $\begin{array}{l}21 \\
22 \\
23 \\
24 \\
25 \\
26 \\
27 \\
28\end{array}$ & $\begin{array}{r}5.02 \\
6.10 \\
6.46 \\
6.85 \\
7.12 \\
4.76 \\
7.44 \\
15.12\end{array}$ & $\begin{array}{l}0.81 \\
0.80 \\
0.75 \\
0.36 \\
0.48 \\
0.68 \\
0.83 \\
0.00\end{array}$ & $\begin{array}{r}20 \\
11 \\
7 \\
6 \\
5 \\
4 \\
6 \\
1\end{array}$ & $\begin{array}{r}5.09 \\
5.19 \\
6.50 \\
7.98 \\
7.88 \\
4.12 \\
8.81 \\
15.36\end{array}$ & $\begin{array}{l}1.09 \\
1.63 \\
1.11 \\
0.65 \\
0.31 \\
0.85 \\
0.92 \\
2.62\end{array}$ & $\begin{array}{r}16 \\
7 \\
12 \\
5 \\
2 \\
13 \\
4 \\
2\end{array}$ \\
\hline $\begin{array}{l}38 \\
37 \\
36 \\
35 \\
34 \\
33 \\
32 \\
31\end{array}$ & \begin{tabular}{|r|}
16.80 \\
7.32 \\
4.83 \\
7.06 \\
6.92 \\
6.14 \\
4.68 \\
4.58
\end{tabular} & $\begin{array}{l}2.03 \\
0.81 \\
0.81 \\
0.57 \\
0.52 \\
0.82 \\
0.79 \\
0.60\end{array}$ & $\begin{array}{r}3 \\
7 \\
3 \\
8 \\
15 \\
14 \\
9 \\
15\end{array}$ & $\begin{array}{r}17.30 \\
9.49 \\
4.30 \\
8.25 \\
7.77 \\
6.69 \\
4.92 \\
4.54\end{array}$ & $\begin{array}{l}0.12 \\
1.19 \\
0.59 \\
0.67 \\
0.30 \\
0.84 \\
1.15 \\
0.90\end{array}$ & $\begin{array}{r}2 \\
4 \\
15 \\
3 \\
5 \\
10 \\
10 \\
13\end{array}$ \\
\hline $\begin{array}{l}41 \\
42 \\
43 \\
44 \\
45 \\
46 \\
47 \\
48\end{array}$ & $\begin{array}{r}4.58 \\
4.67 \\
6.14 \\
6.94 \\
7.04 \\
4.83 \\
7.32 \\
17.09\end{array}$ & $\begin{array}{l}0.60 \\
0.74 \\
0.82 \\
0.50 \\
0.61 \\
0.66 \\
0.81 \\
2.78\end{array}$ & $\begin{array}{r}15 \\
10 \\
14 \\
16 \\
7 \\
4 \\
7 \\
2\end{array}$ & $\begin{array}{r}4.54 \\
4.86 \\
6.77 \\
7.77 \\
8.54 \\
4.30 \\
9.05 \\
17.39\end{array}$ & $\begin{array}{l}0.90 \\
1.21 \\
0.85 \\
0.30 \\
0.63 \\
0.59 \\
0.97 \\
0.00\end{array}$ & $\begin{array}{r}13 \\
9 \\
11 \\
5 \\
2 \\
15 \\
3 \\
1\end{array}$ \\
\hline
\end{tabular}

\begin{tabular}{|r|r|r|r|r|r|}
\hline \multicolumn{6}{|c|}{ INDIAN } \\
\hline \multicolumn{5}{|c|}{ Females } & \multicolumn{3}{|c|}{ Nales } \\
\hline \multicolumn{1}{|c|}{ X } & S.D. & $N$ & $\bar{X}$ & S.D. & $N$ \\
\hline & & & & & \\
15.51 & 2.09 & 7 & 14.67 & 3.06 & 3 \\
8.76 & 0.77 & 16 & 9.23 & 1.49 & 20 \\
8.55 & 0.91 & 2 & 4.90 & 0.70 & 8 \\
7.92 & 1.02 & 17 & 8.81 & 0.87 & 15 \\
6.77 & 0.88 & 17 & 8.52 & 1.20 & 9 \\
6.40 & 0.57 & 15 & 7.22 & 1.37 & 10 \\
5.11 & 0.77 & 19 & 6.36 & 0.86 & 11 \\
& 8 & 5.56 & 0.61 & 9 \\
5.11 & 0.77 & 8 & 5.56 & 0.61 & 9 \\
6.21 & 0.92 & 15 & 6.20 & 0.71 & 10 \\
6.86 & 0.66 & 16 & 7.31 & 1.34 & 11 \\
7.96 & 0.80 & 18 & 8.67 & 1.23 & 10 \\
8.36 & 0.62 & 18 & 8.79 & 0.96 & 17 \\
4.55 & 0.91 & 2 & 4.89 & 0.71 & 8 \\
8.76 & 0.77 & 16 & 9.23 & 1.49 & 20 \\
15.49 & 1.94 & 8 & 14.67 & 3.06 & 3 \\
& & & & & \\
\hline & & & & & \\
14.53 & 2.20 & 3 & 15.94 & 1.86 & 3 \\
8.87 & 0.80 & 13 & 9.35 & 1.10 & 17 \\
4.35 & 0.73 & 3 & 5.02 & 0.67 & 7 \\
8.28 & 0.46 & 19 & 8.95 & 1.23 & 15 \\
7.88 & 0.89 & 24 & 8.66 & 1.08 & 15 \\
6.79 & 0.57 & 15 & 6.70 & 0.74 & 8 \\
5.37 & 0.71 & 8 & 5.40 & 0.38 & 11 \\
4.77 & 0.52 & 6 & 5.42 & 0.48 & 7 \\
& & & & & \\
4.77 & 0.52 & 6 & 5.42 & 0.48 & 7 \\
5.37 & 0.71 & 8 & 5.40 & 0.38 & 11 \\
6.79 & 0.57 & 15 & 6.70 & 0.74 & 8 \\
7.79 & 0.89 & 25 & 8.60 & 1.07 & 16 \\
8.28 & 0.46 & 19 & 8.82 & 1.19 & 15 \\
4.35 & 0.73 & 3 & 4.90 & 0.70 & 8 \\
8.85 & 0.77 & 14 & 9.35 & 1.10 & 17 \\
15.02 & 2.04 & 4 & 16.34 & 1.71 & 4 \\
& & & & & \\
\hline
\end{tabular}


Table X

Mean Age in Years - Root $\frac{1}{2}$ Complete (Calcification Score 8)

\begin{tabular}{|c|c|c|c|c|c|c|}
\hline \multirow{3}{*}{$\begin{array}{l}\text { TOOTH } \\
\text { F.D.I. } \\
\text { NUMBER }\end{array}$} & \multicolumn{6}{|c|}{ INUIT } \\
\hline & \multicolumn{3}{|c|}{ Females } & \multicolumn{3}{|c|}{ Males } \\
\hline & $\bar{x}$ & S.D. & $N$ & $\bar{x}$ & S.D. & N \\
\hline $\begin{array}{l}18 \\
17 \\
16 \\
15 \\
14 \\
13 \\
12 \\
11\end{array}$ & $\begin{array}{r}18.21 \\
10.55 \\
4.97 \\
10.18 \\
9.19 \\
7.64 \\
6.68 \\
6.29\end{array}$ & $\begin{array}{l}0.82 \\
0.36 \\
0.72 \\
0.92 \\
3.21 \\
2.64 \\
0.30 \\
0.67\end{array}$ & $\begin{array}{r}3 \\
3 \\
18 \\
5 \\
8 \\
13 \\
8 \\
8\end{array}$ & $\begin{array}{r}17.37 \\
10.13 \\
4.99 \\
10.13 \\
9.59 \\
8.76 \\
8.11 \\
6.73\end{array}$ & $\begin{array}{l}0.03 \\
0.57 \\
1.17 \\
0.86 \\
1.07 \\
0.82 \\
0.70 \\
0.97\end{array}$ & $\begin{array}{r}2 \\
8 \\
10 \\
8 \\
5 \\
4 \\
4 \\
6\end{array}$ \\
\hline $\begin{array}{l}21 \\
22 \\
23 \\
24 \\
25 \\
26 \\
27 \\
28\end{array}$ & $\begin{array}{r}6.24 \\
6.65 \\
6.93 \\
8.40 \\
10.18 \\
4.97 \\
10.55 \\
18.21\end{array}$ & $\begin{array}{l}0.71 \\
0.30 \\
0.57 \\
1.64 \\
0.92 \\
0.72 \\
0.36 \\
0.82\end{array}$ & $\begin{array}{r}7 \\
9 \\
12 \\
6 \\
5 \\
18 \\
3 \\
3\end{array}$ & $\begin{array}{r}6.73 \\
8.04 \\
8.76 \\
9.78 \\
10.34 \\
4.99 \\
10.15 \\
17.37\end{array}$ & $\begin{array}{l}0.97 \\
0.62 \\
0.82 \\
1.06 \\
0.86 \\
1.17 \\
0.62 \\
0.03\end{array}$ & $\begin{array}{r}6 \\
5 \\
4 \\
6 \\
6 \\
10 \\
7 \\
2\end{array}$ \\
\hline $\begin{array}{l}38 \\
37 \\
36 \\
35 \\
34 \\
33 \\
32 \\
31\end{array}$ & $\begin{array}{r}16.59 \\
10.55 \\
4.77 \\
10.55 \\
10.82 \\
6.91 \\
5.89 \\
5.61\end{array}$ & $\begin{array}{l}1.22 \\
0.36 \\
0.40 \\
0.36 \\
0.00 \\
0.55 \\
0.79 \\
0.44\end{array}$ & $\begin{array}{r}4 \\
3 \\
17 \\
3 \\
1 \\
13 \\
9 \\
6\end{array}$ & $\begin{array}{r}19.11 \\
10.20 \\
4.75 \\
9.95 \\
9.60 \\
8.22 \\
6.63 \\
5.66\end{array}$ & $\begin{array}{l}2.50 \\
0.83 \\
1.14 \\
1.21 \\
1.06 \\
0.58 \\
0.85 \\
0.95\end{array}$ & $\begin{array}{l}2 \\
6 \\
8 \\
6 \\
5 \\
4 \\
5 \\
4\end{array}$ \\
\hline $\begin{array}{l}41 \\
42 \\
43 \\
44 \\
45 \\
46 \\
47 \\
48\end{array}$ & $\begin{array}{r}5.61 \\
5.89 \\
6.91 \\
10.82 \\
10.55 \\
4.77 \\
10.55 \\
16.91\end{array}$ & $\begin{array}{l}0.44 \\
0.79 \\
0.55 \\
0.00 \\
0.36 \\
0.40 \\
0.36 \\
1.27\end{array}$ & $\begin{array}{r}6 \\
9 \\
13 \\
1 \\
3 \\
17 \\
3 \\
3\end{array}$ & $\begin{array}{r}5.66 \\
6.63 \\
8.55 \\
8.96 \\
10.00 \\
4.75 \\
10.29 \\
19.11\end{array}$ & $\begin{array}{l}0.95 \\
0.85 \\
0.52 \\
0.85 \\
1.11 \\
1.14 \\
0.79 \\
2.50\end{array}$ & $\begin{array}{l}4 \\
5 \\
4 \\
3 \\
7 \\
8 \\
7 \\
2\end{array}$ \\
\hline
\end{tabular}

\begin{tabular}{|r|r|r|r|r|r|}
\hline \multicolumn{6}{|c|}{ INDIAN } \\
\hline \multicolumn{3}{|c|}{ Females } & \multicolumn{3}{|c|}{ Males } \\
\hline \multicolumn{1}{|c|}{ X } & S.D. & $N$ & $\bar{X}$ & S.D. & $N$ \\
\hline & & & & & \\
15.76 & 1.45 & 3 & 17.33 & 0.00 & 1 \\
10.05 & 0.97 & 20 & 10.74 & 0.95 & 17 \\
5.52 & 0.78 & 8 & 5.53 & 0.60 & 8 \\
9.72 & 0.90 & 16 & 10.37 & 1.16 & 20 \\
8.60 & 0.67 & 9 & 9.35 & 1.03 & 17 \\
8.22 & 0.64 & 23 & 8.85 & 0.69 & 15 \\
7.89 & 1.05 & 7 & 8.09 & 1.11 & 7 \\
6.76 & 0.65 & 15 & 6.85 & 1.38 & 13 \\
& & & & & \\
6.76 & 0.65 & 15 & 6.85 & 1.38 & 13 \\
7.71 & 0.98 & 9 & 8.05 & 1.11 & 7 \\
8.22 & 0.65 & 22 & 8.90 & 0.69 & 14 \\
8.55 & 0.70 & 8 & 9.34 & 1.08 & 15 \\
9.73 & 0.94 & 14 & 10.42 & 1.24 & 19 \\
5.52 & 0.78 & 8 & 5.53 & 0.60 & 8 \\
10.05 & 0.97 & 20 & 10.74 & 0.95 & 17 \\
15.75 & 1.45 & 3 & 17.33 & 0.00 & 1 \\
& & & & & \\
\hline & & & & & \\
16.23 & 2.06 & 4 & 17.21 & 0.40 & 3 \\
10.15 & 0.93 & 17 & 10.63 & 0.91 & 17 \\
5.49 & 0.73 & 9 & 5.53 & 0.60 & 8 \\
9.77 & 1.07 & 14 & 9.95 & 1.14 & 15 \\
8.92 & 0.79 & 9 & 9.66 & 1.22 & 16 \\
8.17 & 0.58 & 17 & 8.69 & 0.85 & 14 \\
6.78 & 0.57 & 7 & 6.66 & 0.48 & 8 \\
6.11 & 0.58 & 6 & 5.73 & 0.45 & 6 \\
6.11 & 0.58 & 6 & 5.73 & 0.45 & 6 \\
6.72 & 0.63 & 7 & 6.66 & 0.48 & 8 \\
8.17 & 0.58 & 17 & 8.69 & 0.85 & 14 \\
9.01 & 0.84 & 11 & 9.61 & 1.31 & 13 \\
9.94 & 1.33 & 12 & 10.30 & 1.09 & 15 \\
5.49 & 0.73 & 9 & 5.53 & 0.60 & 8 \\
10.03 & 0.94 & 14 & 10.63 & 0.91 & 17 \\
15.23 & 0.54 & 3 & 17.04 & 0.40 & 2 \\
& & & & & \\
\hline
\end{tabular}


Table XI

Mean Age in Years - Root $\frac{3}{4}$ Complete (Calcification Score 9)

\begin{tabular}{|c|c|c|c|c|c|c|c|c|c|c|c|c|}
\hline \multirow{3}{*}{$\begin{array}{l}\text { TOOTH } \\
\text { F.D.I. } \\
\text { NUMBER }\end{array}$} & \multicolumn{6}{|c|}{ INUIT } & \multicolumn{6}{|c|}{ INDIAN } \\
\hline & \multicolumn{3}{|c|}{ Females } & \multicolumn{3}{|c|}{ Males } & \multicolumn{3}{|c|}{ Females } & \multicolumn{3}{|c|}{ Males } \\
\hline & $\bar{x}$ & S.D. & N & $\bar{x}$ & S.D. & $N$ & $\bar{x}$ & S.D. & $N$ & $\bar{x}$ & S.D. & N \\
\hline $\begin{array}{l}18 \\
17 \\
16 \\
15 \\
14 \\
13 \\
12 \\
11\end{array}$ & $\begin{array}{r}16.32 \\
12.45 \\
6.42 \\
13.59 \\
10.21 \\
10.84 \\
7.94 \\
6.95\end{array}$ & $\begin{array}{l}1.33 \\
2.45 \\
0.70 \\
3.74 \\
1.07 \\
1.63 \\
1.26 \\
0.50\end{array}$ & $\begin{array}{r}3 \\
5 \\
21 \\
2 \\
4 \\
7 \\
6 \\
10\end{array}$ & $\begin{array}{r}20.27 \\
11.39 \\
7.02 \\
10.60 \\
10.44 \\
10.19 \\
9.52 \\
8.07\end{array}$ & $\begin{array}{l}0.86 \\
0.07 \\
1.08 \\
0.67 \\
1.01 \\
0.80 \\
0.87 \\
0.62\end{array}$ & $\begin{array}{r}2 \\
2 \\
13 \\
3 \\
5 \\
9 \\
7 \\
5\end{array}$ & $\begin{array}{r}17.45 \\
11.85 \\
7.02 \\
11.21 \\
10.62 \\
10.58 \\
8.55 \\
8.33\end{array}$ & $\begin{array}{l}1.11 \\
1.00 \\
0.66 \\
1.07 \\
1.14 \\
1.24 \\
0.92 \\
0.66\end{array}$ & $\begin{array}{r}5 \\
15 \\
16 \\
19 \\
29 \\
35 \\
24 \\
20\end{array}$ & $\begin{array}{r}17.95 \\
12.25 \\
6.49 \\
11.67 \\
11.14 \\
11.22 \\
9.47 \\
8.95\end{array}$ & $\begin{array}{l}1.12 \\
0.98 \\
0.87 \\
1.31 \\
1.05 \\
1.30 \\
0.95 \\
1.11\end{array}$ & $\begin{array}{r}5 \\
9 \\
10 \\
15 \\
24 \\
39 \\
22 \\
18\end{array}$ \\
\hline $\begin{array}{l}21 \\
22 \\
23 \\
24 \\
25 \\
26 \\
27 \\
28\end{array}$ & $\begin{array}{r}6.93 \\
7.96 \\
10.84 \\
11.98 \\
13.61 \\
6.43 \\
11.41 \\
16.32\end{array}$ & $\begin{array}{l}0.48 \\
1.15 \\
1.63 \\
2.97 \\
2.64 \\
0.72 \\
3.36 \\
1.33\end{array}$ & $\begin{array}{r}11 \\
7 \\
7 \\
5 \\
3 \\
20 \\
6 \\
3\end{array}$ & $\begin{array}{r}8.07 \\
9.43 \\
10.21 \\
10.44 \\
10.19 \\
7.02 \\
11.39 \\
20.89\end{array}$ & $\begin{array}{l}0.62 \\
0.92 \\
0.86 \\
1.01 \\
0.97 \\
1.08 \\
0.07 \\
0.00\end{array}$ & $\begin{array}{r}5 \\
6 \\
8 \\
5 \\
4 \\
13 \\
2 \\
1\end{array}$ & $\begin{array}{r}8.33 \\
8.62 \\
10.58 \\
10.66 \\
11.25 \\
7.09 \\
11.77 \\
17.45\end{array}$ & $\begin{array}{l}0.66 \\
0.87 \\
1.24 \\
1.13 \\
1.01 \\
0.75 \\
0.99 \\
1.11\end{array}$ & $\begin{array}{r}20 \\
23 \\
35 \\
28 \\
19 \\
16 \\
14 \\
5\end{array}$ & $\begin{array}{r}9.07 \\
9.31 \\
11.17 \\
11.10 \\
11.49 \\
6.59 \\
12.26 \\
17.95\end{array}$ & $\begin{array}{l}1.03 \\
0.82 \\
1.20 \\
1.16 \\
1.10 \\
0.87 \\
0.92 \\
1.12\end{array}$ & $\begin{array}{r}17 \\
21 \\
37 \\
23 \\
13 \\
10 \\
10 \\
5\end{array}$ \\
\hline $\begin{array}{l}38 \\
37 \\
36 \\
35 \\
34 \\
33 \\
32 \\
31\end{array}$ & $\begin{array}{r}- \\
12.02 \\
6.39 \\
10.24 \\
10.82 \\
10.33 \\
6.85 \\
6.60\end{array}$ & $\begin{array}{l}- \\
1.69 \\
0.73 \\
1.10 \\
1.79 \\
0.89 \\
0.40 \\
0.67\end{array}$ & $\begin{array}{r}- \\
5 \\
20 \\
4 \\
6 \\
6 \\
15 \\
13\end{array}$ & $\begin{array}{r}- \\
10.88 \\
7.01 \\
10.45 \\
10.31 \\
10.16 \\
7.70 \\
6.89\end{array}$ & $\begin{array}{l}- \\
0.64 \\
1.01 \\
0.62 \\
0.92 \\
0.81 \\
0.89 \\
0.76\end{array}$ & $\begin{array}{r}- \\
2 \\
14 \\
5 \\
5 \\
9 \\
6 \\
6\end{array}$ & $\begin{array}{r}17.09 \\
11.65 \\
7.16 \\
11.09 \\
10.79 \\
10.14 \\
7.64 \\
6.83\end{array}$ & $\begin{array}{l}0.50 \\
1.10 \\
0.78 \\
1.14 \\
0.99 \\
1.27 \\
0.98 \\
0.64\end{array}$ & $\begin{array}{l}5 \\
17 \\
17 \\
24 \\
27 \\
36 \\
20 \\
12\end{array}$ & $\begin{array}{r}18.64 \\
12.17 \\
6.74 \\
11.71 \\
11.44 \\
10.87 \\
8.98 \\
7.67\end{array}$ & $\begin{array}{l}0.98 \\
1.05 \\
0.87 \\
1.38 \\
1.04 \\
1.25 \\
1.05 \\
1.81\end{array}$ & $\begin{array}{r}4 \\
11 \\
12 \\
22 \\
24 \\
39 \\
12 \\
13\end{array}$ \\
\hline $\begin{array}{l}41 \\
42 \\
43 \\
44 \\
45 \\
46 \\
47 \\
48\end{array}$ & $\begin{array}{r}6.60 \\
6.85 \\
10.33 \\
10.82 \\
10.01 \\
6.40 \\
12.02 \\
15.63\end{array}$ & $\begin{array}{l}0.67 \\
0.40 \\
0.89 \\
1.79 \\
1.22 \\
0.71 \\
1.69 \\
0.00\end{array}$ & $\begin{array}{r}13 \\
15 \\
6 \\
6 \\
3 \\
21 \\
5 \\
1\end{array}$ & $\begin{array}{r}6.89 \\
7.70 \\
10.28 \\
10.34 \\
10.50 \\
7.01 \\
10.88 \\
-\end{array}$ & $\begin{array}{c}0.76 \\
0.89 \\
0.69 \\
0.71 \\
0.71 \\
1.01 \\
0.64 \\
-\end{array}$ & \begin{tabular}{|r|}
6 \\
6 \\
9 \\
8 \\
4 \\
14 \\
2 \\
-
\end{tabular} & $\begin{array}{r}6.83 \\
7.72 \\
10.18 \\
10.81 \\
10.79 \\
7.16 \\
11.51 \\
17.45\end{array}$ & $\begin{array}{l}0.64 \\
0.92 \\
1.28 \\
1.00 \\
1.07 \\
0.78 \\
1.10 \\
0.99\end{array}$ & $\begin{array}{r}12 \\
19 \\
37 \\
26 \\
24 \\
17 \\
20 \\
6\end{array}$ & $\begin{array}{r}7.67 \\
9.01 \\
10.90 \\
11.24 \\
11.58 \\
6.74 \\
11.94 \\
18.64\end{array}$ & $\begin{array}{l}1.81 \\
1.00 \\
1.26 \\
1.09 \\
1.48 \\
0.87 \\
0.78 \\
0.98\end{array}$ & $\begin{array}{r}13 \\
13 \\
38 \\
24 \\
23 \\
12 \\
10 \\
4\end{array}$ \\
\hline
\end{tabular}


Table XII

Mean Age in Years - Root Complete - Open Apex (Calcification Score 10)

\begin{tabular}{|c|c|c|c|c|c|c|}
\hline \multirow{3}{*}{$\begin{array}{l}\text { TOOTH } \\
\text { F.D.I. } \\
\text { NUMBER }\end{array}$} & \multicolumn{6}{|c|}{ INUIT } \\
\hline & \multicolumn{3}{|c|}{ Females } & \multicolumn{3}{|c|}{ Males } \\
\hline & $\bar{X}$ & S.D. & $N$ & $\bar{X}$ & S.D. & $\mathbf{N}$ \\
\hline $\begin{array}{l}18 \\
17 \\
16 \\
15 \\
14 \\
13 \\
12 \\
11\end{array}$ & $\begin{array}{r}20.83 \\
15.48 \\
7.87 \\
14.09 \\
11.87 \\
14.53 \\
10.86 \\
10.08\end{array}$ & $\begin{array}{l}0.00 \\
1.93 \\
1.97 \\
4.69 \\
1.31 \\
2.36 \\
1.91 \\
2.07\end{array}$ & $\begin{array}{l}1 \\
6 \\
4 \\
2 \\
2 \\
6 \\
6 \\
9\end{array}$ & $\begin{array}{r}17.99 \\
15.36 \\
9.81 \\
16.23 \\
17.21 \\
14.28 \\
11.92 \\
10.91\end{array}$ & $\begin{array}{l}0.00 \\
2.62 \\
1.17 \\
2.40 \\
0.00 \\
4.15 \\
2.63 \\
2.24\end{array}$ & $\begin{array}{r}1 \\
2 \\
7 \\
3 \\
1 \\
2 \\
6 \\
11\end{array}$ \\
\hline $\begin{array}{l}21 \\
22 \\
23 \\
24 \\
25 \\
26 \\
27 \\
28\end{array}$ & $\begin{array}{r}10.08 \\
11.43 \\
14.78 \\
12.60 \\
14.55 \\
7.87 \\
15.48 \\
20.83\end{array}$ & $\begin{array}{l}2.07 \\
1.48 \\
2.24 \\
1.57 \\
3.41 \\
1.97 \\
1.76 \\
0.00\end{array}$ & $\begin{array}{l}9 \\
5 \\
7 \\
3 \\
3 \\
4 \\
7 \\
1\end{array}$ & $\begin{array}{r}10.91 \\
11.92 \\
14.28 \\
17.21 \\
16.23 \\
9.77 \\
15.36 \\
17.99\end{array}$ & $\begin{array}{l}2.24 \\
2.63 \\
4.15 \\
0.00 \\
2.40 \\
1.27 \\
2.62 \\
0.00\end{array}$ & $\begin{array}{r}11 \\
6 \\
2 \\
1 \\
3 \\
6 \\
2 \\
1\end{array}$ \\
\hline $\begin{array}{l}38 \\
37 \\
36 \\
35 \\
34 \\
33 \\
32 \\
31\end{array}$ & $\begin{array}{r}20.83 \\
15.84 \\
7.68 \\
14.94 \\
13.40 \\
14.66 \\
9.40 \\
7.54\end{array}$ & $\begin{array}{l}0.00 \\
1.81 \\
1.79 \\
1.73 \\
2.19 \\
2.17 \\
1.66 \\
1.56\end{array}$ & $\begin{array}{r}1 \\
6 \\
5 \\
6 \\
4 \\
7 \\
7 \\
10\end{array}$ & $\begin{array}{r}17.99 \\
17.21 \\
9.81 \\
15.36 \\
14.28 \\
14.28 \\
9.92 \\
8.83\end{array}$ & $\begin{array}{l}0.00 \\
0.00 \\
1.17 \\
2.62 \\
4.15 \\
4.15 \\
1.13 \\
1.46\end{array}$ & $\begin{array}{l}1 \\
1 \\
7 \\
2 \\
2 \\
2 \\
8 \\
7\end{array}$ \\
\hline $\begin{array}{l}41 \\
42 \\
43 \\
44 \\
45 \\
46 \\
47 \\
48\end{array}$ & $\begin{array}{r}7.25 \\
9.40 \\
14.66 \\
14.56 \\
13.54 \\
7.46 \\
15.52 \\
20.83\end{array}$ & $\begin{array}{l}1.35 \\
1.66 \\
2.17 \\
2.87 \\
1.92 \\
1.68 \\
1.64 \\
0.00\end{array}$ & $\begin{array}{l}9 \\
7 \\
7 \\
4 \\
5 \\
6 \\
6 \\
1\end{array}$ & $\begin{array}{r}8.83 \\
9.92 \\
14.28 \\
14.02 \\
15.36 \\
9.81 \\
15.36 \\
17.99\end{array}$ & $\begin{array}{l}1.45 \\
1.13 \\
4.15 \\
2.97 \\
2.62 \\
1.17 \\
2.62 \\
0.00\end{array}$ & $\begin{array}{l}7 \\
8 \\
2 \\
3 \\
2 \\
7 \\
2 \\
1\end{array}$ \\
\hline
\end{tabular}

\begin{tabular}{|r|r|r|r|r|r|}
\hline \multicolumn{5}{|c|}{ INDIAN } \\
\hline \multicolumn{3}{|c|}{ Females } & \multicolumn{3}{|c|}{ Males } \\
\hline $\bar{X}$ & S.D. & N & $\bar{X}$ & S.D. & N \\
\hline & & & & & \\
21.33 & 3.02 & 7 & 20.96 & 2.60 & 2 \\
13.62 & 1.37 & 15 & 13.94 & 1.64 & 16 \\
8.46 & 1.10 & 24 & 9.17 & 1.11 & 23 \\
13.28 & 1.36 & 15 & 13.22 & 1.27 & 8 \\
12.52 & 1.36 & 15 & 13.16 & 1.35 & 9 \\
13.15 & 1.53 & 18 & 14.00 & 1.12 & 7 \\
10.65 & 1.04 & 22 & 11.48 & 1.07 & 24 \\
10.31 & 1.19 & 29 & 11.01 & 1.25 & 30 \\
& & & & & \\
10.25 & 1.21 & 30 & 11.01 & 1.25 & 30 \\
10.65 & 1.04 & 22 & 11.48 & 1.07 & 24 \\
13.15 & 1.53 & 18 & 13.58 & 1.72 & 9 \\
12.54 & 1.31 & 16 & 12.67 & 1.64 & 11 \\
13.07 & 1.14 & 14 & 12.97 & 1.43 & 11 \\
8.41 & 1.10 & 25 & 9.17 & 1.11 & 23 \\
13.58 & 1.34 & 16 & 14.05 & 1.65 & 15 \\
20.25 & 1.06 & 6 & 20.96 & 2.60 & 2 \\
& & & & & \\
\hline 8.25 & & & & & \\
21.52 & 3.25 & 6 & 22.80 & 0.00 & 1 \\
13.73 & 1.40 & 16 & 13.90 & 1.65 & 16 \\
8.35 & 1.16 & 21 & 9.24 & 1.08 & 20 \\
13.24 & 1.37 & 15 & 13.53 & 1.44 & 7 \\
12.61 & 1.18 & 13 & 13.16 & 1.60 & 6 \\
12.94 & 1.49 & 21 & 13.99 & 1.19 & 10 \\
9.36 & 1.16 & 26 & 10.46 & 1.56 & 24 \\
8.26 & 0.80 & 20 & 9.16 & 1.12 & 17 \\
8.26 & 0.80 & 20 & 9.16 & 1.12 & 17 \\
9.36 & 1.15 & 26 & 10.46 & 1.56 & 24 \\
13.01 & 1.50 & 20 & 13.99 & 1.19 & 10 \\
12.63 & 1.14 & 14 & 13.13 & 1.46 & 7 \\
13.28 & 1.27 & 16 & 13.62 & 1.35 & 8 \\
8.31 & 1.18 & 20 & 9.24 & 1.11 & 19 \\
13.62 & 1.37 & 15 & 13.93 & 1.60 & 17 \\
21.52 & 3.25 & 6 & - & - & - \\
\hline
\end{tabular}


Table XIII

Mean Age in Years for Each Calcification Score by Tooth Type

(Males and Females Combined)

\begin{tabular}{|c|c|}
\hline \multicolumn{2}{|c|}{$\begin{array}{l}\text { CALCIFICATION } \\
\text { SCORE }\end{array}$} \\
\hline $\begin{array}{c}\text { Maxillary } \\
\text { Central } \\
\text { Incisor }\end{array}$ & $\begin{array}{r}4 \\
5 \\
6 \\
7 \\
8 \\
9 \\
10\end{array}$ \\
\hline $\begin{array}{l}\text { Maxillary } \\
\text { Lateral } \\
\text { Incisor }\end{array}$ & $\begin{array}{r}2 \\
3 \\
4 \\
5 \\
6 \\
7 \\
8 \\
9 \\
10\end{array}$ \\
\hline $\begin{array}{l}\text { Maxillary } \\
\text { Canine }\end{array}$ & $\begin{array}{r}2 \\
3 \\
4 \\
5 \\
6 \\
7 \\
8 \\
9 \\
10\end{array}$ \\
\hline
\end{tabular}

\begin{tabular}{|r|r|r|}
\hline \multicolumn{3}{|c|}{ INUIT } \\
\hline $\bar{X}$ & S.D. & $N$ \\
\hline 2.43 & 0.00 & 2 \\
3.24 & 0.42 & 20 \\
4.19 & 0.64 & 29 \\
5.06 & 0.93 & 72 \\
6.48 & 0.81 & 27 \\
7.31 & 0.74 & 31 \\
10.54 & 2.13 & 40 \\
& & \\
\hline & & \\
3.04 & 0.70 & 4 \\
3.59 & 0.20 & 12 \\
3.96 & 0.66 & 31 \\
5.00 & 0.80 & 50 \\
5.80 & 1.20 & 38 \\
7.16 & 0.80 & 26 \\
8.72 & 1.27 & 26 \\
11.54 & 2.14 & 23 \\
& & \\
\hline & & \\
& & \\
3.23 & 0.42 & 16 \\
3.74 & 0.57 & 29 \\
5.04 & 0.93 & 79 \\
6.45 & 0.95 & 37 \\
7.66 & 1.83 & 33 \\
10.49 & 1.24 & 31 \\
14.58 & 2.42 & 17 \\
& & \\
\hline
\end{tabular}

\begin{tabular}{|r|r|r|}
\hline \multicolumn{3}{|c|}{ INDIAN } \\
\hline $\bar{X}$ & S.D. & $N$ \\
\hline & & \\
3.37 & 0.72 & 24 \\
5.50 & 0.59 & 4 \\
5.35 & 0.70 & 34 \\
6.81 & 1.03 & 56 \\
8.65 & 0.93 & 75 \\
10.66 & 1.27 & 119 \\
& & \\
\hline & & \\
& & \\
2.82 & 0.34 & 6 \\
3.80 & 0.74 & 21 \\
5.35 & 0.70 & 23 \\
6.31 & 0.86 & 55 \\
7.92 & 1.02 & 30 \\
8.98 & 0.97 & 90 \\
11.09 & 1.13 & 92 \\
& & \\
\hline & & \\
2.43 & 0.00 & 2 \\
2.81 & 0.08 & 3 \\
3.70 & 0.69 & 22 \\
5.45 & 0.69 & 45 \\
7.00 & 0.99 & 51 \\
8.48 & 0.73 & 74 \\
10.91 & 1.28 & 146 \\
13.35 & 1.51 & 52 \\
& & \\
\hline
\end{tabular}

\begin{tabular}{|c|c|c|}
\hline \multicolumn{3}{|c|}{ WHITE* } \\
\hline $\bar{x}$ & S.D. & $N$ \\
\hline $\begin{array}{r}5.26 \\
5.79 \\
6.77 \\
8.52 \\
11.26\end{array}$ & $\begin{array}{l}0.83 \\
0.68 \\
0.63 \\
0.81 \\
1.53\end{array}$ & $\begin{array}{r}7 \\
5 \\
7 \\
15 \\
40\end{array}$ \\
\hline 3.08 & 0.00 & 1 \\
\hline 3.81 & 0.81 & 8 \\
\hline $\begin{array}{r}5.73 \\
6.68 \\
8.07 \\
9.05 \\
11.22\end{array}$ & $\begin{array}{l}1.19 \\
1.29 \\
0.91 \\
0.68 \\
1.38\end{array}$ & $\begin{array}{r}15 \\
12 \\
14 \\
8 \\
46\end{array}$ \\
\hline 3.08 & 0.00 & 2 \\
\hline 4.55 & 1.14 & 21 \\
\hline $\begin{array}{r}5.92 \\
7.02 \\
8.92 \\
10.70 \\
13.58\end{array}$ & $\begin{array}{l}1.41 \\
1.25 \\
0.98 \\
1.04 \\
1.70\end{array}$ & $\begin{array}{l}18 \\
23 \\
24 \\
33 \\
51\end{array}$ \\
\hline
\end{tabular}

* Nevile (1973) 
Table XIII (Cont'd)

Mean Age in Years for Each Calcification Score by Tooth Type (Males and Females Combined)

\begin{tabular}{|c|c|}
\hline \multicolumn{2}{|c|}{$\begin{array}{l}\text { CALCIFICATION } \\
\text { SCORE }\end{array}$} \\
\hline $\begin{array}{l}\text { Maxillary } \\
\text { First } \\
\text { Premolar }\end{array}$ & $\begin{array}{r}0 \\
1 \\
2 \\
3 \\
4 \\
5 \\
6 \\
7 \\
8 \\
9 \\
10\end{array}$ \\
\hline $\begin{array}{l}\text { Maxillary } \\
\text { Second } \\
\text { Premolar }\end{array}$ & $\begin{array}{r}0 \\
1 \\
2 \\
3 \\
4 \\
5 \\
6 \\
7 \\
8 \\
9 \\
10\end{array}$ \\
\hline
\end{tabular}

\begin{tabular}{|c|c|c|}
\hline \multicolumn{3}{|c|}{ INUIT } \\
\hline $\bar{X}$ & S.D. & $N$ \\
\hline 3.55 & 0.00 & 2 \\
2.50 & 0.25 & 4 \\
3.44 & 0.80 & 4 \\
3.87 & 0.62 & 14 \\
3.95 & 0.43 & 24 \\
4.83 & 0.88 & 43 \\
6.16 & 0.77 & 53 \\
7.35 & 0.77 & 22 \\
9.23 & 2.07 & 25 \\
10.80 & 1.78 & 19 \\
13.71 & 2.64 & 7 \\
& & \\
\hline 3.59 & 0.91 & 15 \\
3.83 & 0.61 & 17 \\
3.64 & 0.86 & 10 \\
4.20 & 0.54 & 12 \\
5.10 & 0.77 & 18 \\
5.69 & 0.71 & 35 \\
6.93 & 0.78 & 40 \\
7.39 & 0.54 & 15 \\
10.21 & 0.83 & 24 \\
11.72 & 2.38 & 12 \\
15.39 & 2.80 & 11 \\
& & \\
\hline
\end{tabular}

\begin{tabular}{|r|r|r|}
\hline \multicolumn{3}{|c|}{ INDIAN } \\
\hline $\bar{X}$ & \multicolumn{1}{|c|}{$S . D}$. & $N$ \\
\hline & & \\
2.83 & 0.02 & 3 \\
3.22 & 0.21 & 5 \\
& & \\
3.66 & 0.66 & 11 \\
5.18 & 0.87 & 40 \\
6.49 & 0.83 & 48 \\
8.17 & 1.01 & 54 \\
9.09 & 0.99 & 49 \\
10.86 & 1.14 & 104 \\
12.68 & 1.39 & 51 \\
& & \\
\hline 3.01 & 0.67 & 13 \\
3.22 & 0.04 & 6 \\
4.03 & 0.87 & 7 \\
4.34 & 0.47 & 6 \\
5.27 & 0.60 & 12 \\
5.70 & 0.58 & 35 \\
7.04 & 0.82 & 48 \\
3.61 & 0.88 & 67 \\
10.11 & 1.12 & 69 \\
11.39 & 1.11 & 66 \\
13.14 & 1.27 & 48 \\
& & \\
\hline & & \\
\hline
\end{tabular}

\begin{tabular}{|r|r|r|}
\hline \multicolumn{3}{|c|}{ WHITE* } \\
\hline $\bar{X}$ & S.D. & $N$ \\
\hline & & \\
3.08 & 0.00 & 1 \\
3.48 & 0.62 & 9 \\
4.78 & 0.73 & 24 \\
6.95 & 1.12 & 25 \\
8.41 & 1.00 & 24 \\
10.03 & 1.17 & 23 \\
11.57 & 1.73 & 30 \\
13.94 & 1.33 & 38 \\
\hline 3.54 & 0.56 & 11 \\
3.88 & 0.78 & 5 \\
5.08 & 0.67 & 12 \\
5.89 & 0.94 & 18 \\
7.72 & 0.98 & 27 \\
9.43 & 1.47 & 20 \\
10.76 & 1.44 & 23 \\
11.73 & 1.45 & 22 \\
14.17 & 1.55 & 41 \\
\hline & & \\
\hline
\end{tabular}

* Nevile (1973) 
Table XIII (Cont'd)

Mean Age in Years for Each Calcification Score by Tooth Type

(Males and Females Combined)

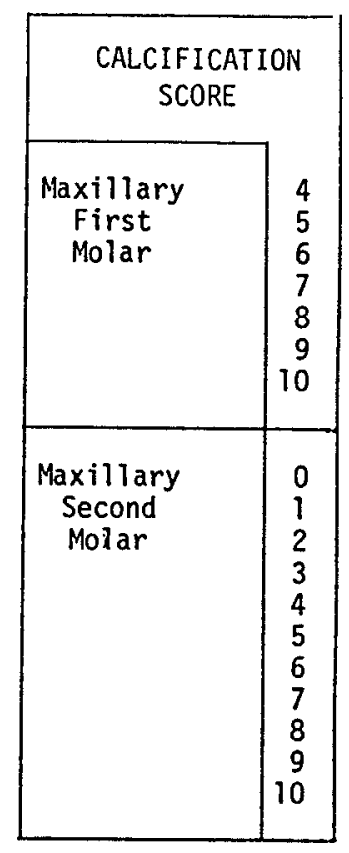

\begin{tabular}{|c|c|c|}
\hline \multicolumn{3}{|c|}{ INUIT } \\
\hline $\bar{X}$ & S.D. & $N$ \\
\hline & & \\
& & \\
3.39 & 0.65 & 48 \\
4.29 & 0.83 & 35 \\
4.98 & 0.88 & 56 \\
6.66 & 0.90 & 67 \\
9.06 & 1.70 & 21 \\
& & \\
\hline & & \\
3.07 & 0.60 & 23 \\
2.87 & 0.67 & 3 \\
3.98 & 0.36 & 19 \\
4.36 & 0.75 & 35 \\
4.81 & 0.80 & 17 \\
5.45 & 0.77 & 30 \\
6.54 & 0.97 & 63 \\
7.88 & 0.96 & 19 \\
10.26 & 0.54 & 21 \\
11.76 & 2.46 & 15 \\
15.46 & 1.79 & 17 \\
& & \\
\hline
\end{tabular}

\begin{tabular}{|c|c|r|}
\hline \multicolumn{3}{|c|}{ INDIAN } \\
\hline $\bar{X}$ & S.D. & $N$ \\
\hline & & \\
& & \\
3.72 & 0.00 & 2 \\
3.19 & 0.43 & 23 \\
4.83 & 0.69 & 20 \\
5.53 & 0.67 & 32 \\
6.88 & 0.79 & 52 \\
8.80 & 1.15 & 95 \\
& & \\
\hline & & \\
2.96 & 0.33 & 16 \\
3.19 & 0.00 & 1 \\
3.21 & 0.00 & 2 \\
3.81 & 0.32 & 6 \\
4.81 & 0.34 & 11 \\
5.57 & 0.68 & 29 \\
7.25 & 1.11 & 89 \\
9.02 & 1.23 & 72 \\
10.37 & 1.01 & 74 \\
11.99 & 0.98 & 48 \\
13.80 & 1.49 & 62 \\
& & \\
\hline
\end{tabular}

\begin{tabular}{|r|r|r|}
\hline \multicolumn{3}{|c|}{ WHITE* } \\
\hline $\bar{X}$ & S.D. & $N$ \\
\hline 3.42 & 0.56 & 6 \\
& & \\
3.76 & 0.64 & 10 \\
5.19 & 0.90 & 14 \\
5.85 & 0.91 & 19 \\
7.61 & 1.10 & 23 \\
10.22 & 1.59 & 60 \\
& & \\
\hline 3.49 & 0.91 & 11 \\
4.17 & 0.13 & 6 \\
4.80 & 0.55 & 7 \\
& & 16 \\
5.48 & 0.62 & 16 \\
6.98 & 1.43 & 23 \\
9.00 & 1.30 & 39 \\
10.39 & 0.81 & 21 \\
12.42 & 1.37 & 13 \\
14.53 & 1.69 & 54 \\
\hline
\end{tabular}

* Nevile (1973) 
Table XIII (Cont'd)

Mean Age in Years for Each Calcification Score by Tooth Type

(Males and Females Combined)

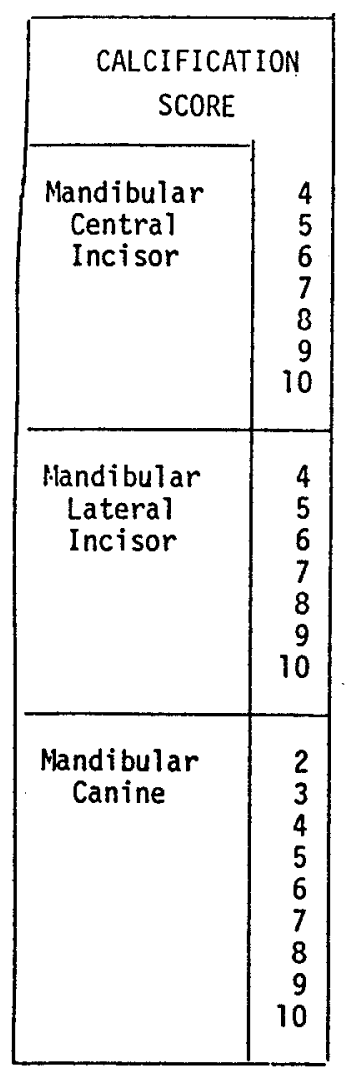

\begin{tabular}{|r|r|r|}
\hline \multicolumn{3}{|c|}{ INUIT } \\
\hline $\bar{X}$ & S.D. & NI \\
\hline & & \\
2.49 & 0.42 & 6 \\
3.53 & 0.53 & 38 \\
4.56 & 0.74 & 56 \\
5.63 & 0.63 & 20 \\
6.70 & 0.69 & 38 \\
8.01 & 1.57 & 33 \\
& & \\
\hline & & \\
2.03 & 0.00 & 2 \\
3.38 & 0.64 & 30 \\
4.36 & 0.77 & 46 \\
4.79 & 0.96 & 38 \\
6.16 & 0.85 & 28 \\
7.09 & 0.68 & 42 \\
9.68 & 1.35 & 30 \\
\hline & & \\
\hline & & \\
& & \\
3.02 & 0.66 & 8 \\
3.92 & 0.76 & 55 \\
4.64 & 0.88 & 57 \\
6.40 & 0.86 & 49 \\
7.26 & 0.83 & 34 \\
10.27 & 0.77 & 30 \\
14.58 & 2.32 & 18 \\
& & \\
\hline
\end{tabular}

\begin{tabular}{|r|r|r|}
\hline \multicolumn{3}{|c|}{ INDIAN } \\
\hline $\bar{X}$ & S.D. & $N$ \\
\hline & & \\
& & \\
3.33 & 0.58 & 22 \\
5.12 & 0.57 & 26 \\
5.92 & 0.53 & 24 \\
7.27 & 1.40 & 50 \\
8.68 & 1.05 & 74 \\
& & \\
\hline 2.43 & 0.00 & 1 \\
3.19 & 0.37 & 18 \\
4.37 & 1.00 & 15 \\
5.40 & 0.52 & 38 \\
6.71 & 0.52 & 30 \\
8.20 & 1.16 & 64 \\
9.90 & 1.46 & 100 \\
& & \\
\hline & & \\
& & \\
2.71 & 0.34 & 5 \\
3.67 & 0.79 & 27 \\
5.34 & 0.59 & 44 \\
6.76 & 0.62 & 46 \\
8.41 & 0.75 & 62 \\
10.54 & 1.31 & 150 \\
13.31 & 1.46 & 61 \\
& & \\
\hline & & \\
\hline
\end{tabular}

\begin{tabular}{|r|r|r|}
\hline \multicolumn{3}{|c|}{ WHITE* } \\
\hline $\bar{X}$ & S.D. & $N$ \\
\hline 3.08 & 0.00 & 6 \\
3.87 & 0.54 & 7 \\
4.75 & 0.13 & 6 \\
5.41 & 0.53 & 14 \\
6.95 & 0.58 & 11 \\
9.23 & 1.33 & 46 \\
\hline 3.23 & 0.38 & 7 \\
3.88 & 0.55 & 7 \\
5.25 & 0.64 & 17 \\
6.12 & 0.94 & 14 \\
7.56 & 0.65 & 11 \\
9.66 & 1.14 & 40 \\
\hline 3.08 & 0.00 & 1 \\
3.68 & 0.87 & 13 \\
4.65 & 0.58 & 9 \\
5.66 & 0.80 & 28 \\
7.73 & 0.80 & 25 \\
9.80 & 0.90 & 36 \\
12.74 & 1.73 & 39 \\
\hline & & \\
\hline
\end{tabular}

* Nevile (1973) 
Table XIII (Cont'd)

Mean Age in Years for Each Calcification Score by Tooth Type

(Males and Females Combined)

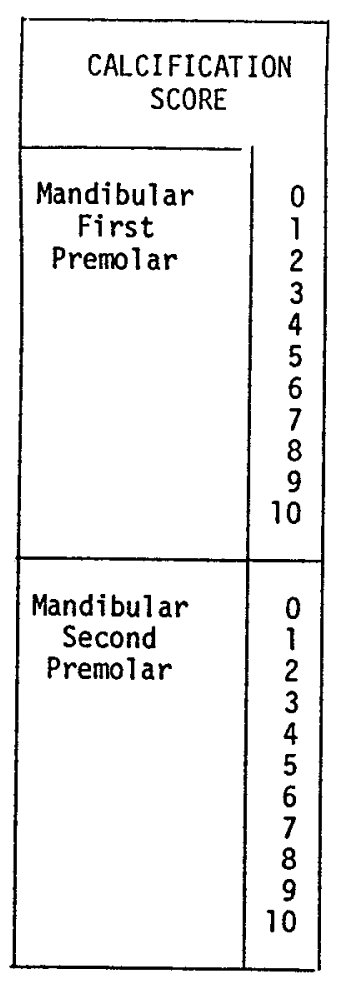

\begin{tabular}{|r|r|r|}
\hline \multicolumn{3}{|c|}{ INUIT } \\
\hline $\bar{X}$ & S.D. & $N$ \\
\hline 3.55 & 0.00 & 2 \\
2.43 & 0.00 & 2 \\
2.99 & 0.63 & 8 \\
3.31 & 0.50 & 16 \\
3.96 & 0.40 & 24 \\
4.52 & 0.77 & 54 \\
6.00 & 0.93 & 54 \\
7.14 & 0.59 & 41 \\
9.66 & 1.06 & 10 \\
10.57 & 1.30 & 25 \\
14.04 & 2.53 & 13 \\
& & \\
\hline & & \\
3.38 & 0.69 & 18 \\
3.47 & 0.70 & 25 \\
3.91 & 0.78 & 19 \\
4.16 & 0.39 & 15 \\
4.94 & 0.44 & 25 \\
5.70 & 1.03 & 54 \\
6.80 & 0.74 & 34 \\
7.39 & 0.81 & 20 \\
10.16 & 0.96 & 19 \\
10.33 & 0.83 & 16 \\
14.59 & 1.93 & 15 \\
\hline & & \\
\hline
\end{tabular}

\begin{tabular}{|c|r|r|}
\hline \multicolumn{3}{|c|}{ INDIAN } \\
\hline $\bar{X}$ & S.D. & $N$ \\
\hline & & \\
2.85 & 0.00 & 2 \\
2.66 & 0.18 & 6 \\
3.31 & 0.05 & 4 \\
3.68 & 0.41 & 10 \\
4.83 & 0.92 & 37 \\
6.29 & 0.77 & 52 \\
8.15 & 1.03 & 80 \\
9.37 & 1.13 & 49 \\
11.06 & 1.06 & 101 \\
12.80 & 1.26 & 40 \\
& & \\
\hline 2.84 & 0.29 & 12 \\
3.26 & 0.00 & 2 \\
3.47 & 0.36 & 11 \\
4.50 & 0.51 & 9 \\
5.18 & 0.74 & 13 \\
5.78 & 0.83 & 43 \\
7.00 & 0.89 & 44 \\
8.56 & 0.91 & 68 \\
10.00 & 1.14 & 56 \\
11.29 & 1.31 & 93 \\
13.37 & 1.31 & 46 \\
& & \\
\hline
\end{tabular}

\begin{tabular}{|c|c|c|}
\hline \multicolumn{3}{|c|}{ WHITE* } \\
\hline $\bar{X}$ & S.D. & $N$ \\
\hline & & \\
3.28 & 0.39 & 9 \\
4.43 & 0.68 & 14 \\
5.55 & 0.65 & 26 \\
7.33 & 0.69 & 18 \\
9.02 & 0.97 & 34 \\
10.89 & 1.19 & 33 \\
12.24 & 1.32 & 32 \\
\hline & & \\
\hline 3.48 & 0.50 & 7 \\
3.95 & 0.90 & 11 \\
5.29 & 0.73 & 11 \\
5.65 & 0.78 & 16 \\
6.95 & 1.04 & 22 \\
8.68 & 0.84 & 26 \\
10.49 & 1.37 & 21 \\
11.68 & 1.30 & 28 \\
13.41 & 1.33 & 28 \\
\hline
\end{tabular}

* Nevile (1973) 
Table XIII (Cont'd)

Mean Age in Years for Each Calcification Score by Tooth Type

(Males and Females Combined)

\begin{tabular}{|c|r|}
\hline \multicolumn{2}{|c|}{ CALCIFICATION } \\
SCORE \\
Mandibular & 6 \\
First & 7 \\
Molar & 8 \\
& 9 \\
& 10 \\
& \\
\hline \multirow{2}{*}{ Mandibular } & 0 \\
Second & 1 \\
Molar & 2 \\
& 3 \\
& 4 \\
& 5 \\
& 6 \\
& 7 \\
& 8 \\
& 9 \\
& 10 \\
\hline
\end{tabular}

\begin{tabular}{|c|c|c|}
\hline \multicolumn{3}{|c|}{ INUIT } \\
\hline $\bar{X}$ & S.D. & $N$ \\
\hline & & \\
3.21 & 0.55 & 46 \\
4.40 & 0.63 & 37 \\
4.77 & 0.69 & 50 \\
6.65 & 0.89 & 69 \\
8.82 & 1.76 & 25 \\
& & \\
\hline & & \\
2.81 & 0.60 & 15 \\
3.38 & 0.40 & 26 \\
4.05 & 0.47 & 11 \\
4.09 & 0.58 & 27 \\
4.86 & 0.64 & 38 \\
5.95 & 0.83 & 29 \\
6.57 & 1.05 & 56 \\
7.99 & 1.28 & 21 \\
10.35 & 0.67 & 19 \\
11.70 & 1.45 & 14 \\
15.74 & 1.69 & 15 \\
\hline
\end{tabular}

\begin{tabular}{|r|r|r|}
\hline \multicolumn{3}{|c|}{ INDIAII } \\
\hline $\bar{X}$ & S.D. & $N$ \\
\hline 3.12 & 0.41 & 24 \\
4.79 & 0.70 & 21 \\
5.51 & 0.67 & 34 \\
6.99 & 0.82 & 58 \\
8.78 & 1.21 & 80 \\
& & \\
\hline & & \\
2.71 & 0.18 & 8 \\
3.16 & 0.22 & 8 \\
3.59 & 0.40 & 5 \\
4.46 & 0.68 & 10 \\
4.57 & 0.47 & 9 \\
5.91 & 0.82 & 43 \\
7.44 & 1.11 & 83 \\
9.14 & 0.99 & 61 \\
10.38 & 0.95 & 65 \\
11.75 & 1.05 & 58 \\
13.80 & 1.49 & 64 \\
\hline
\end{tabular}

\begin{tabular}{|r|r|r|}
\hline \multicolumn{3}{|c|}{ WHITE* } \\
\hline $\bar{X}$ & S.D. & $N$ \\
\hline 3.23 & 0.32 & 10 \\
4.28 & 0.21 & 10 \\
5.31 & 0.49 & 22 \\
7.20 & 0.85 & 26 \\
9.83 & 1.34 & 58 \\
& & \\
\hline & & \\
4.46 & 0.18 & 4 \\
3.58 & 0.55 & 16 \\
4.71 & 0.18 & 4 \\
& & \\
5.33 & 0.35 & 10 \\
6.51 & 0.90 & 26 \\
8.70 & 1.16 & 30 \\
9.82 & 0.88 & 28 \\
11.96 & 1.16 & 24 \\
14.51 & 1.49 & 54 \\
\hline
\end{tabular}

* Nevile (1973) 


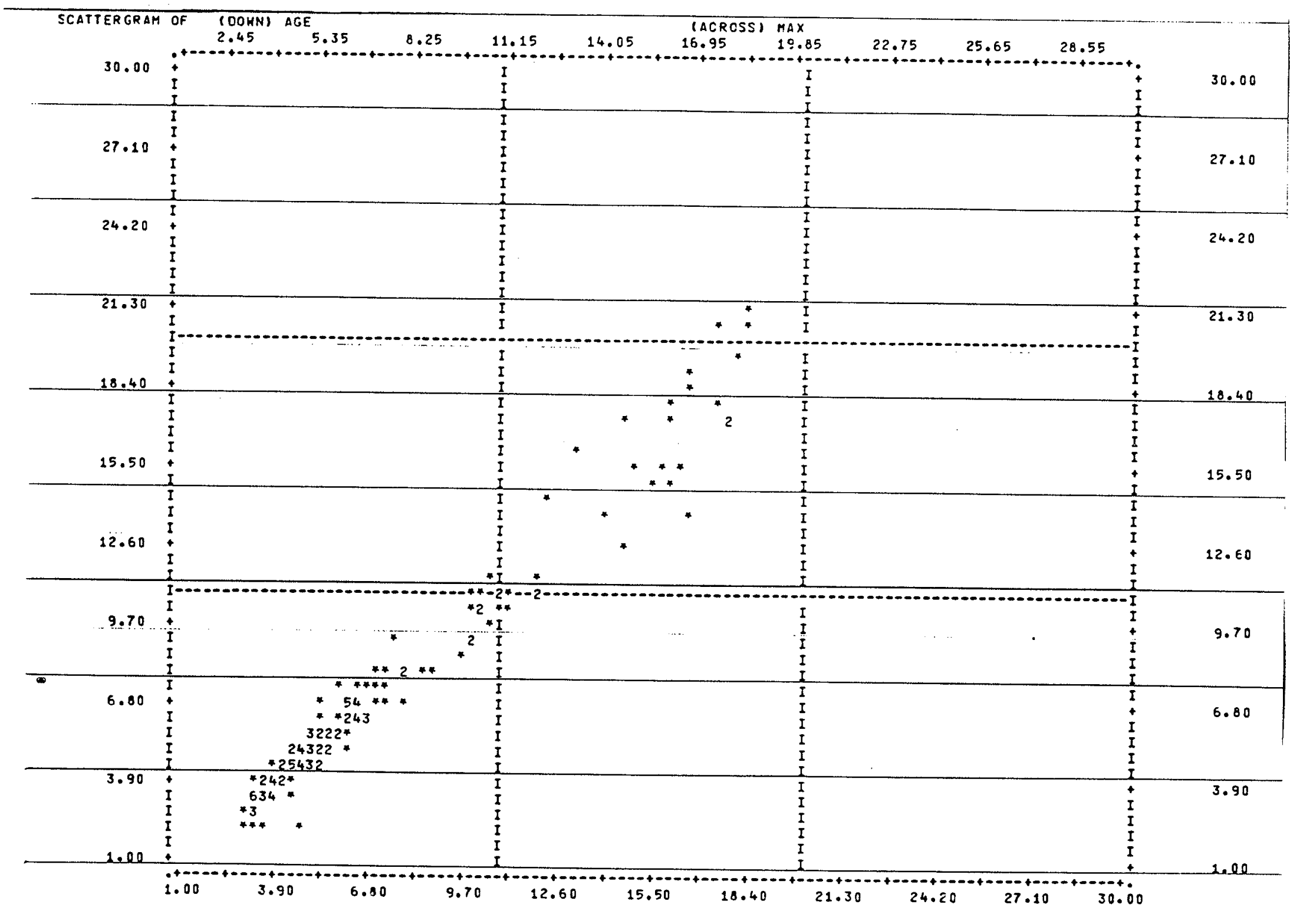

FIGURE 3: Scattergram of Maxillary Calcification Index and Chronological Age for Inuit, Sexes Combined 


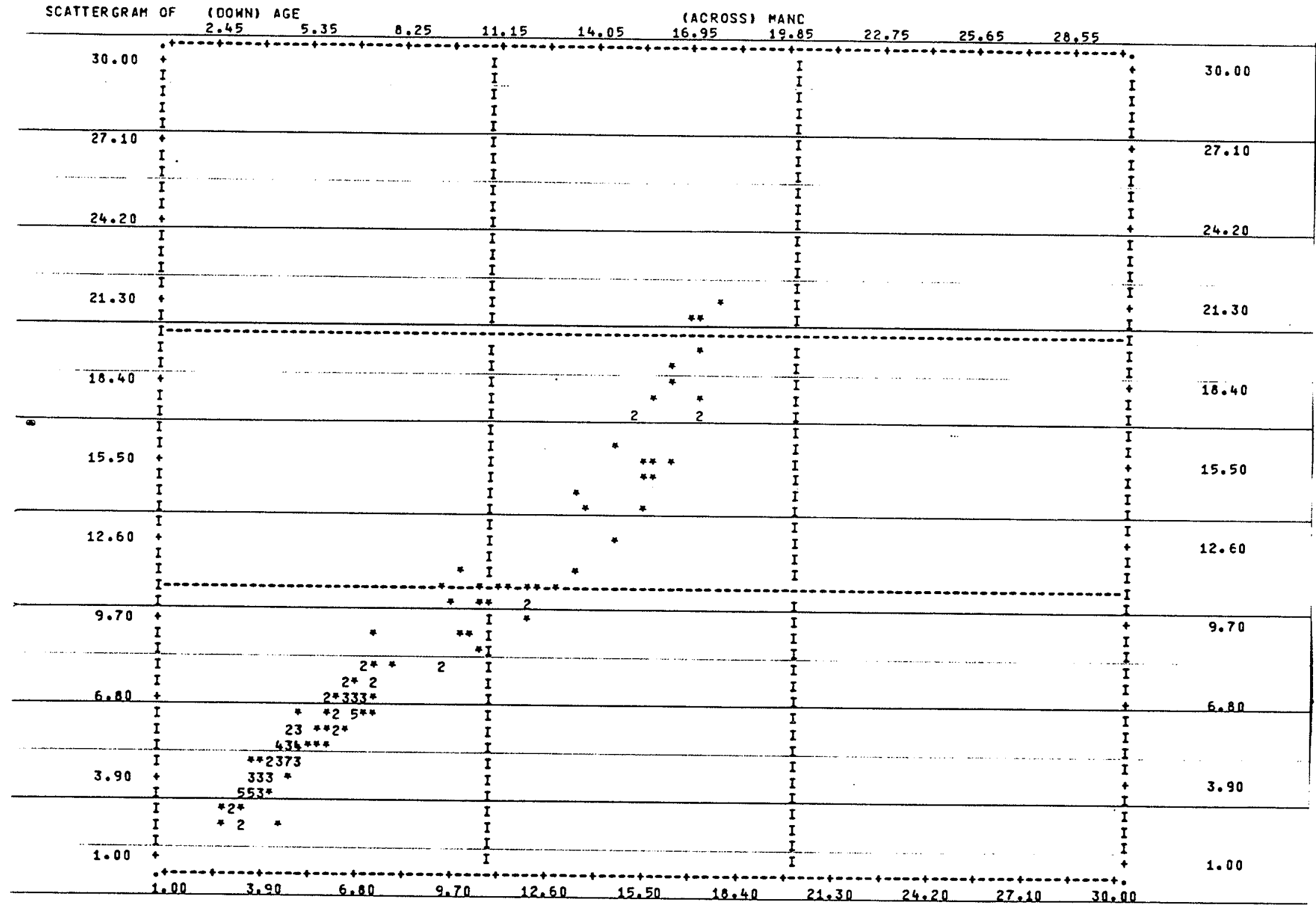

FIGURE 4: Scattergram of Mandibular Calcification Index and Chronological Age for Inuit, Sexes Combined 


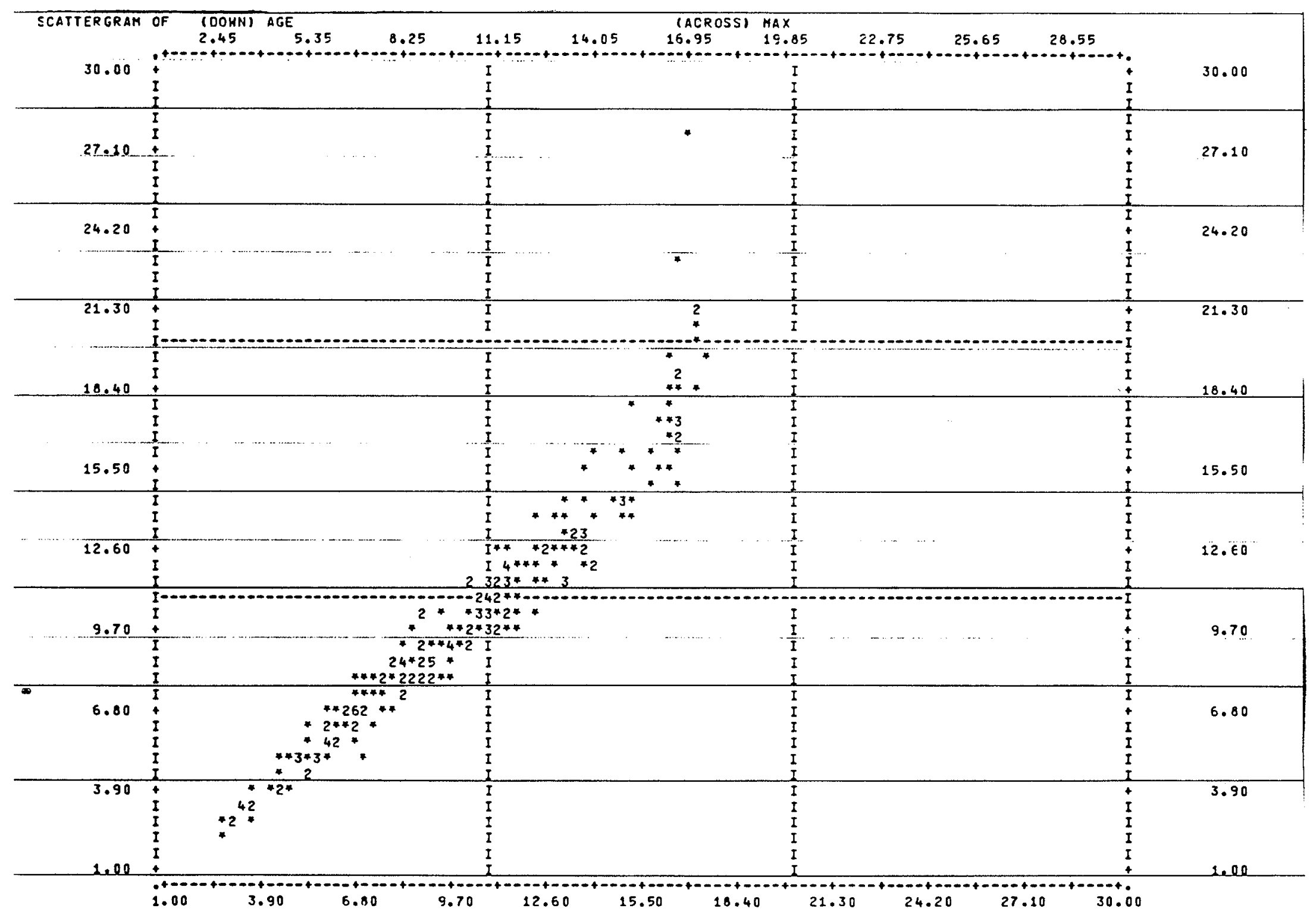

FIGURE 5; Scattergram of Maxillary Calcification Index and Chronological Age for Indian, Sexes Combined 


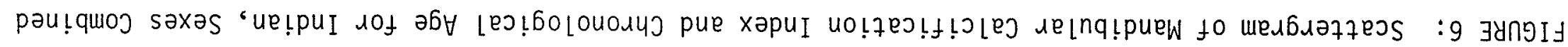

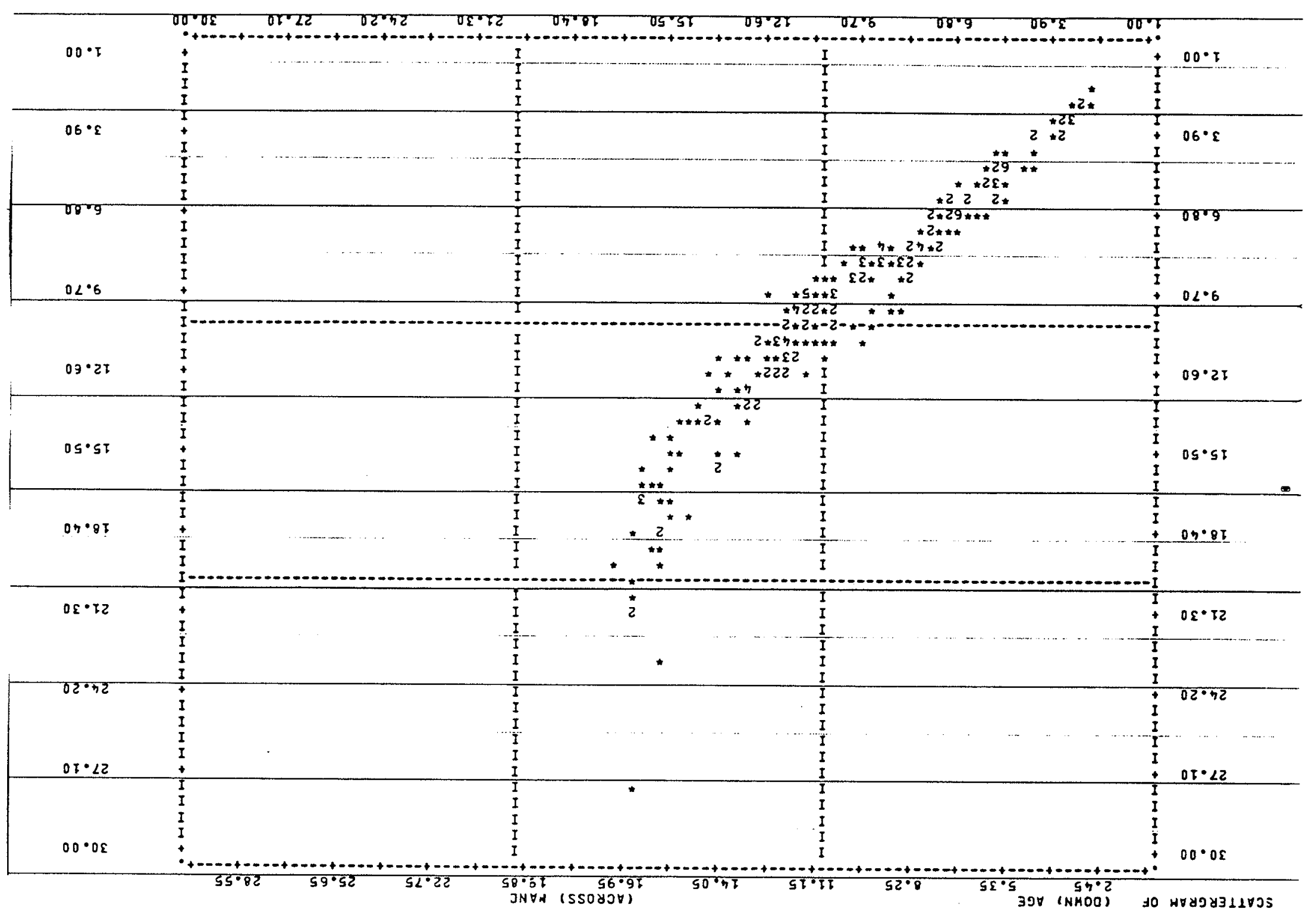


Table XIV

Mean Age in Years of Stage I of Eruption (Pre-eruption, Crown Complete)

\begin{tabular}{|c|}
\hline TOOTH \\
F.D.I. \\
NUMBER \\
\hline \\
18 \\
17 \\
16 \\
15 \\
14 \\
13 \\
12 \\
11 \\
\\
21 \\
22 \\
23 \\
24 \\
25 \\
26 \\
27 \\
28 \\
\\
\hline
\end{tabular}

\begin{tabular}{|r|r|r|r|r|r|}
\hline \multicolumn{5}{|c|}{ INUIT } \\
\hline \multicolumn{5}{|c|}{ Females } & \multicolumn{3}{|c|}{ Males } \\
\hline X & S.0. & N & $\bar{X}$ & S.D. & $N$ \\
\hline 14.52 & 2.20 & 8 & 16.02 & 2.18 & 3 \\
6.68 & 1.22 & 29 & 8.00 & 1.81 & 19 \\
3.67 & 0.82 & 19 & 3.78 & 0.74 & 25 \\
7.37 & 1.42 & 22 & 8.11 & 1.85 & 16 \\
6.36 & 1.18 & 25 & 6.70 & 1.25 & 11 \\
6.36 & 2.15 & 50 & 6.92 & 2.29 & 38 \\
5.43 & 1.04 & 34 & 5.71 & 1.53 & 21 \\
5.00 & 0.99 & 34 & 4.98 & 1.26 & 25 \\
& & & & & \\
5.04 & 1.01 & 35 & 4.92 & 1.22 & 25 \\
5.55 & 1.08 & 34 & 5.73 & 1.47 & 21 \\
6.09 & 1.51 & 47 & 6.82 & 2.23 & 37 \\
6.40 & 1.18 & 26 & 7.14 & 1.47 & 14 \\
7.36 & 1.51 & 21 & 8.38 & 1.89 & 19 \\
3.82 & 0.95 & 18 & 3.78 & 0.74 & 25 \\
6.70 & 1.24 & 28 & 7.87 & 1.76 & 18 \\
13.23 & 3.21 & 9 & 16.02 & 2.18 & 3 \\
& & & & & \\
\hline & & & & & \\
14.23 & 2.76 & 9 & 15.36 & 2.79 & 5 \\
6.74 & 1.49 & 26 & 7.70 & 1.62 & 14 \\
3.45 & 0.68 & 16 & 3.78 & 0.74 & 25 \\
7.11 & 1.38 & 22 & 8.65 & 1.78 & 15 \\
6.36 & 1.20 & 28 & 6.85 & 1.30 & 19 \\
5.73 & 1.19 & 34 & 5.99 & 1.64 & 30 \\
4.96 & 0.99 & 31 & 4.75 & 1.25 & 24 \\
4.41 & 0.89 & 27 & 4.15 & 0.91 & 26 \\
4.41 & 0.87 & 28 & 4.15 & 0.89 & 27 \\
4.93 & 0.94 & 33 & 4.75 & 1.25 & 24 \\
5.71 & 1.18 & 37 & 5.82 & 1.59 & 30 \\
6.38 & 1.23 & 26 & 7.05 & 1.48 & 19 \\
7.03 & 1.07 & 19 & 8.75 & 1.77 & 16 \\
3.39 & 0.65 & 15 & 3.69 & 0.71 & 23 \\
6.58 & 1.28 & 25 & 7.09 & 1.14 & 11 \\
15.03 & 2.20 & 6 & 15.36 & 2.79 & 5 \\
& & & & & \\
\hline
\end{tabular}

\begin{tabular}{|r|r|r|r|r|r|}
\hline \multicolumn{5}{|c|}{ INDIAN } \\
\hline \multicolumn{5}{|c|}{ Females } & \multicolumn{3}{|c|}{ Males } \\
\hline X & S.D. & $N$ & $\bar{X}$ & S.D. & $N$ \\
\hline 14.70 & 2.42 & 23 & 13.95 & 1.75 & 12 \\
8.07 & 1.25 & 47 & 8.47 & 1.82 & 44 \\
3.48 & 0.68 & 10 & 4.09 & 0.97 & 10 \\
8.49 & 1.54 & 48 & 9.06 & 1.64 & 39 \\
7.40 & 1.13 & 37 & 8.15 & 1.70 & 27 \\
7.45 & 1.63 & 55 & 8.25 & 2.39 & 53 \\
6.04 & 1.24 & 23 & 6.03 & 0.83 & 21 \\
5.76 & 1.01 & 14 & 6.11 & 1.60 & 20 \\
& & & & & \\
5.58 & 0.98 & 12 & 6.08 & 1.64 & 19 \\
6.07 & 1.22 & 24 & 6.14 & 0.95 & 22 \\
7.53 & 1.79 & 56 & 7.98 & 2.03 & 52 \\
7.41 & 1.24 & 35 & 8.39 & 1.79 & 30 \\
8.31 & 1.62 & 51 & 9.06 & 1.61 & 39 \\
3.48 & 0.68 & 10 & 4.09 & 0.97 & 10 \\
8.07 & 1.26 & 46 & 8.48 & 1.79 & 45 \\
14.41 & 2.01 & 22 & 13.73 & 1.23 & 12 \\
& & & & & \\
\hline & & & & & \\
14.30 & 1.98 & 17 & 14.38 & 1.80 & 15 \\
7.97 & 1.14 & 40 & 8.53 & 1.68 & 32 \\
4.78 & 0.52 & 6 & 3.91 & 1.04 & 10 \\
8.41 & 1.41 & 49 & 9.12 & 1.56 & 39 \\
7.70 & 1.27 & 48 & 8.26 & 1.78 & 40 \\
7.26 & 1.41 & 46 & 7.59 & 1.88 & 45 \\
5.16 & 1.16 & 14 & 5.59 & 0.66 & 18 \\
3.96 & 1.09 & 11 & 4.50 & 1.09 & 11 \\
3.96 & 1.09 & 11 & 4.51 & 1.04 & 12 \\
5.23 & 1.14 & 15 & 5.52 & 0.87 & 20 \\
7.26 & 1.42 & 47 & 7.58 & 1.94 & 44 \\
7.68 & 1.40 & 47 & 8.23 & 1.83 & 38 \\
8.31 & 1.51 & 45 & 9.23 & 1.70 & 39 \\
5.01 & 0.77 & 7 & 3.91 & 1.04 & 10 \\
8.02 & 1.13 & 41 & 8.49 & 1.70 & 33 \\
14.21 & 1.94 & 17 & 14.13 & 1.57 & 14 \\
\hline & & & & & \\
\hline
\end{tabular}


Table XV

Mean Age in Years of Stage II of Eruption (Alveolar Emergence)

\begin{tabular}{|c|c|c|c|c|c|c|}
\hline \multirow{3}{*}{$\begin{array}{l}\text { TOOTH } \\
\text { F.D.I. } \\
\text { NUMBER }\end{array}$} & \multicolumn{6}{|c|}{ INUIT } \\
\hline & \multicolumn{3}{|c|}{ Females } & \multicolumn{3}{|c|}{ Males } \\
\hline & $\bar{x}$ & S.D. & $N$ & $\bar{x}$ & S.D. & N \\
\hline $\begin{array}{l}18 \\
17 \\
16 \\
15 \\
14 \\
13 \\
12 \\
11\end{array}$ & $\begin{array}{r}17.37 \\
10.41 \\
4.96 \\
9.35 \\
7.67 \\
14.07 \\
6.76 \\
6.55\end{array}$ & $\begin{array}{l}1.71 \\
0.39 \\
0.41 \\
1.84 \\
0.71 \\
0.00 \\
0.27 \\
0.59\end{array}$ & $\begin{array}{r}3 \\
2 \\
16 \\
2 \\
4 \\
1 \\
3 \\
2\end{array}$ & $\begin{array}{c}- \\
10.46 \\
4.79 \\
9.30 \\
8.24 \\
- \\
7.16 \\
6.00\end{array}$ & $\begin{array}{c}- \\
1.04 \\
1.04 \\
1.38 \\
1.19 \\
- \\
1.27 \\
1.45\end{array}$ & $\begin{array}{c}- \\
5 \\
9 \\
3 \\
6 \\
- \\
5 \\
3\end{array}$ \\
\hline $\begin{array}{l}21 \\
22 \\
23 \\
24 \\
25 \\
26 \\
27 \\
28\end{array}$ & $\begin{array}{r}6.96 \\
6.79 \\
10.73 \\
7.45 \\
9.20 \\
5.01 \\
10.41 \\
18.12\end{array}$ & $\begin{array}{l}0.00 \\
0.34 \\
0.05 \\
0.82 \\
2.05 \\
0.44 \\
0.39 \\
0.69\end{array}$ & $\begin{array}{r}1 \\
3 \\
2 \\
5 \\
2 \\
17 \\
2 \\
4\end{array}$ & $\begin{array}{r}5.41 \\
7.99 \\
10.71 \\
8.83 \\
10.62 \\
4.77 \\
10.45 \\
17.39\end{array}$ & $\begin{array}{l}0.00 \\
0.18 \\
0.00 \\
1.75 \\
0.27 \\
1.11 \\
0.93 \\
0.00\end{array}$ & $\begin{array}{l}1 \\
3 \\
1 \\
5 \\
2 \\
8 \\
6 \\
1\end{array}$ \\
\hline $\begin{array}{l}38 \\
37 \\
36 \\
35 \\
34 \\
33 \\
32 \\
31\end{array}$ & $\begin{array}{r}16.51 \\
8.60 \\
4.97 \\
10.66 \\
7.89 \\
7.72 \\
6.08 \\
5.81\end{array}$ & $\begin{array}{l}1.33 \\
0.00 \\
0.41 \\
0.00 \\
1.71 \\
1.62 \\
0.23 \\
0.84\end{array}$ & $\begin{array}{r}4 \\
1 \\
14 \\
1 \\
5 \\
6 \\
3 \\
4\end{array}$ & $\begin{array}{r}20.89 \\
10.05 \\
4.51 \\
10.80 \\
10.38 \\
10.63 \\
6.68 \\
5.41\end{array}$ & $\begin{array}{l}0.00 \\
1.12 \\
1.17 \\
0.76 \\
1.26 \\
0.73 \\
0.31 \\
0.00\end{array}$ & $\begin{array}{l}1 \\
8 \\
6 \\
2 \\
3 \\
3 \\
2 \\
1\end{array}$ \\
\hline $\begin{array}{l}41 \\
42 \\
43 \\
44 \\
45 \\
46 \\
47 \\
48\end{array}$ & $\begin{array}{r}6.04 \\
6.21 \\
7.89 \\
7.70 \\
10.71 \\
4.88 \\
9.81 \\
19.12\end{array}$ & $\begin{array}{l}0.70 \\
0.44 \\
1.75 \\
1.79 \\
0.06 \\
0.36 \\
1.08 \\
2.41\end{array}$ & $\begin{array}{r}4 \\
3 \\
5 \\
5 \\
3 \\
15 \\
3 \\
2\end{array}$ & $\begin{array}{r}4.95 \\
6.68 \\
9.81 \\
10.73 \\
10.09 \\
4.56 \\
9.89 \\
20.89\end{array}$ & $\begin{array}{l}0.00 \\
0.31 \\
0.74 \\
0.69 \\
1.74 \\
1.00 \\
0.97 \\
0.00\end{array}$ & $\begin{array}{r}1 \\
2 \\
3 \\
3 \\
3 \\
8 \\
10 \\
1\end{array}$ \\
\hline
\end{tabular}

\begin{tabular}{|r|r|r|r|r|r|}
\hline \multicolumn{5}{|c|}{ INDIAN } \\
\hline \multicolumn{5}{|c|}{ Females } & \multicolumn{3}{|c|}{ Males } \\
\hline \multicolumn{1}{|c|}{ X } & S.D. & N & $\bar{X}$ & S.D. & $N$ \\
\hline 17.44 & 0.09 & 2 & 17.76 & 1.00 & 6 \\
10.66 & 1.15 & 19 & 11.23 & 1.23 & 18 \\
5.34 & 0.78 & 5 & 5.55 & 0.57 & 10 \\
10.10 & 0.90 & 9 & 10.97 & 1.39 & 10 \\
8.89 & 0.57 & 6 & 9.73 & 1.45 & 8 \\
10.03 & 1.06 & 6 & 10.84 & 0.60 & 6 \\
7.55 & 0.90 & 9 & 7.89 & 0.62 & 4 \\
7.36 & 0.53 & 3 & 6.95 & 0.00 & 1 \\
& & & & & \\
7.50 & 0.64 & 6 & 7.17 & 0.85 & 2 \\
7.61 & 0.89 & 9 & 7.53 & 0.82 & 2 \\
9.21 & 0.90 & 5 & 10.47 & 0.83 & 8 \\
8.95 & 0.77 & 13 & 10.61 & 1.39 & 5 \\
10.82 & 1.28 & 8 & 11.81 & 1.06 & 4 \\
5.32 & 0.70 & 6 & 5.43 & 0.47 & 9 \\
10.61 & 1.38 & 20 & 11.61 & 1.22 & 19 \\
18.40 & 0.95 & 3 & 17.86 & 0.94 & 7 \\
& & & & & \\
\hline & & & & & \\
19.08 & 3.97 & 7 & 18.63 & 1.00 & 4 \\
10.34 & 1.17 & 18 & 10.27 & 0.85 & 14 \\
4.77 & 0.52 & 6 & 5.59 & 0.63 & 8 \\
11.07 & 1.47 & 5 & 12.16 & 1.56 & 3 \\
9.92 & 1.27 & 4 & 10.49 & 1.84 & 4 \\
8.78 & 1.11 & 10 & 10.19 & 0.98 & 7 \\
6.74 & 0.55 & 2 & 6.21 & 1.05 & 3 \\
4.84 & 0.00 & 1 & 6.13 & 0.40 & 3 \\
5.02 & 0.25 & 2 & 6.08 & 0.47 & 3 \\
6.74 & 0.55 & 2 & 6.59 & 1.42 & 3 \\
10.12 & 3.81 & 9 & 10.11 & 0.77 & 7 \\
10.63 & 4.42 & 7 & 10.27 & 0.69 & 7 \\
10.52 & 1.43 & 5 & 11.29 & 1.93 & 8 \\
5.01 & 0.76 & 7 & 5.46 & 0.69 & 9 \\
10.53 & 1.09 & 14 & 10.74 & 1.40 & 17 \\
18.59 & 4.55 & 6 & 18.20 & 1.08 & 6 \\
\hline & & & & & \\
\hline
\end{tabular}


Table XVI

Mean Age in Years of Stage III of Eruption (Gingival Emergence)

\begin{tabular}{|c|}
\hline TOOTH \\
F. D.I. \\
NUMBER \\
\hline \\
18 \\
17 \\
16 \\
15 \\
14 \\
13 \\
12 \\
11 \\
\\
21 \\
22 \\
23 \\
24 \\
25 \\
26 \\
27 \\
28 \\
\\
\hline \\
38 \\
37 \\
36 \\
35 \\
34 \\
33 \\
32 \\
31 \\
41 \\
42 \\
43 \\
44 \\
45 \\
46 \\
47 \\
48 \\
\hline
\end{tabular}

\begin{tabular}{|c|c|c|c|c|c|}
\hline \multicolumn{5}{|c|}{ INUIT } \\
\hline \multicolumn{5}{|c|}{ Females } & \multicolumn{3}{|c|}{ Males } \\
\hline $\bar{X}$ & S.D. & $N$ & $\bar{X}$ & S.D. & $N$ \\
\hline 16.66 & 1.69 & 2 & 19.14 & 2.47 & 2 \\
11.75 & 1.64 & 3 & - & - & - \\
5.87 & 0.76 & 5 & 6.92 & 0.74 & 3 \\
- & - & - & 10.02 & 0.00 & 1 \\
8.87 & 1.84 & 6 & 10.16 & 0.73 & 5 \\
10.77 & 0.00 & 1 & 10.80 & 0.76 & 2 \\
8.49 & 2.60 & 6 & - & - & - \\
7.04 & 0.66 & 10 & 7.81 & 1.38 & 3 \\
& & & & & \\
7.01 & 0.70 & 10 & 7.28 & 1.17 & 6 \\
7.75 & 0.60 & 4 & 7.33 & 0.00 & 1 \\
14.07 & 0.00 & 1 & 10.26 & 0.00 & 1 \\
9.81 & 1.39 & 4 & 10.42 & 0.39 & 3 \\
- & - & - & 17.99 & 0.00 & 1 \\
5.70 & 0.54 & 4 & 6.43 & 1.15 & 4 \\
11.75 & 1.64 & 3 & 17.39 & 0.00 & 1 \\
15.55 & 0.12 & 2 & 20.89 & 0.00 & 1 \\
& & & & & \\
\hline & & & & & \\
\hline- & - & - & 15.55 & 0.12 & 2 \\
11.48 & 1.89 & 3 & 10.71 & 0.00 & 1 \\
4.90 & 0.31 & 3 & 5.61 & 0.77 & 3 \\
8.60 & 0.00 & 1 & - & - & - \\
8.60 & 0.00 & 1 & 9.83 & 0.57 & 4 \\
9.81 & 1.08 & 3 & 10.35 & 0.49 & 4 \\
7.23 & 0.35 & 4 & 6.95 & 1.16 & 2 \\
6.57 & 0.84 & 9 & 6.64 & 1.03 & 7 \\
6.51 & 0.88 & 9 & 6.72 & 0.85 & 8 \\
7.20 & 0.31 & 5 & 7.63 & 1.43 & 3 \\
8.60 & 0.00 & 1 & 10.53 & 0.74 & 4 \\
8.17 & 0.60 & 2 & 9.11 & 1.08 & 3 \\
9.37 & 1.08 & 2 & 8.99 & 0.00 & 1 \\
5.11 & 0.48 & 4 & 5.61 & 0.77 & 3 \\
10.66 & 0.00 & 1 & 11.02 & 0.44 & 2 \\
16.74 & 1.57 & 2 & 17.99 & 0.00 & 1 \\
\hline & & & & & \\
\hline
\end{tabular}

\begin{tabular}{|r|r|r|r|r|r|}
\hline \multicolumn{5}{|c|}{ INDIAN } \\
\hline \multicolumn{3}{|c|}{ Females } & \multicolumn{3}{c|}{ Males } \\
\hline $\bar{X}$ & S.D. & N & $\bar{X}$ & S.D. & N \\
\hline & & & & & \\
20.51 & 3.59 & 7 & - & - & - \\
11.34 & 0.89 & 5 & 12.22 & 1.07 & 5 \\
5.61 & 0.51 & 2 & 6.02 & 0.73 & 4 \\
10.94 & 0.62 & 3 & 11.91 & 1.59 & 2 \\
9.74 & 1.15 & 8 & 10.85 & 1.54 & 7 \\
11.48 & 1.37 & 13 & 11.58 & 1.35 & 11 \\
8.43 & 0.80 & 8 & 8.83 & 0.84 & 5 \\
7.24 & 0.85 & 13 & 7.83 & 0.48 & 5 \\
& & & & & \\
7.06 & 0.81 & 12 & 7.83 & 0.59 & 4 \\
8.37 & 0.63 & 5 & 9.08 & 1.00 & 9 \\
11.68 & 2.26 & 16 & 11.81 & 1.25 & 9 \\
9.65 & 1.32 & 5 & 9.39 & 1.06 & 5 \\
10.31 & 1.04 & 3 & 11.41 & 2.01 & 5 \\
5.63 & 0.00 & 1 & 6.29 & 0.77 & 5 \\
11.05 & 1.00 & 5 & 11.63 & 0.40 & 3 \\
19.80 & 1.99 & 3 & - & - & - \\
& & & & & \\
\hline & & & & & \\
20.19 & 1.81 & 4 & 17.06 & 0.42 & 2 \\
10.55 & 0.37 & 3 & 11.96 & 1.37 & 7 \\
5.76 & 0.53 & 3 & 4.81 & 0.28 & 2 \\
11.66 & 1.68 & 9 & 11.90 & 1.85 & 11 \\
10.04 & 0.98 & 6 & 11.01 & 1.00 & 10 \\
10.52 & 2.82 & 3 & 11.39 & 1.12 & 10 \\
6.99 & 0.63 & 8 & 8.00 & 0.31 & 2 \\
6.37 & 0.85 & 9 & 5.85 & 0.68 & 8 \\
6.46 & 0.83 & 7 & 5.86 & 0.67 & 8 \\
7.20 & 0.54 & 7 & 9.29 & 3.30 & 2 \\
10.82 & 2.37 & 6 & 11.16 & 1.46 & 9 \\
9.93 & 1.20 & 6 & 11.33 & 1.67 & 8 \\
11.61 & 3.61 & 8 & 11.53 & 1.95 & 9 \\
5.43 & 0.27 & 2 & 5.25 & 0.00 & 1 \\
11.02 & 0.78 & 4 & 11.18 & 1.47 & 4 \\
19.09 & 1.90 & 3 & 17.37 & 0.00 & 1 \\
\hline & & & & & \\
\hline
\end{tabular}


MEAN AGE OF GINGIVAL EMERGEHCE

INUIT FEMALES (Compared to Other Native Samples)

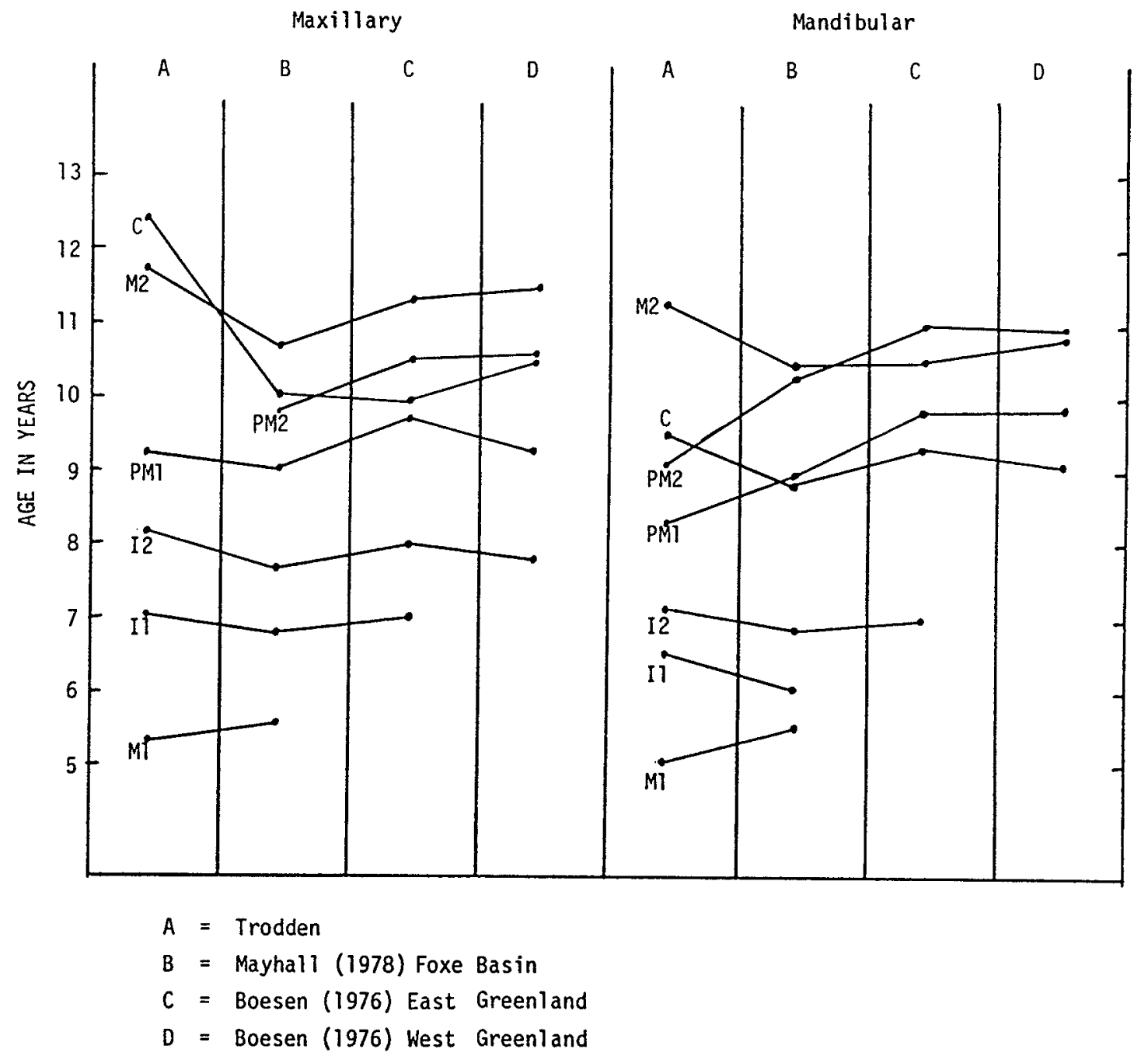

FIGURE 7 
MEAN AGE OF GINGIVAL EMERGENCE

INUIT MALES (Compared to Other Native Samples)

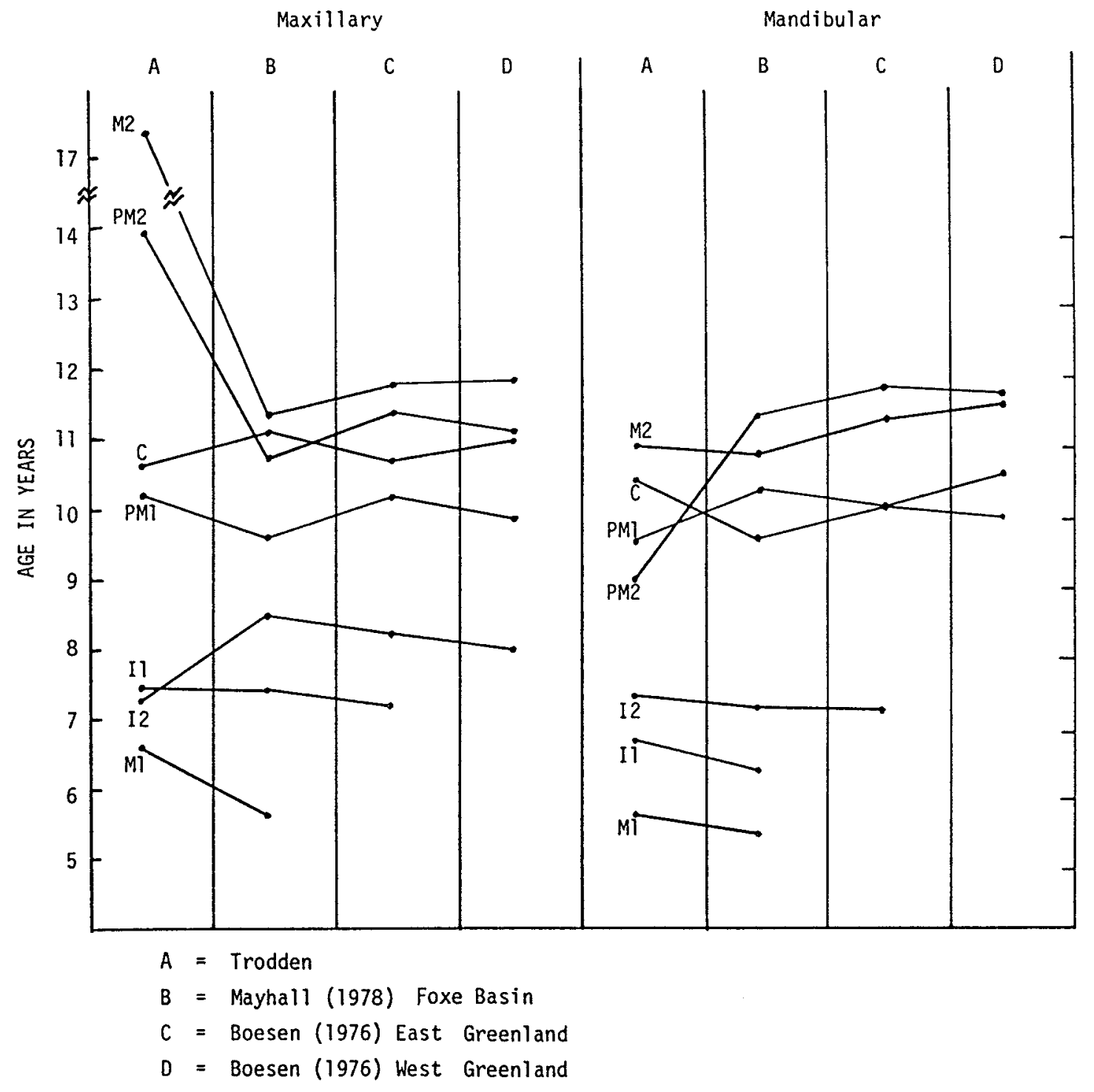

FIGURE 8 
MEAN AGE OF GINGIVAL EMERGEIVE

INDIAN FEMALES (Compared to Other Native Samples)

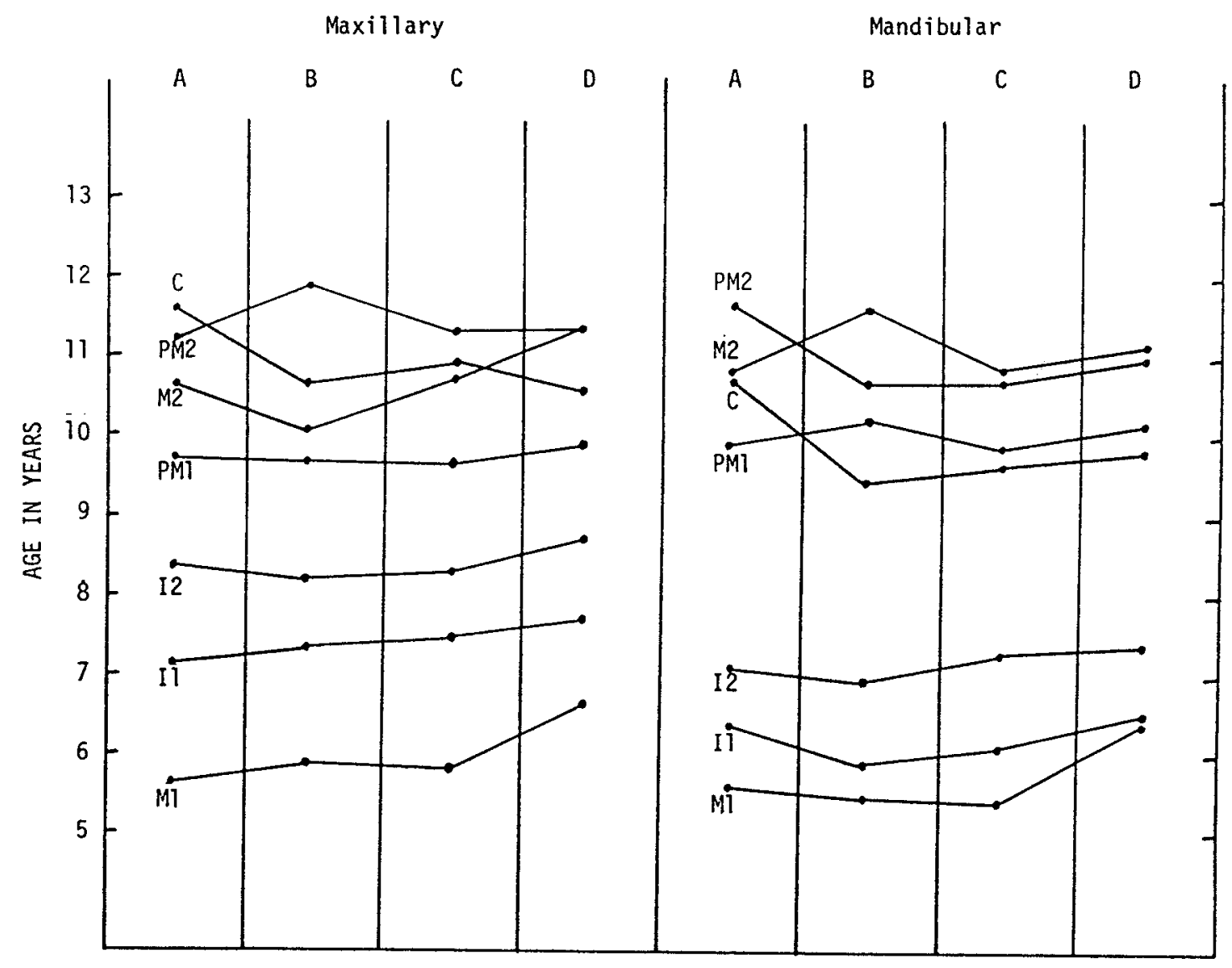

$A=$ Trodden

$B=$ Mayhal1 (1977) Foxe Basin

$C=$ Dahlberg (1958) Pima

D = Steggerda and Hill (1942) Navajo

FIGURE 9 
MEAN AGE OF GINGIVAL EMERGENCE

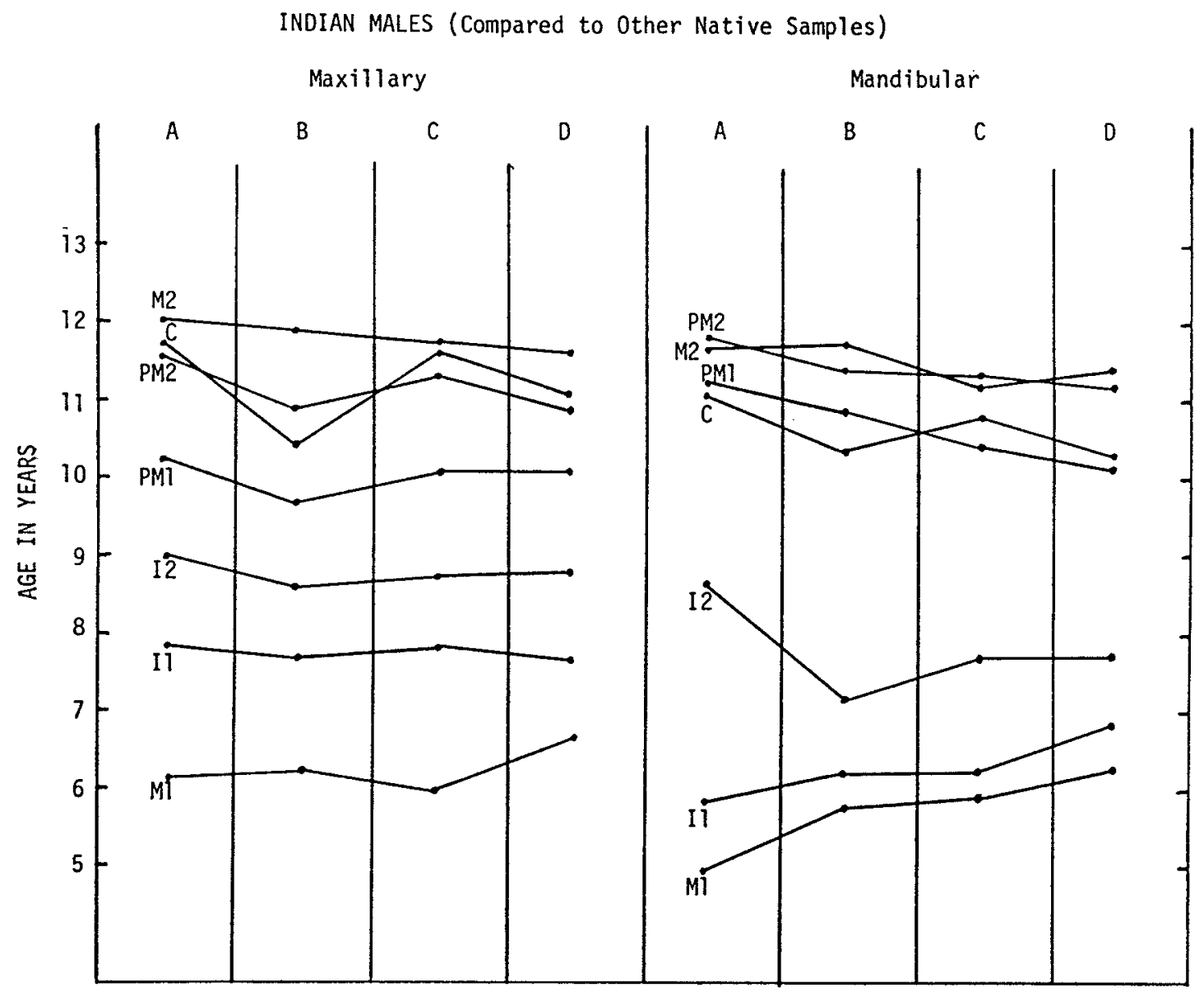

$A=$ Trodden

$B=$ Mayhall (1977) Cree and 0jibwa

$C=$ Dahlberg (1958) Pima

$D=$ Steggerda and Hill (1942) Navajo

FIGURE 10 
MEAN $\Lambda$ GE OF GINGIVAL EMERGENCE

FEMALES (Compared to Other Non-Native Samples)

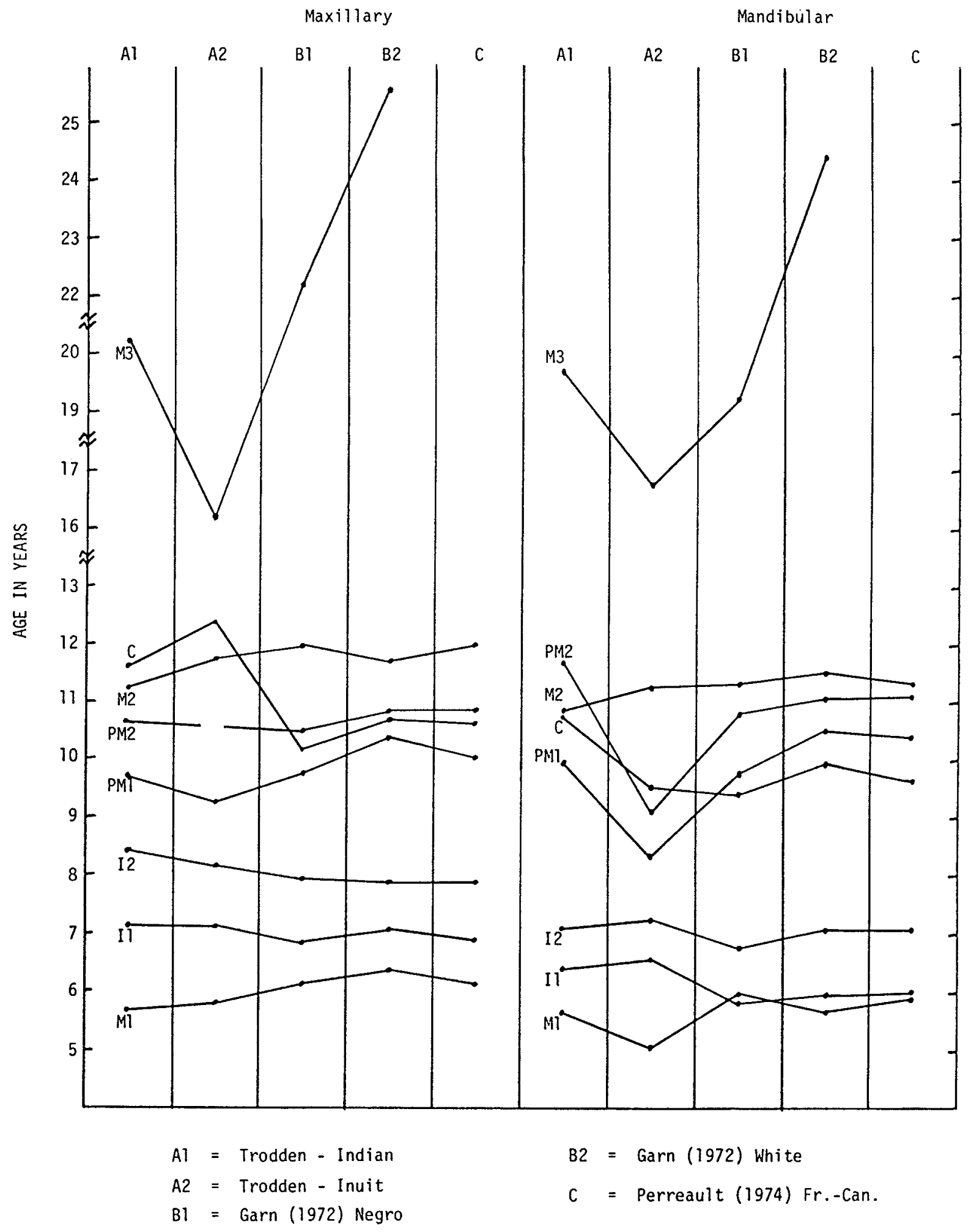

FIGURE 11 
MEAN AGE OF GINGIVAL EMERGENCE

MALES (Compared to Other Non-Native Samples)

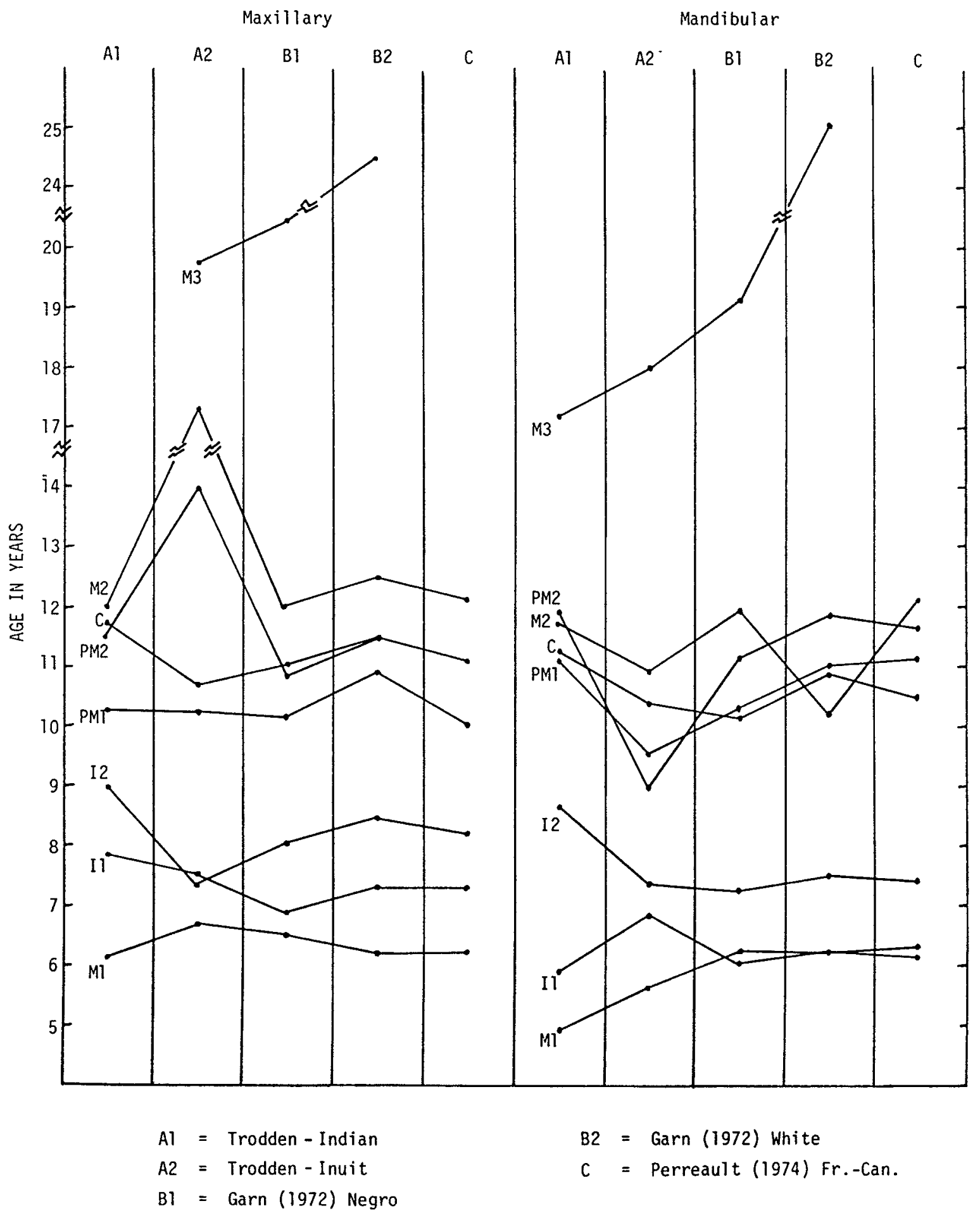

FIGURE 12 
Table XVII

Root Calcification Attained at Alveolar Emergence

Maxillary Arch

\begin{tabular}{|c|c|}
\hline Toothi & Sex \\
& \\
\hline 8 & $M$ \\
& $F$ \\
7 & $M$ \\
6 & $M$ \\
5 & $F$ \\
& $M$ \\
4 & $M$ \\
3 & $F$ \\
& $M$ \\
2 & $M$ \\
& $F$ \\
\hline & $M$ \\
& $F$ \\
\hline
\end{tabular}

\begin{tabular}{|r|r|r|r|r|r|r|}
\hline \multicolumn{7}{|c|}{ INUIT } \\
\hline \multirow{2}{*}{$N$} & \multicolumn{5}{|c|}{ Percentage of Individuals } \\
\cline { 2 - 7 } & Sc 6 & Sc 7 & Sc 8 & Sc 9 & Sc 10 & Sc 11 \\
\hline 1 & & & 100 & & & \\
7 & & & 71 & 29 & & \\
11 & & 18 & 46 & 36 & & \\
4 & & & 100 & & & \\
17 & & 12 & 76 & 12 & & \\
33 & & 12 & 79 & 9 & & \\
5 & 20 & & 60 & 20 & & \\
4 & & 50 & 50 & & & \\
10 & 20 & 30 & 40 & 10 & & \\
9 & & 33 & 45 & 22 & & \\
1 & & & & 100 & & \\
3 & & & & 67 & 33 & \\
7 & 14 & 14 & 43 & 29 & & \\
6 & & 50 & 33 & 17 & & \\
4 & & 25 & 75 & & & \\
3 & & 67 & 33 & & & \\
& & & & & & \\
\end{tabular}

\begin{tabular}{|r|r|r|r|r|r|r|}
\hline \multicolumn{6}{|c|}{ INDIAN } \\
\hline \multirow{2}{*}{$N$} & \multicolumn{5}{|c|}{ Percentage of Individuals } \\
\cline { 2 - 7 } & Sc 6 & Sc 7 & Sc 8 & Sc 9 & Sc 10 & Sc 11 \\
\hline 13 & & 15 & 15 & 70 & & \\
5 & & & & 80 & 20 & \\
37 & & 3 & 65 & 24 & 8 & \\
40 & 2 & 12 & 58 & 28 & & \\
19 & & 21 & 68 & 11 & & \\
11 & & 18 & 82 & & & \\
14 & & 29 & 21 & 50 & & \\
17 & & 12 & 41 & 41 & 6 & \\
13 & & 31 & 23 & 46 & & \\
18 & & 44 & 28 & 28 & & \\
14 & & & & 100 & & \\
11 & & & 9 & 91 & & \\
6 & & & & 100 & & \\
17 & & 35 & 30 & 35 & & \\
3 & & 33 & 34 & 33 & & \\
9 & & & 67 & 22 & 11 & \\
\hline
\end{tabular}


Table XVII (Cont'd)

Root Calcification Attained at Alveolar Emergence

Mandibular Arch

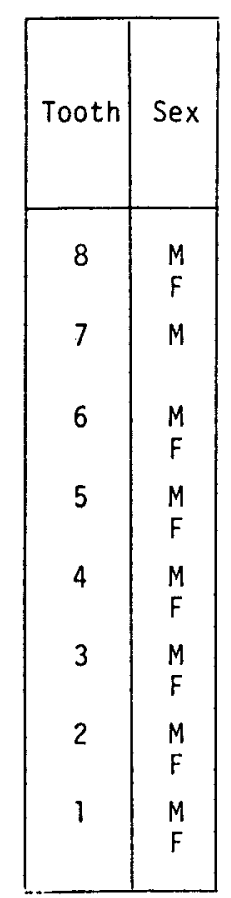

\begin{tabular}{|r|r|r|r|r|r|r|}
\hline \multicolumn{6}{|c|}{ INUIT } \\
\hline \multirow{2}{*}{$N$} & \multicolumn{5}{|c|}{ Percentage of Individuals } \\
\cline { 2 - 7 } & Sc 6 & Sc 7 & Sc 8 & Sc 9 & Sc 10 & Sc 11 \\
\hline 2 & & & 100 & & & \\
3 & & 16 & 68 & & 16 & \\
18 & & 33 & 50 & 17 & & \\
4 & & 50 & 50 & & & \\
14 & & 36 & 64 & & & \\
29 & & 14 & 83 & 3 & & \\
5 & & & 20 & 80 & & \\
4 & & & 25 & 75 & & \\
6 & & & 17 & 83 & & \\
10 & 20 & 60 & & 20 & & \\
6 & & & 17 & 83 & & \\
11 & & 9 & 73 & 18 & & \\
4 & & 50 & 50 & & & \\
6 & & 67 & 33 & & & \\
2 & & 50 & 50 & & & \\
3 & & 12 & 50 & 38 & & \\
\hline
\end{tabular}

\begin{tabular}{|c|r|r|r|r|r|r|}
\hline \multicolumn{7}{|c|}{ INDIAN } \\
\hline \multirow{2}{*}{$N$} & \multicolumn{6}{|c|}{ Percentage of Individuals } \\
\cline { 2 - 7 } & Sc 6 & Sc 7 & Sc 8 & Sc 9 & Sc 10 & Sc 11 \\
\hline 10 & & 10 & 15 & 70 & & \\
13 & & & 15 & 62 & 23 & \\
31 & & 13 & 77 & 7 & 3 & \\
31 & & 10 & 68 & 22 & & \\
17 & & 35 & 53 & 12 & & \\
13 & & 31 & 69 & & & \\
11 & & & 18 & 82 & & \\
10 & & 10 & 10 & 80 & & \\
11 & & & 55 & 45 & & \\
11 & 9 & 37 & 9 & 36 & & 9 \\
14 & & & 7 & 93 & & \\
19 & & 5 & 27 & 63 & & 5 \\
6 & & 33 & 50 & 17 & & \\
4 & & & 50 & 50 & & \\
6 & & 33 & 67 & & & \\
3 & & 100 & & & & \\
\hline
\end{tabular}


Table XVIII

Root Calcification Attained at Gingival Emergence Maxillary Arch

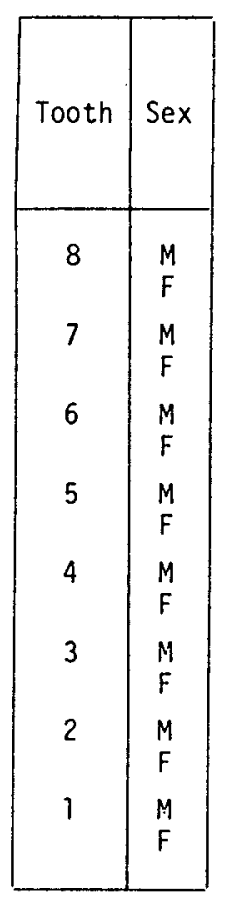

\begin{tabular}{|r|r|r|r|r|}
\hline \multicolumn{5}{|c|}{ INUIT } \\
\hline \multirow{2}{*}{$\mathrm{N}$} & \multicolumn{4}{|c|}{ Percentage of Individuals } \\
\cline { 2 - 5 } & Sc 7 & Sc 8 & Sc 9 & Sc 10 \\
\hline 3 & & 33 & 67 & \\
4 & & & 100 & \\
0 & & & & \\
6 & & & 100 & \\
7 & & 43 & 57 & \\
9 & & & 100 & \\
2 & & & 50 & 50 \\
0 & & & & \\
7 & & 57 & 43 & \\
10 & 10 & 70 & 20 & \\
3 & & & 67 & 33 \\
2 & & & 50 & 50 \\
1 & & 100 & & \\
9 & & 33 & 67 & \\
9 & 12 & 44 & 44 & \\
20 & & 25 & 25 & 20 \\
\hline
\end{tabular}

\begin{tabular}{|r|r|r|r|r|}
\hline \multicolumn{5}{|c|}{ INDIAN } \\
\hline \multirow{2}{*}{$N$} & \multicolumn{4}{|c|}{ Percentage of Individuals } \\
\cline { 2 - 5 } & SC 7 & Sc 8 & SC 9 & Sc 10 \\
\hline 0 & & & & \\
10 & & & 30 & 70 \\
8 & & & 62 & 38 \\
10 & & & 100 & \\
9 & & 33 & 67 & \\
3 & & 67 & 33 & \\
5 & & 20 & 40 & 40 \\
6 & & 17 & 66 & 17 \\
12 & 17 & 8 & 58 & 17 \\
12 & 17 & 25 & 41 & 17 \\
20 & & & 95 & 5 \\
28 & & & 75 & 25 \\
14 & 7 & 7 & 72 & 14 \\
13 & & 31 & 69 & \\
9 & & 56 & 44 & \\
25 & & 68 & 28 & 4 \\
& & & & \\
\hline
\end{tabular}

\begin{tabular}{|r|r|r|r|r|}
\hline \multicolumn{5}{|c|}{ WHITE $^{*}$} \\
\hline \multirow{2}{*}{$N$} & \multicolumn{3}{|c|}{ Percentage of Individuals } \\
\cline { 2 - 5 } & Sc 7 & SC 8 & Sc 9 & Sc 10 \\
\hline 0 & & & & \\
0 & & & & \\
0 & & & & \\
0 & & & & \\
0 & & & & \\
0 & & & & \\
0 & & & & \\
0 & & & & \\
0 & & & & \\
0 & & & & \\
0 & & & & \\
0 & & & & \\
52 & 4 & 19 & 65 & 12 \\
52 & 0 & 23 & 69 & 8 \\
50 & 0 & 32 & 64 & 4 \\
50 & 6 & 30 & 62 & 2 \\
\hline
\end{tabular}

* Gron (1962) 
Table XVIII (Cont'd)

Root Calcifcation Attained at Gingival Emergence

Mandibular Arch

\begin{tabular}{|c|c|}
\hline & \\
Tooth & Sex \\
\hline 8 & \\
\hline & $M$ \\
7 & $\mathrm{~F}$ \\
& $\mathrm{~F}$ \\
6 & $\mathrm{~N}$ \\
& $\mathrm{~F}$ \\
5 & $\mathrm{M}$ \\
& $\mathrm{F}$ \\
4 & $\mathrm{M}$ \\
& $\mathrm{F}$ \\
3 & $\mathrm{M}$ \\
& $\mathrm{F}$ \\
2 & $\mathrm{M}$ \\
& $\mathrm{F}$ \\
1 & $\mathrm{M}$ \\
& $\mathrm{F}$ \\
\hline
\end{tabular}

\begin{tabular}{|c|c|c|c|c|}
\hline \multicolumn{5}{|c|}{ INUIT } \\
\hline \multirow{2}{*}{$N$} & \multicolumn{3}{|c|}{ Percentage of Individuals } \\
\cline { 2 - 5 } & Sc 7 & Sc 8 & Sc 9 & Sc 10 \\
\hline 2 & & & & 100 \\
2 & & 50 & 50 & \\
3 & & 67 & 33 & \\
4 & & 25 & 75 & \\
6 & & 67 & 33 & \\
7 & & 86 & 14 & \\
1 & & 100 & & \\
3 & & 33 & 67 & \\
6 & & 50 & 50 & \\
3 & 33 & & 67 & \\
7 & & & 100 & \\
4 & & & 100 & \\
5 & & 40 & 40 & 20 \\
9 & & & 100 & \\
15 & 7 & 20 & 60 & 13 \\
18 & & 6 & 83 & 11 \\
& & & & \\
\end{tabular}

\begin{tabular}{|r|r|r|r|r|}
\hline \multicolumn{5}{|c|}{ INDIAN } \\
\hline \multirow{2}{*}{$N$} & \multicolumn{3}{|c|}{ Percentage of Individuals } \\
\cline { 2 - 5 } & Sc 7 & Sc 8 & Sc 9 & Sc 10 \\
\hline 3 & & 33 & 67 & \\
7 & & & 29 & 71 \\
11 & & 55 & 18 & 27 \\
7 & & 29 & 71 & \\
3 & & 100 & & \\
5 & & 100 & & \\
20 & & 15 & 75 & 10 \\
15 & 7 & 13 & 60 & 20 \\
18 & & 22 & 78 & \\
12 & 8 & 17 & 75 & \\
19 & & & 89 & 11 \\
9 & & & 67 & 33 \\
4 & & 25 & 50 & 25 \\
13 & & 46 & 54 & \\
16 & & 50 & 50 & \\
16 & 19 & 50 & 19 & 12 \\
\hline
\end{tabular}

\begin{tabular}{|r|c|c|c|c|}
\hline \multicolumn{5}{|c|}{ WHITE* } \\
\hline \multirow{2}{*}{$N$} & \multicolumn{3}{|c|}{ Percentage of Individua Is } \\
\cline { 2 - 5 } & Sc 7 & Sc 8 & Sc 9 & Sc 10 \\
\hline 0 & & & & \\
0 & & & & \\
58 & & 10 & 64 & 26 \\
57 & & 5 & 74 & 21 \\
30 & 6 & 67 & 27 & \\
35 & 6 & 44 & 50 & \\
50 & 6 & 34 & 54 & 6 \\
48 & 6 & 23 & 69 & 2 \\
51 & & 27 & 71 & 2 \\
52 & 2 & 25 & 65 & 8 \\
50 & & 10 & 80 & 10 \\
52 & & 2 & 77 & 22 \\
52 & 2 & 25 & 65 & 8 \\
50 & & 20 & 62 & 18 \\
41 & & 56 & 44 & \\
44 & 7 & 57 & 34 & 2 \\
& & & & \\
\hline
\end{tabular}

* Gron (1962) 
FIGURE 13

\section{DURATION OF ALVEOLAR-GINGIVAL EMERGENCE AND ROOT CALCIFICATION SCORES FOR INUIT AND INDIAN, SAMPLES AND SEXES COMBINED.}

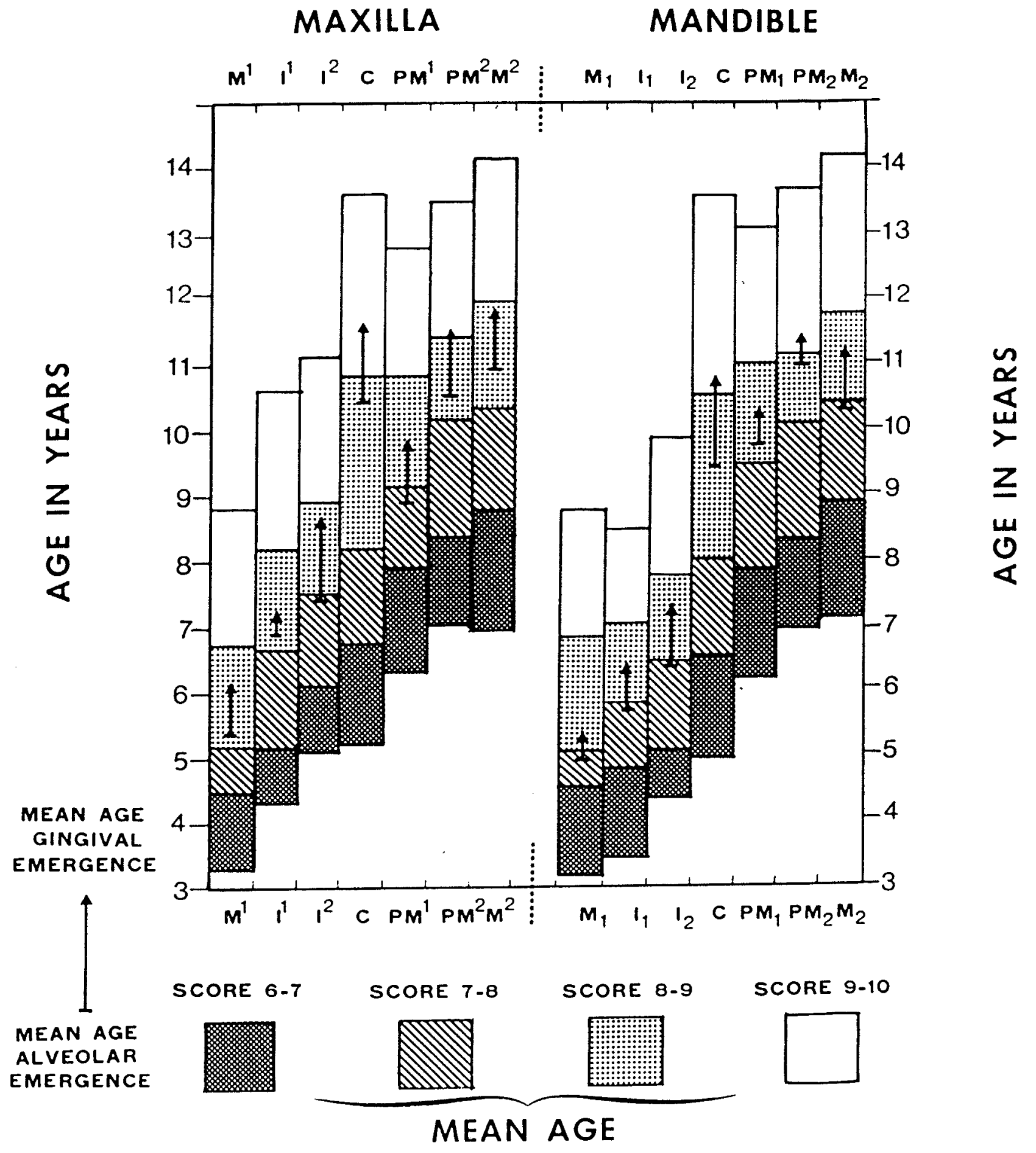


Table XIX

Time Consumed from Alveolar Emergence -

Gingival Emergence in Years

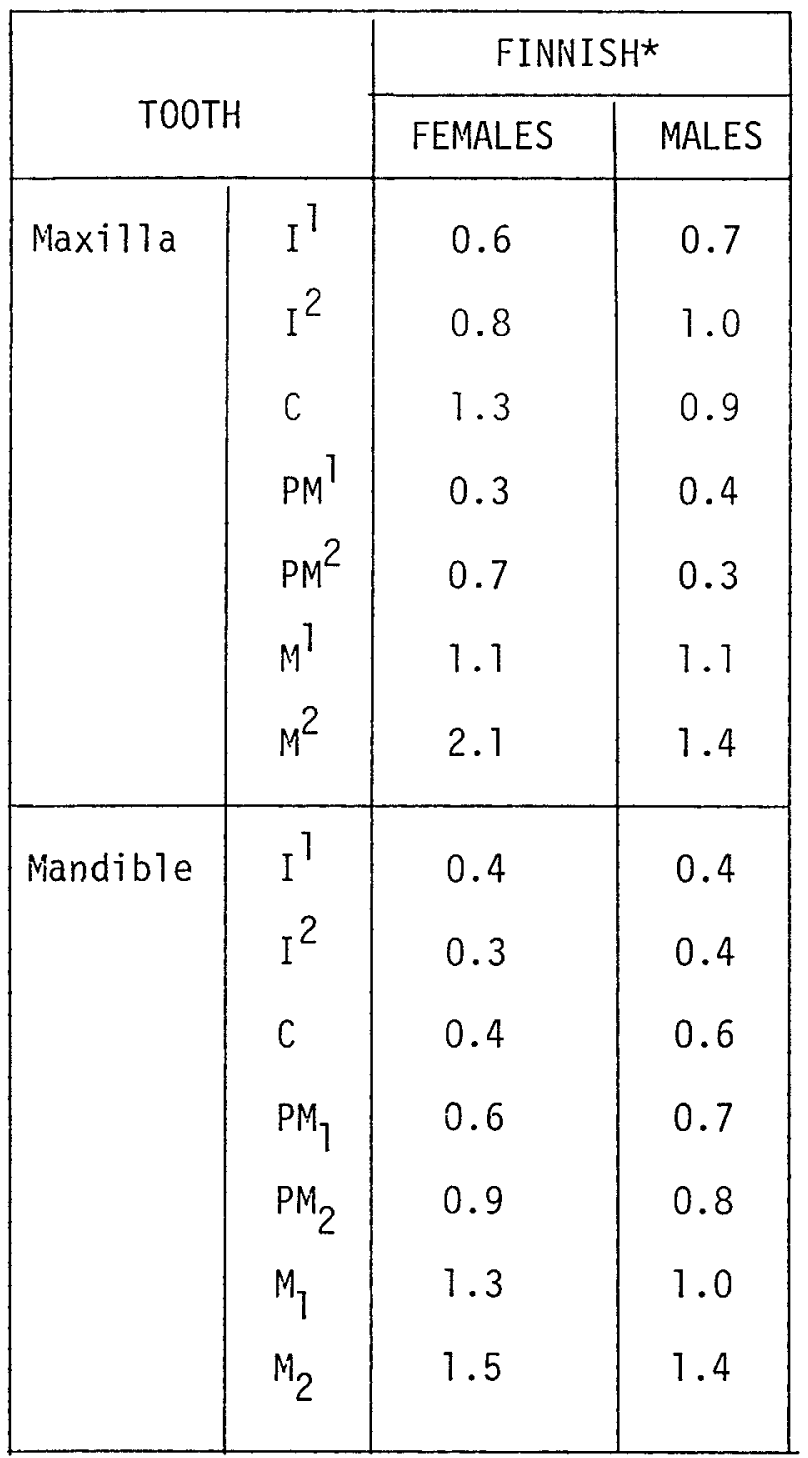

* Haavikko (1970) 


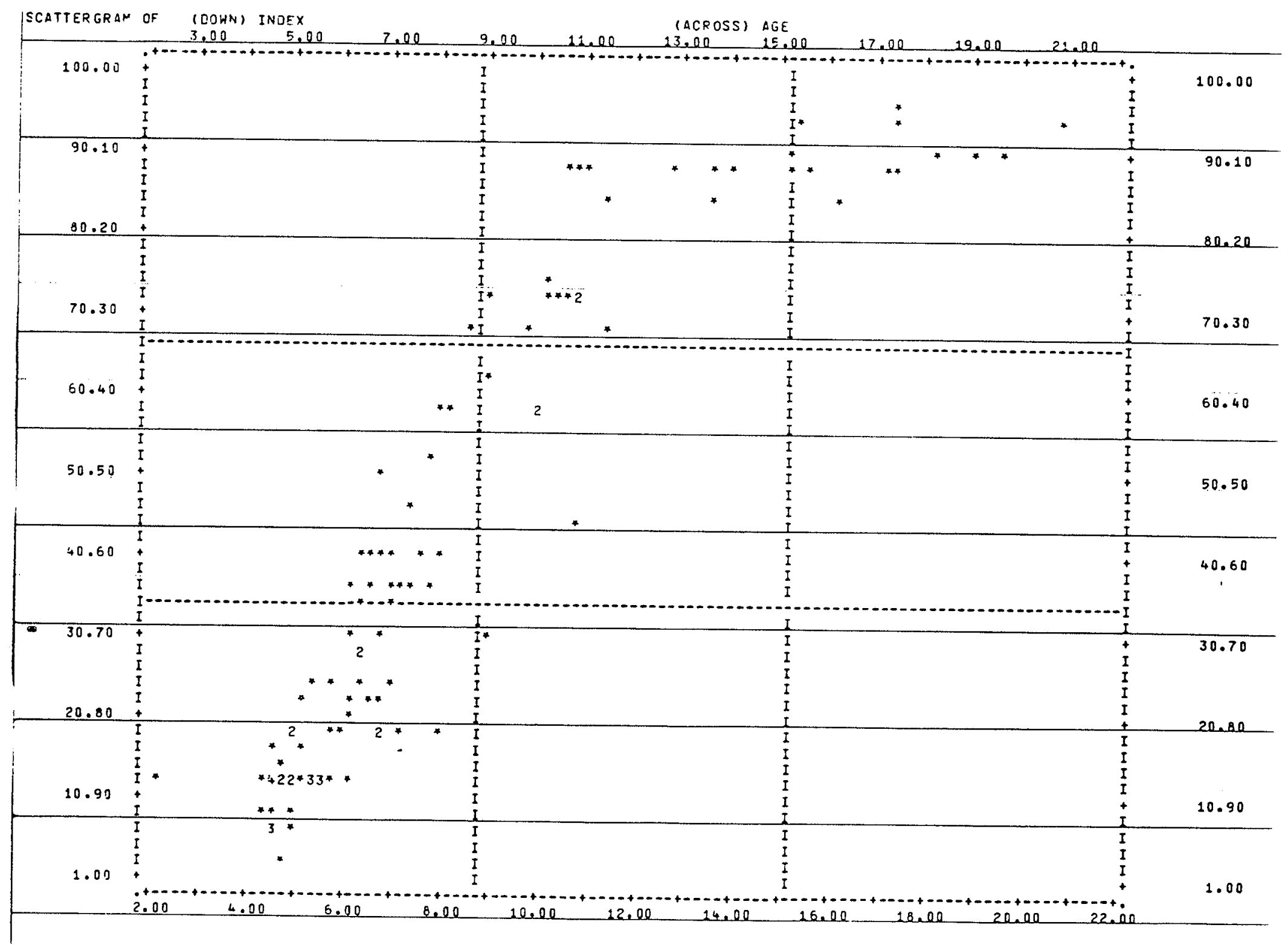

FIGURE 14: Scattergram of Emergence Index and Chronological Age for Inuit, Sexes Combined 


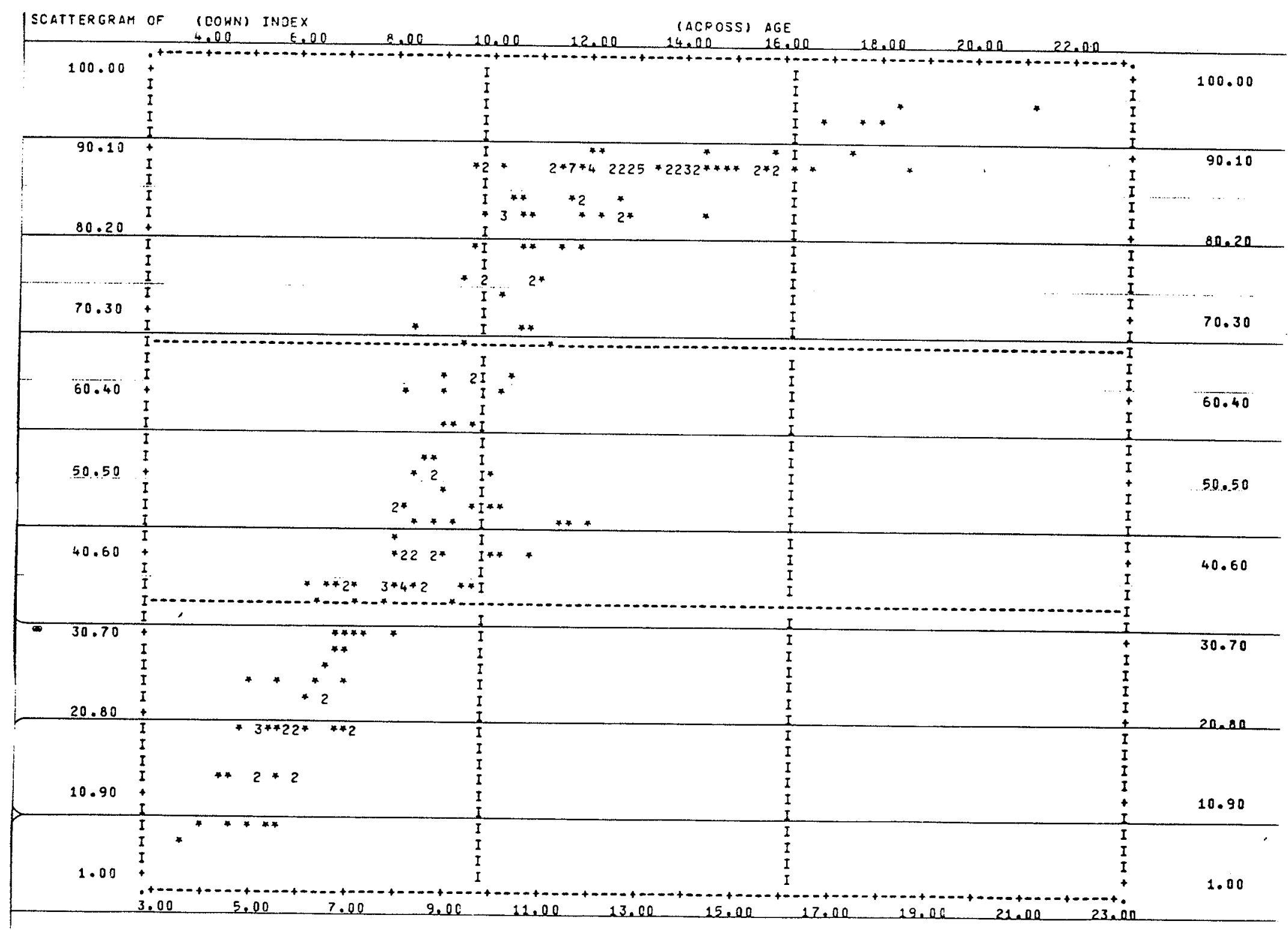

FIGURE 15: Scattergram of Emergence Index and Chronological Age for Indians, Sexes Combined 
A P PENDIX B 
UNIVERS ITY OF MANITOBA

ANTHROPOLOGY DEPARTMENT

B.J. Trodden - M.A. Thesis Research

\section{RESEARCH NUMBER}

I.D. NUMBER
INDIAN

INUIT
NAME surname

first name

SEX $m$ or $f$

COMAUNITY OR RESERVE

SIBLINGS OR COUSINS

ALSO IN THE STUDY

BIRTHDATE $\frac{1}{\text { day }}$

\begin{tabular}{|l|l|l|l|l|}
\hline PANOREX & DATE OF RADIOGRAPHS & DECIMA.L AGE & YEARS & MONTHS \\
\hline BITEWINGS & & & & \\
\hline OTHER & & & & \\
\hline
\end{tabular}

TREATMENT RECORD(include all information related to:)

1. Extraction of Deciduous Teeth.

2. Extraction of Permanent Teeth.

3. Pulpal Involvement of Caries in Deciduous Teeth.

4. Space Maintenance.

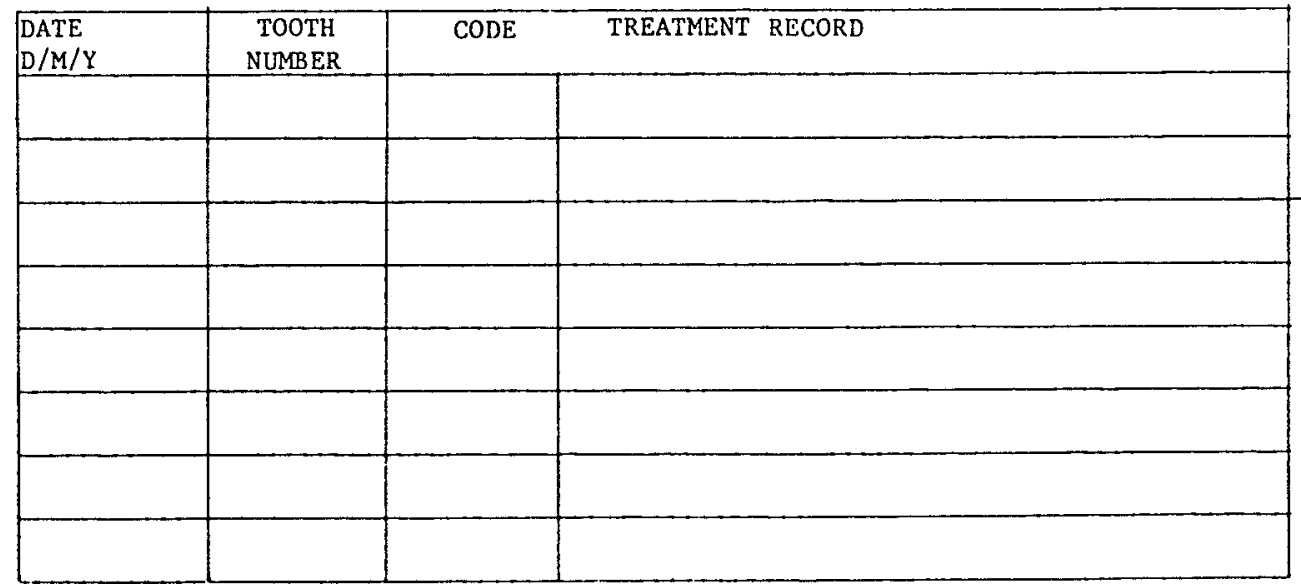

FIGURE 16: Chart Data Recording Form 
RADIOGRAPHIC DATA

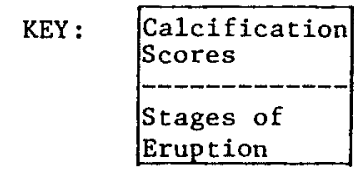

RESEARCH NUMBER

Eruption

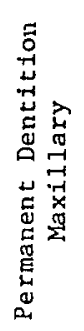

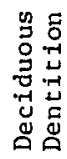
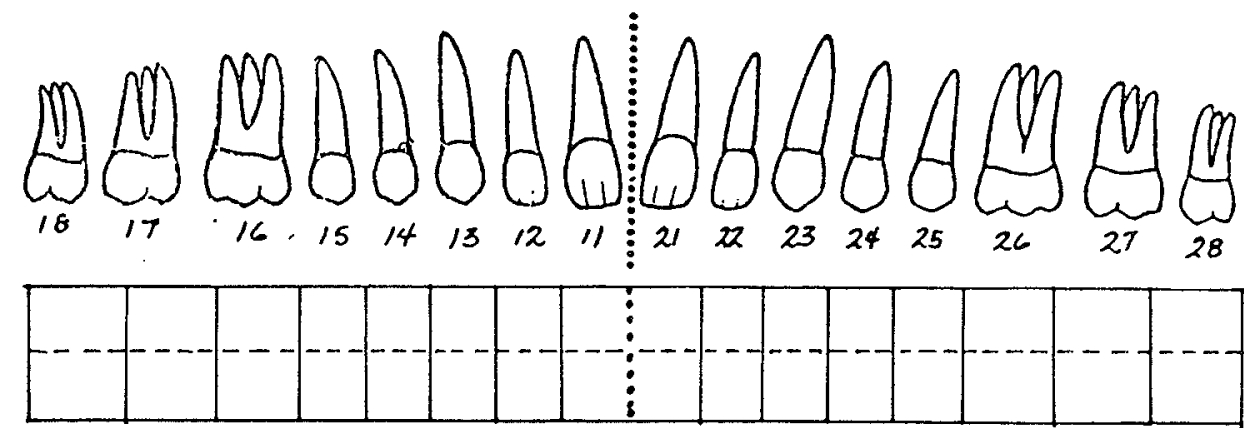

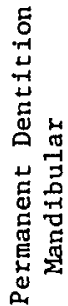

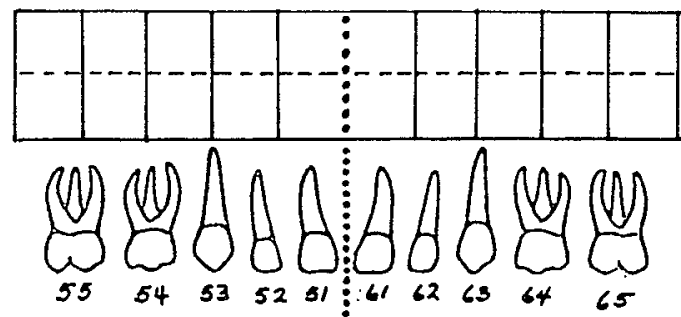

RIGHT
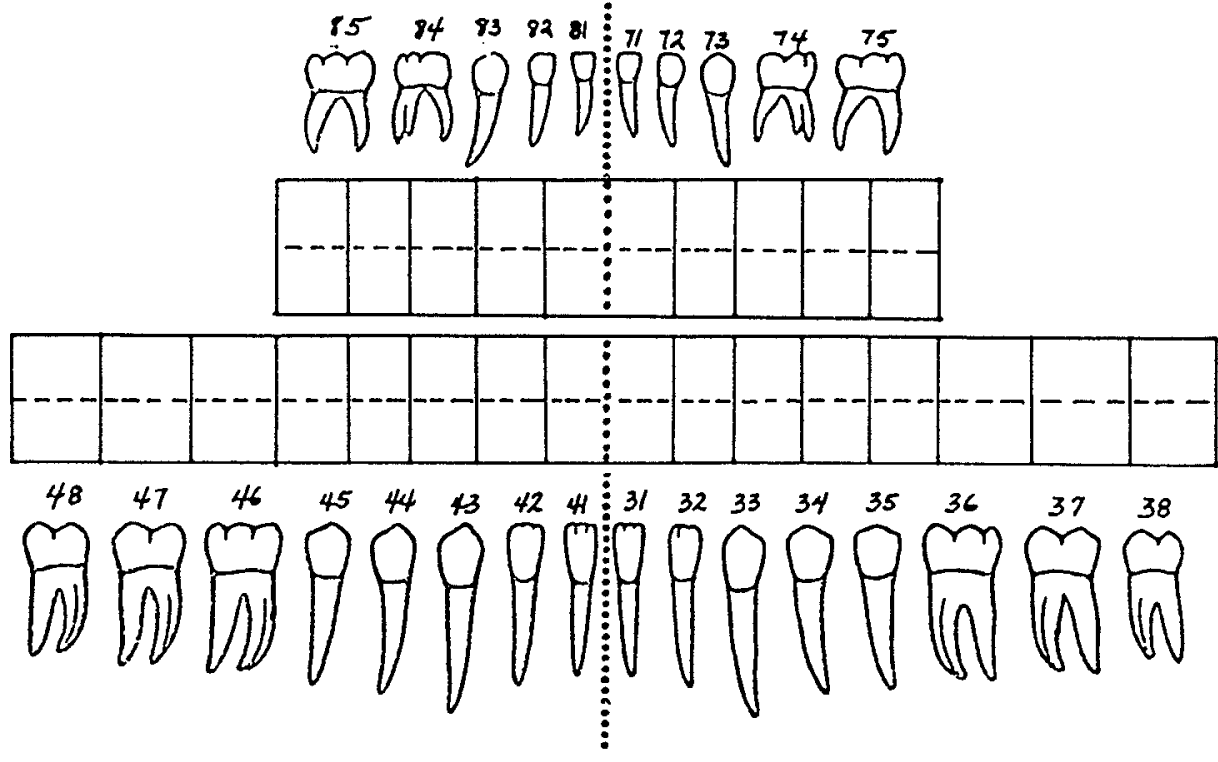

FIGURE 17: Recording Form 
TOOTH DEVELOPMENT SCORING SYSTEM

\section{Calcification Scores}

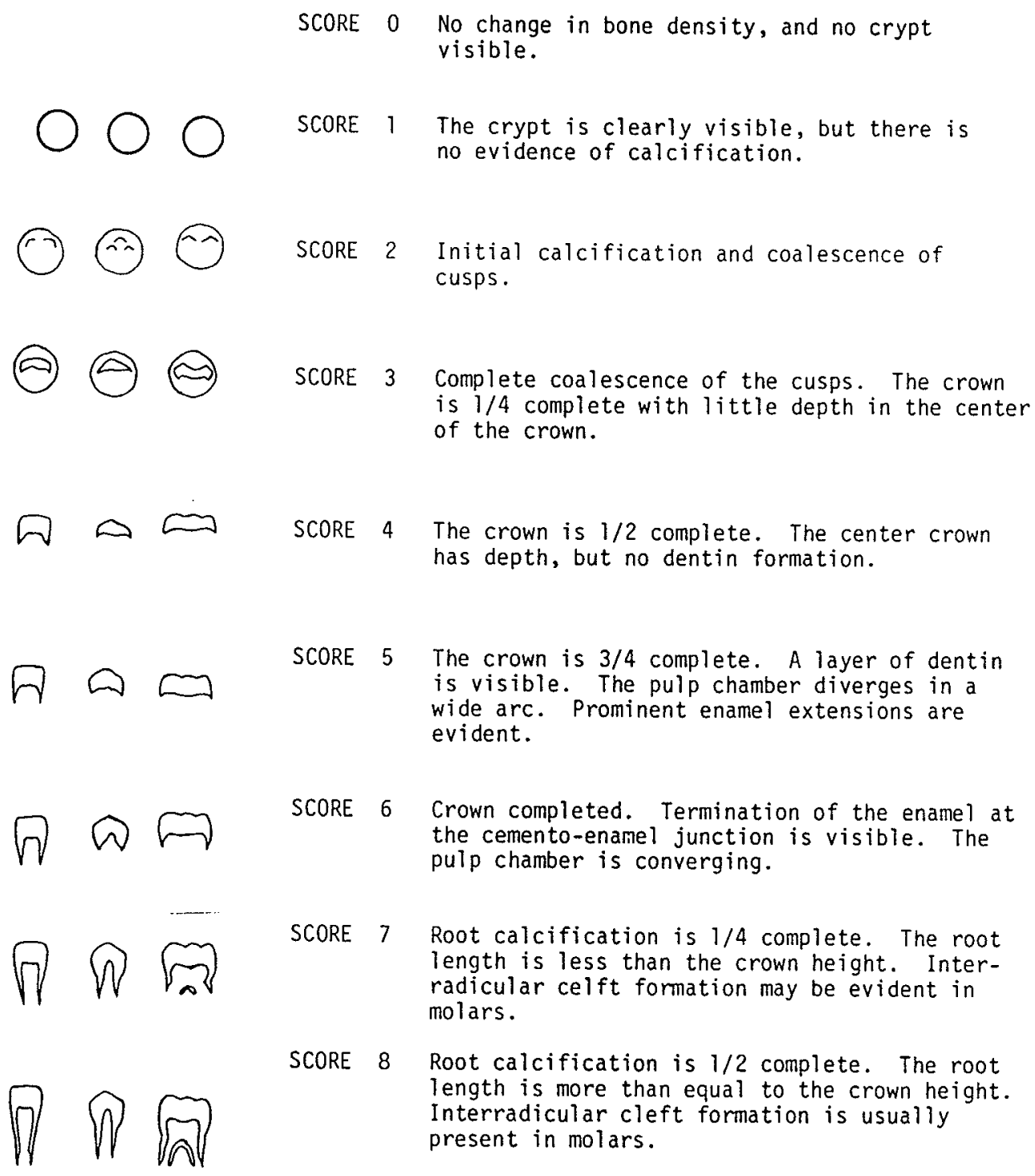

FIGURE 18 


\section{TOOTH DEVELOPMENT SCORING SYSTEM}

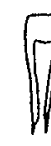<smiles>CCCCCCCCCC=C1C=CCCC1</smiles>

SCORE

9

The root calcification is $3 / 4$ complete. The root length is greater than the crown height. The root apex is widely divergent.

SCORE 10 Root iength is completed with the apex convergent. Initiation of apical closure.

SCORE 11 Termination of root calcification with apical closure complete or almost complete.

SCORE 12 Resorption of 1/4 of at least one Deciduous root.

(7)

SCORE 13 Resorption of $1 / 2$ of at least one Deciduous root.

(1) 2

SCORE 14 Resorption of $3 / 4$ of all the Deciduous roots.

(17)

SCORE 15 Complete resorption of the Deciduous root(s).

(n)

SCORE 16 Complete exfoliation of the Deciduous tooth. (Eruption Stage V.)

SCORE 17 Where evidence exists that the Permanent or Deciduous tooth has been extracted. (Eruption Stage V.)

SCORE 18 Where evidence exists that a tooth is congenitally missing, (if over 2.0 years for the first molar, incisors and canines; if over 4.0 years for the premolars and second molar; if over 12.0 years for the third molar) (Eruption Stage 0.)

FIGURE 18 (Cont'd) 
TOOTH DEVELOPMENT SCORING SYSTEM

SCORE 19 Missing Permanent teeth where the reason is unknown. The tooth has probably been extracted, but it may be congenitally missing. (Eruption Stage V.)

SCORE 98 If the tooth is obviously present but an accurate determination of calcification is not possible due to an abnormal inclination of the tooth, or movement during exposure of the radiograph. Where possible, the Eruption Stage is assessed.

SCORE 99 Where the presence or absence of the tooth is not known dur to a faulty radiograph.

SCORE " $V$ " Interradicular cleft formation is recorded separately for the Permanent molars.

\section{ERUPTION STAGES}

STAGE 0 A zero is recorded either if the tooth is congenitally missing or has not reached the Calcification score of 6 .

STAGE I Initial stages of tooth movement. Every tooth that has reached the Calcification Score of 6 , but has not pierced the alveolar crypt. The crypt margin (lamina dura) appears unbroken, or there is evidence of the crypt occlusal to the tooth crown.

STAGE II Alveolar emergence. The elevation of the cusps, or incisal ridge, above the margin of the alveolar crypt, and if the occlusal margin of the crypt appears to be broken.

STAGE III Gingival emergence. The emergence of any portion of the tooth crown through the gingiva. No evidence of soft tissue occlusal to the tooth crown.

STAGE IV Attainment of the occlusal level. Full occlusal contact as determined by the overall line of occlusion (Curve of Spee), and the approximation of the contact areas. If a tooth is malaligned, only a portion of the occlusal (incisal) surface may be in occlusion.

STAGE $V$ Missing teeth. If the tooth has been exfoliated (Score 16), extracted (Score 17), probably extracted (Score 19), or if the presence or absence of the tooth is unknown (Score 99).

FIGURE 18 (Cont'd) 


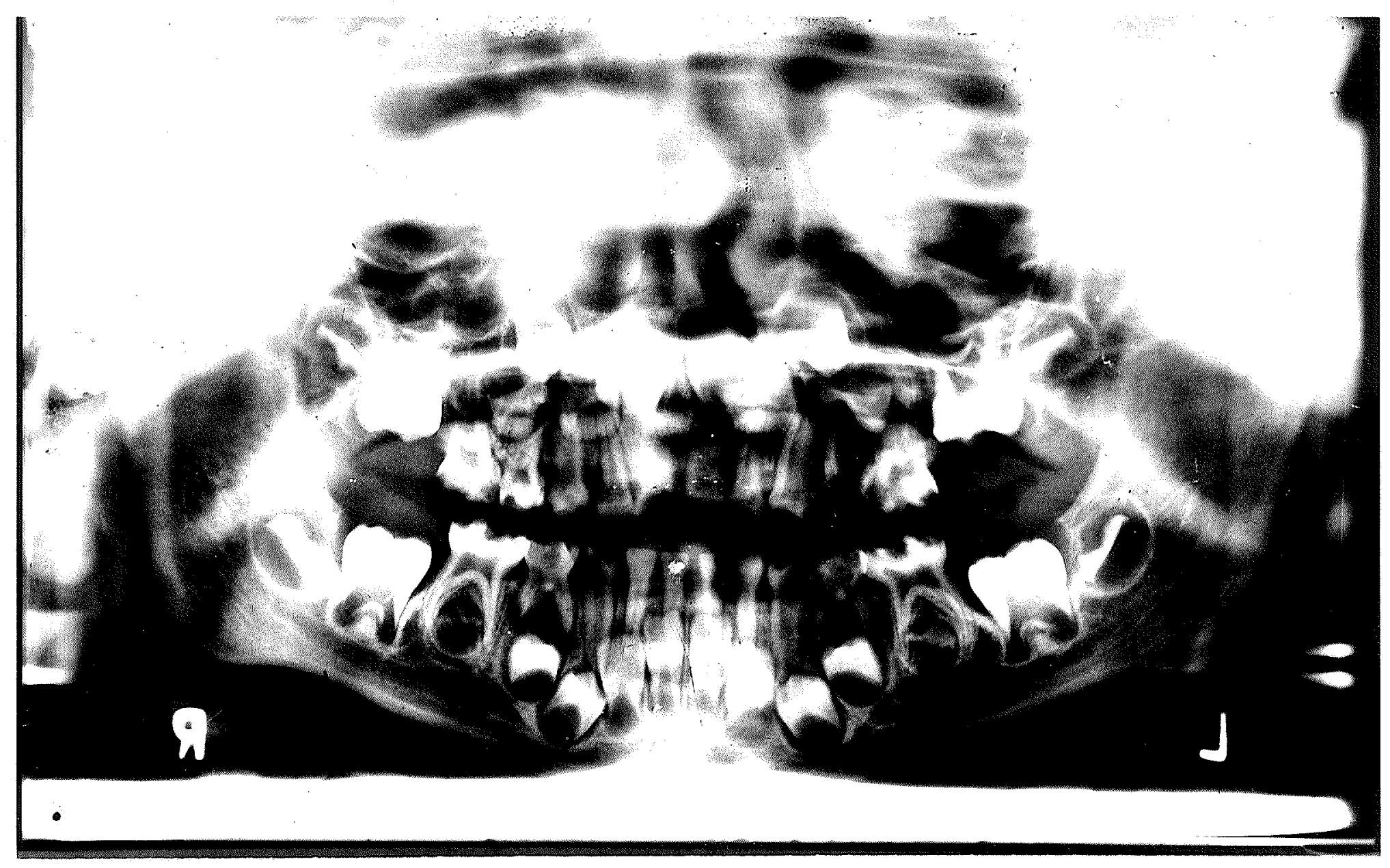

FIGURE 19: Inuit male, 2.26 years

(Case No. 694) 


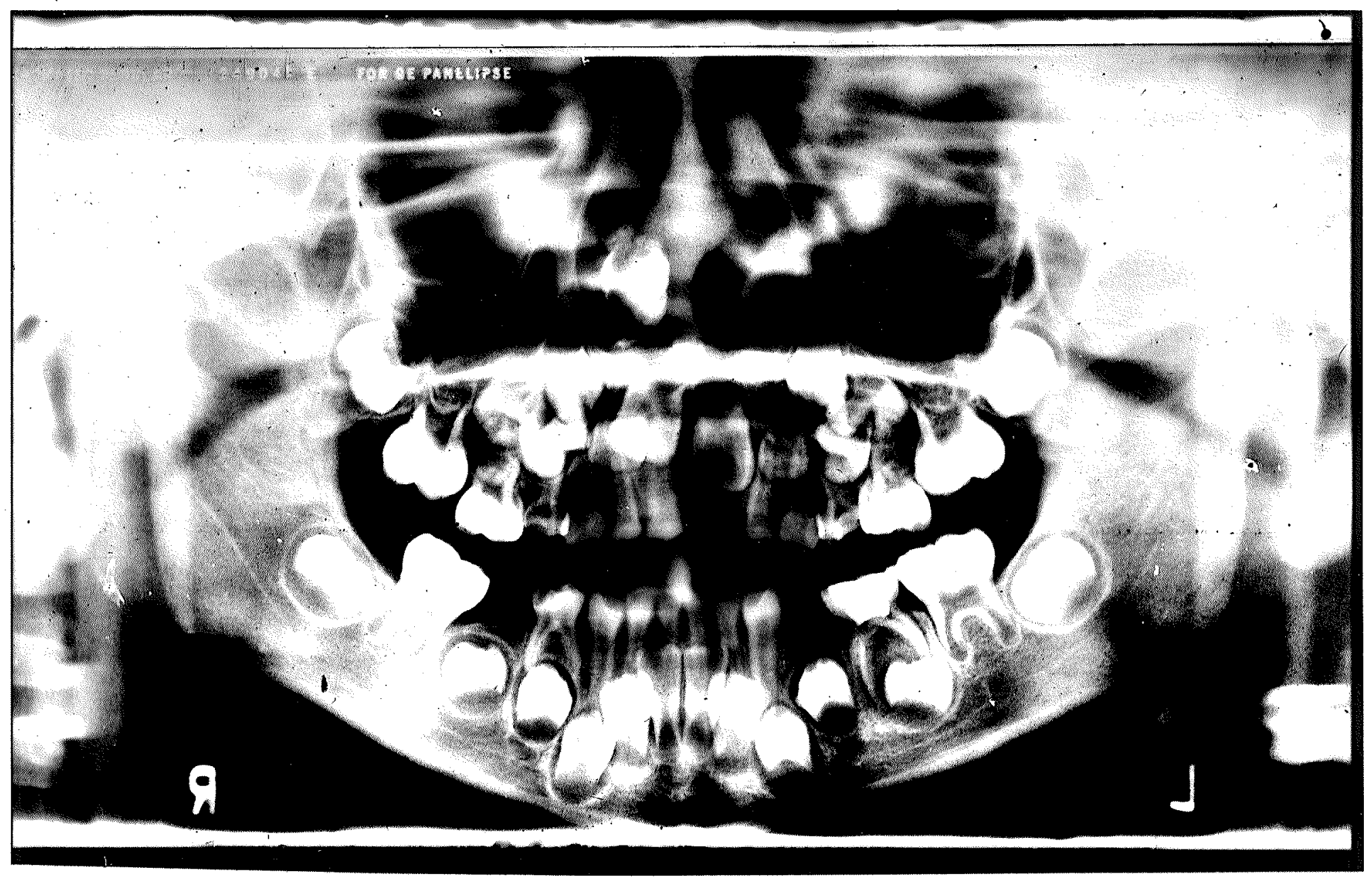

FIGURE 20: Indian female, 5.90 years (Case No. 079) 


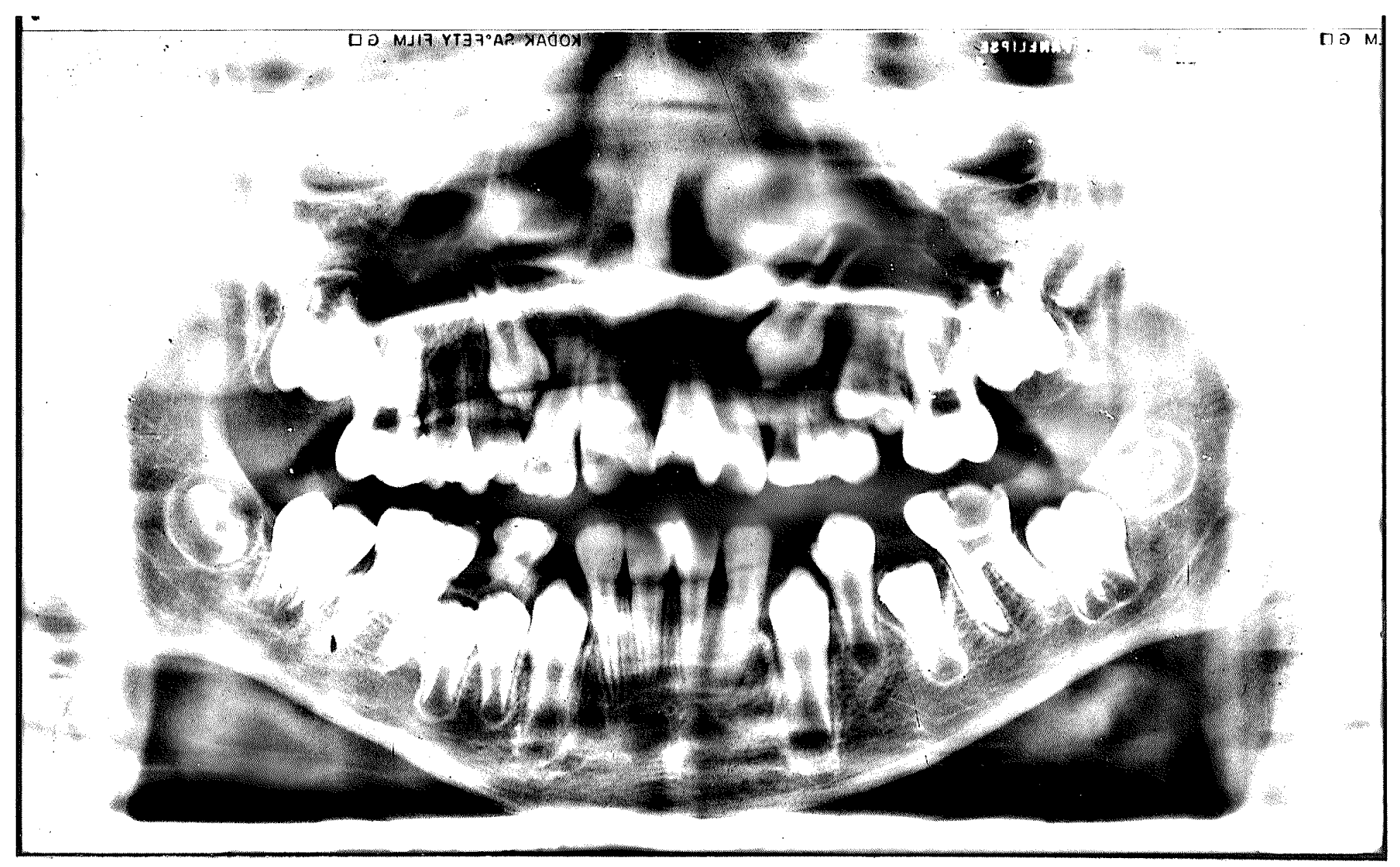

FIGURE 21: Inuit male, 10.02 years

(Case No. 675) 


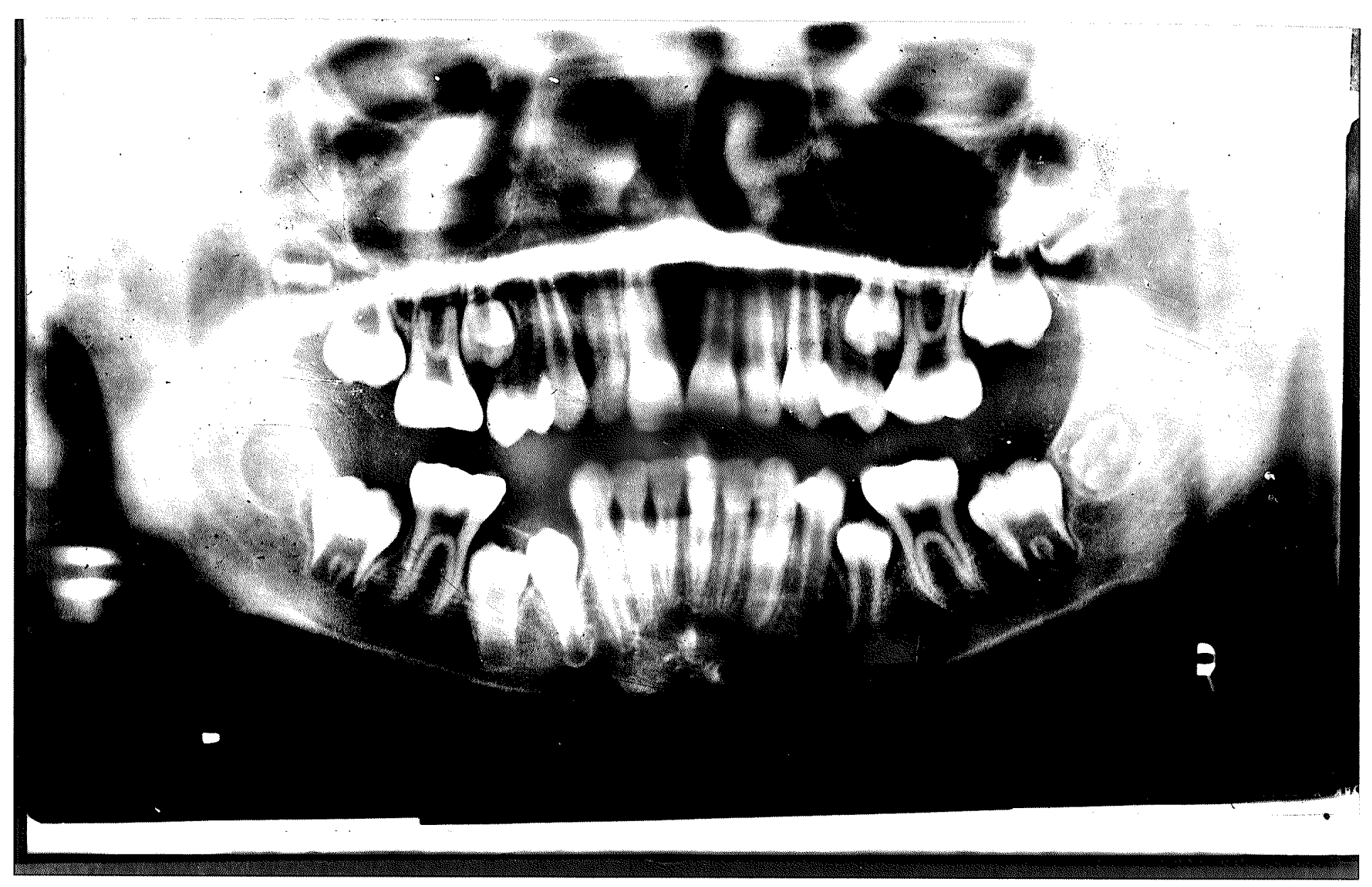

FIGURE 22: Indian female, 11.38 years

(Case No. 133) 